\title{
Learning is not a Spectator Sport: Incorporating Active Learning into High Risk Business Courses
}

\author{
Ashley Brooke Tasker
}

Follow this and additional works at: https://researchrepository.wvu.edu/etd

\section{Recommended Citation}

Tasker, Ashley Brooke, "Learning is not a Spectator Sport: Incorporating Active Learning into High Risk Business Courses" (2017). Graduate Theses, Dissertations, and Problem Reports. 6776.

https://researchrepository.wvu.edu/etd/6776

This Dissertation is protected by copyright and/or related rights. It has been brought to you by the The Research Repository @ WVU with permission from the rights-holder(s). You are free to use this Dissertation in any way that is permitted by the copyright and related rights legislation that applies to your use. For other uses you must obtain permission from the rights-holder(s) directly, unless additional rights are indicated by a Creative Commons license in the record and/ or on the work itself. This Dissertation has been accepted for inclusion in WVU Graduate Theses, Dissertations, and Problem Reports collection by an authorized administrator of The Research Repository @ WVU.

For more information, please contact researchrepository@mail.wvu.edu. 
LEARNING IS NOT A SPECTATOR SPORT: INCORPORATING ACTIVE LEARNING

\section{INTO HIGH RISK BUSINESS COURSES}

Ashley Brooke Tasker

Dissertation submitted to the

College of Education and Human Services

at West Virginia University in partial fulfillment of the requirements for the degree of

DOCTOR OF EDUCATION

in

Curriculum and Instruction

Joy Saab, Ed.D., Co-Chair

Samuel Stack, Ph.D., Co-Chair

Allison Swan Dagen, Ph.D.

George Mamboleo, Ph.D.

Christina Lavorata, Ed.D.

College of Education and Human Services

Morgantown, West Virginia

2017

Key Words: Higher Education, Active Learning, Business Courses

Copyright, 2017, Ashley Brooke Tasker 


\begin{abstract}
Learning is Not a Spectator Sport: Incorporating Active Learning into High Risk Business Courses
\end{abstract}

Ashley Brooke Tasker

This quantitative study examined courses that have incorporated active learning, including peer mentoring, into courses with high rates of Ds, Fs, and withdrawals, to determine if these techniques increase student success, measured by overall course grades. The study also focused on analyzing factors, such as gender, socioeconomic status, and ACT composite scores to see if there were statistically significant differences among those and student success. The intent is to contribute and build on to the current active learning research which lacks in the quantitative, non-laboratory courses such as business. The results indicated that there is a significant difference in success rates when comparing students in classes that incorporate active learning and students who were in the baseline, lecture courses. There is a higher proportion of students who succeed in active learning courses than there were in lecture based courses. Additional findings suggest students who passed the course on average were female, had a higher ACT composite score, and had a higher socioeconomic status. In addition, there was a correlation between students having ever attended at least one peer mentoring sessions and passing the course. 


\section{Dedication}

\section{My Father}

A strong and authentic individual who taught me independence and hard work. For supporting and encouraging me to believe in myself. I would give anything for you to be here with me today.

\section{My Grandparents, Bob and Lois Strawser}

For providing your unconditional love, kindness, humor and life lessons. I sure miss the both of you dearly.

\section{Dr. Patricia Obenauf}

One of the kindest, most genuine souls I have met. I was blessed with your expertise and love throughout my doctoral career.

Lastly, this is dedicated to the mom who is exhausted, overwhelmed, and feeling like she is not doing anything quite well. To juggling a full-time job, running to practices, games, and

tournaments, family time, nurturing and maintaining friendships...this is dedicated to you- the one who truly is a rock star! 


\section{Acknowledgements}

I always jokingly said my acknowledgments would be the most difficult to write of my entire dissertation. However, this has become a reality, and is definitely the most difficult to complete since so many people have impacted my life. They say I should only acknowledge the individuals who have impacted my doctoral studies, and even with that, I must first acknowledge two elementary school teachers, Ms. Stacy Richardson (Borror) and Ms. Cathy Robinson, who were compassionate and energetic teachers, sparking my love for education. I had several additional educators throughout my academic career who impacted me, but the two who need acknowledged the most are Drs. Joe and Ann Shaver. Being a first-generation college student, I only aspired to complete my bachelor's degree. Without the guidance and encouragement these two provided, I would have done only that. So, thank you for your love, guidance, and extra push in the right direction.

To my committee members- Dr. Saab, you are an absolute blessing and role model. If I become half the professional and mother as you are, I will consider myself blessed. Thank you for encouraging me when I needed it, and for sacrificing time and energy when you should have been enjoying retirement. I was lucky to have such a wonderful and dynamic advisor throughout my doctoral studies. Dr. Mamboleo, thank you for being such a kind and caring person. Drs. Stack and Dagen, thank you both for stepping in when I needed you the most. And last, but definitely not least, Dr. Lavorata, thank you for being a kindhearted and compassionate woman. I aspire to be a leader among faculty like you have done. I appreciate each and every one of you for taking on another doctoral student and committee, despite the immense faculty and administrative duties you face daily. Also, I am forever indebted to David Loomis, a graduate assistant in the Program Evaluation and Research Center at WVU. Without your SPSS skills and research assistance, this would have been a lot more painful!

Thank you to all the students, peer mentors, and faculty, who have made this research possible. To Dr. Gina Fantasia, your overall vision of the peer mentoring program and dedication to the grant writing is more than appreciated! Special thanks to Dr. Joe Kremer and Ms. Leisa Muto for allowing me to utilize examples of your course redesigns, to Dr. Amy Godfrey for your research expertise, to Dr. Jim 
Matthews for answering my desperate editing plea, to Ms. Amantha Cole for managing the grant so well, and to Dean Richard Harvey, for your leadership and dedication to the School of Business! Dr. Richard Strasburger, thank you for being an inspirational mentor over the years.

To my family and friends, thanks for enduring my agony, and sometimes mild crankiness exhibited as a direct result of my dissertation. Special thanks to Jason Bolyard for being a great motivator and dissertation friend who I can commiserate with! Thank you for being genuinely interested in my research, even though it has nothing to do with engineering. To my mother, Vicki Hardesty, words cannot express my love and gratitude I have for encouraging me to be an independent woman. You have taught me the strength to persevere when things get tough. To my brother, Scott, thank you for having a new found love for life, and giving me ease to put my energy towards completing this dissertation. I know you have definitely outdone me with your hand-written pages, and I cannot argue that yours are far more important than mine!

And last, but definitely not least, to my two favorite people, my husband, AJ, and my daughter, Jayden, thank you. Your support, either praise or tough love, is more than I ever deserve. AJ, thank you for always believing in my abilities and allowing me to pursue my crazy ambitions. If it was not for you and your love, I would have never been able to balance everything to finish. Not many individuals are as lucky as I am to have a partner in life like you! I truly adore and love you dearly! Jayden, you definitely put life into perspective to me. Thank you, beautiful, for motivating and encouraging me to keep striving for the best. I am humbled to raise such an amazing, young woman! I love you beyond words! 


\section{Table of Contents}

Table of Contents .................................................................................................... vi

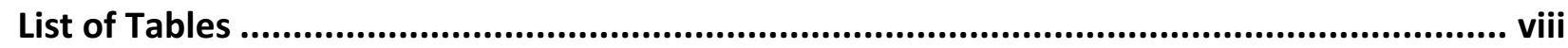

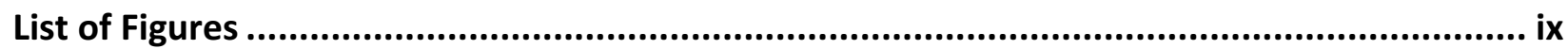

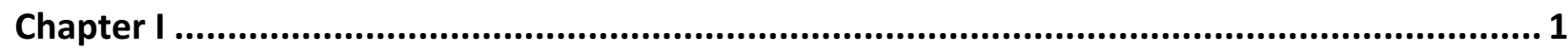

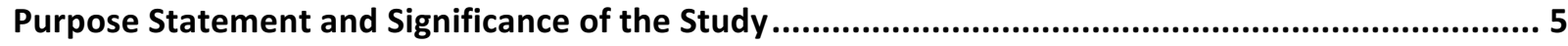

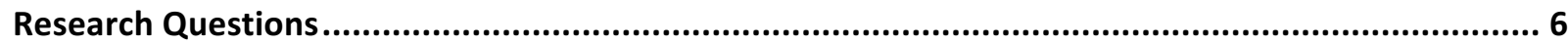

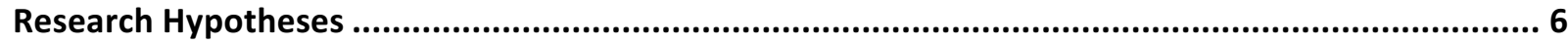

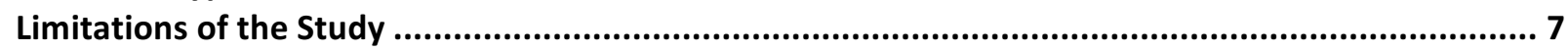

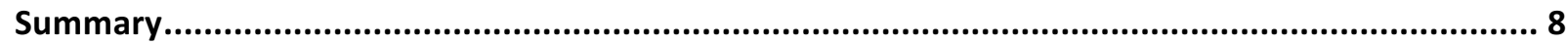

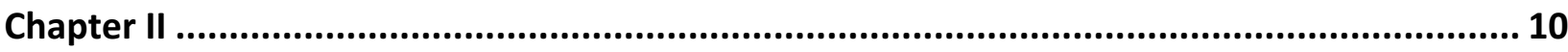

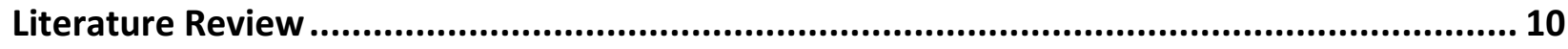

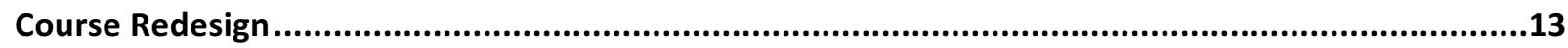

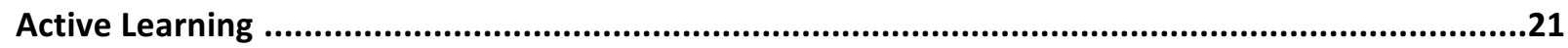

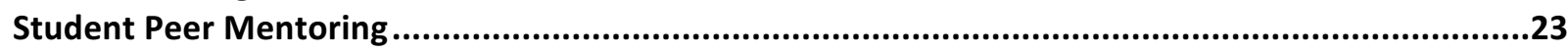

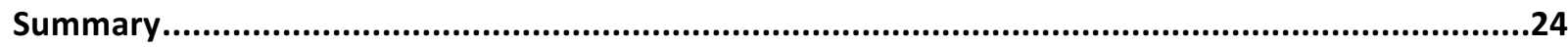

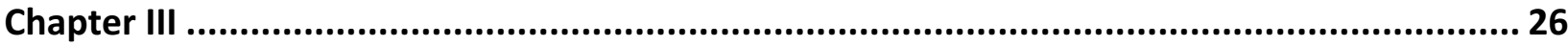

Research Design and Methodology....................................................................... 26

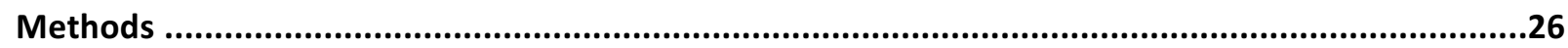

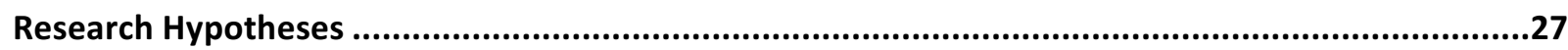

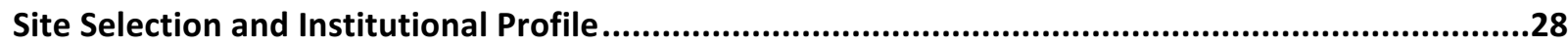

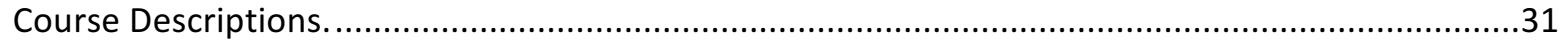

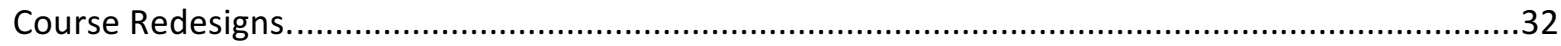

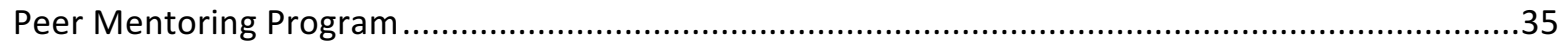

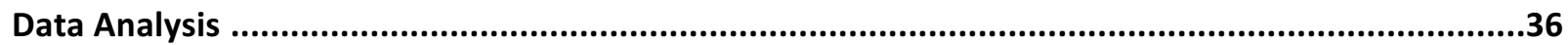

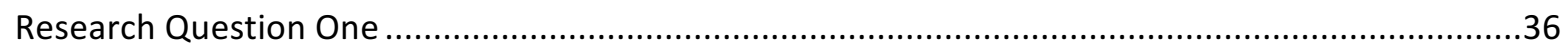

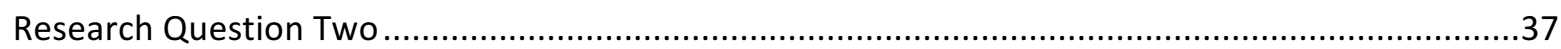

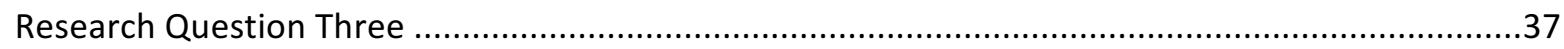

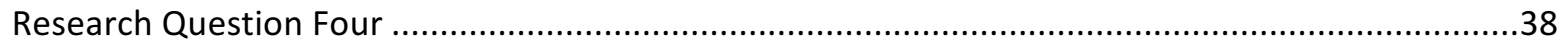

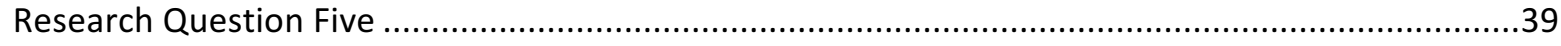

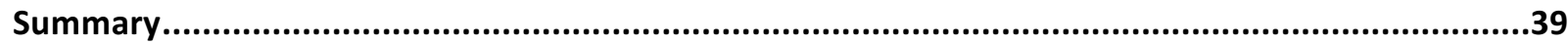

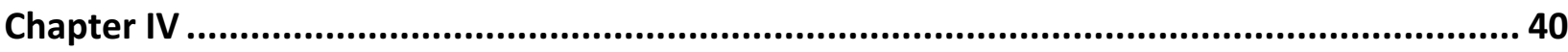

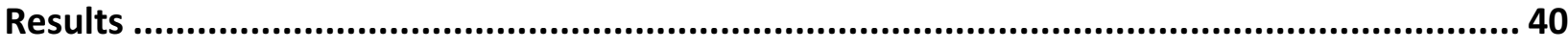

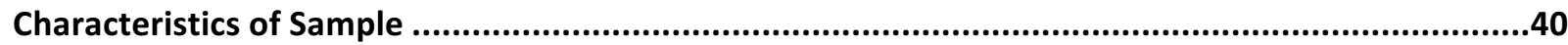

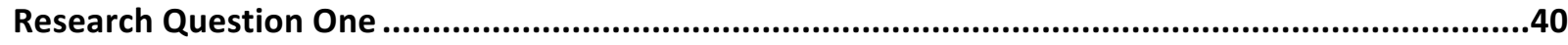

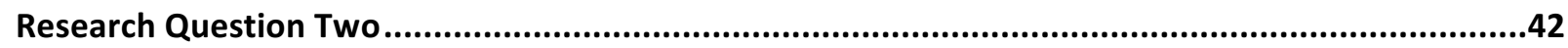

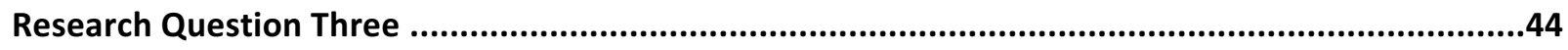

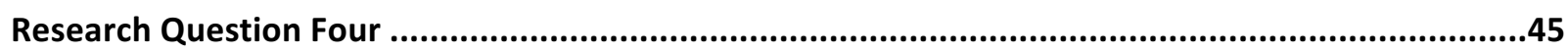

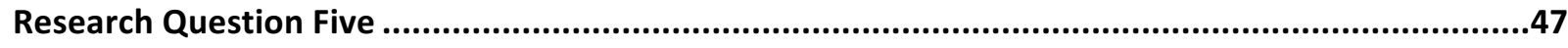

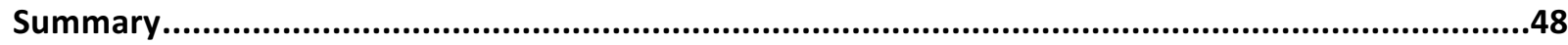




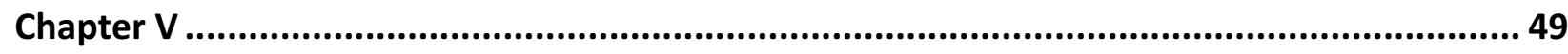

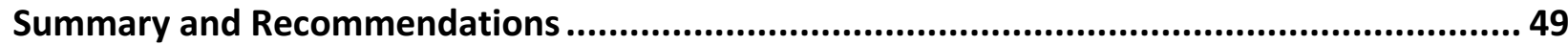

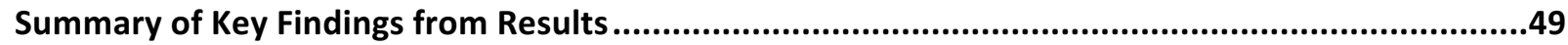

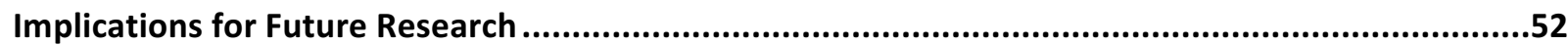

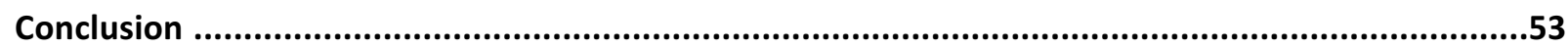

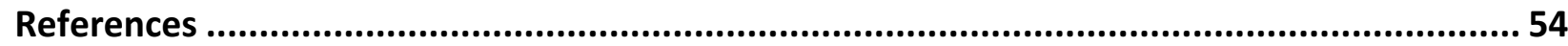

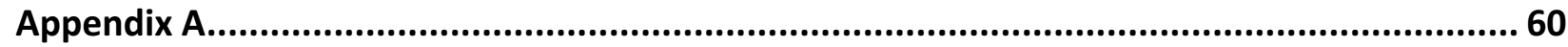

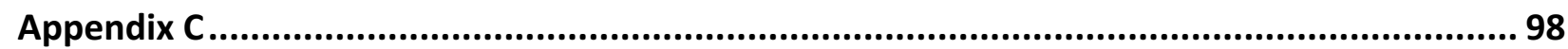

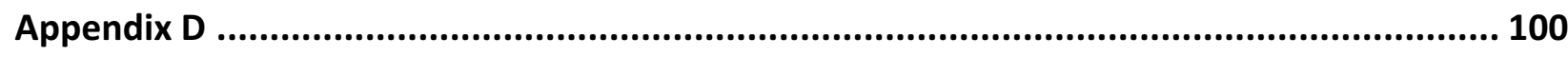

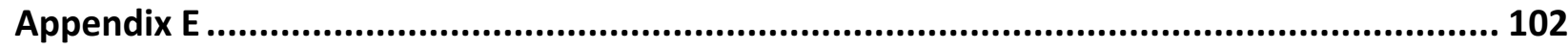

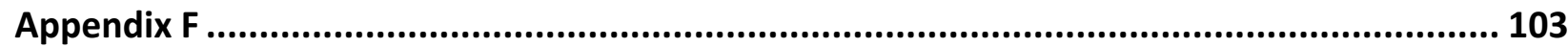




\section{List of Tables}

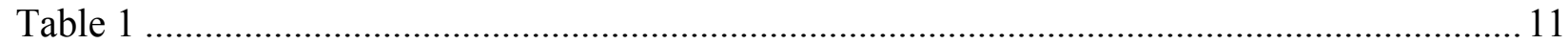

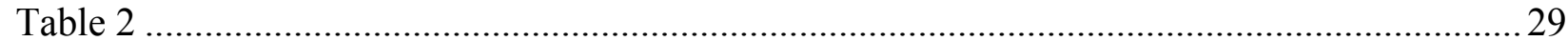

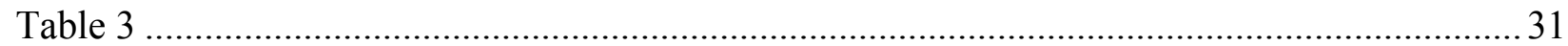

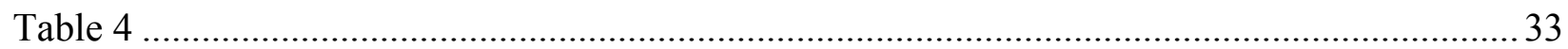

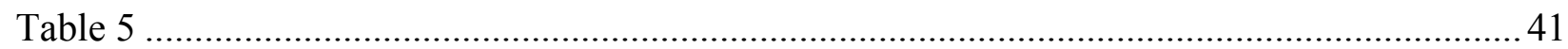

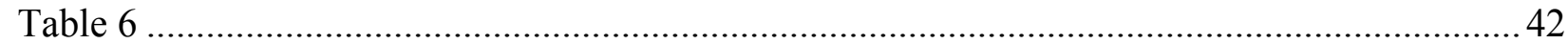

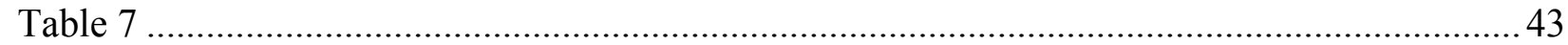

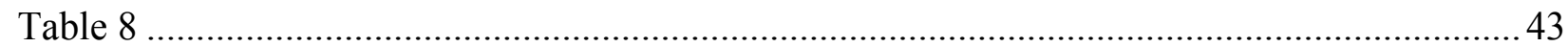

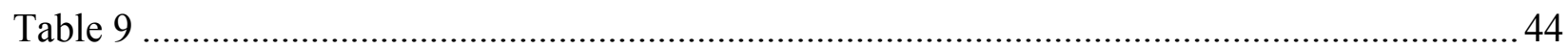

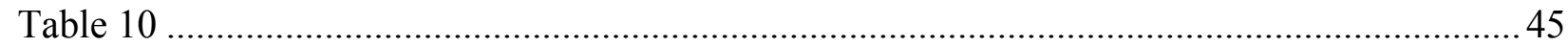

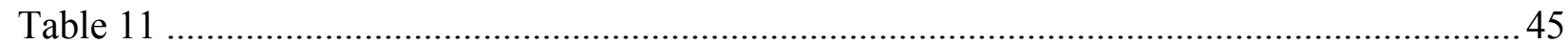

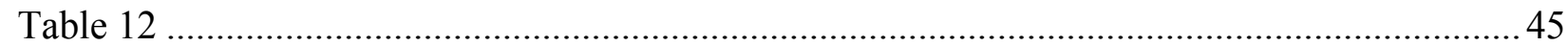

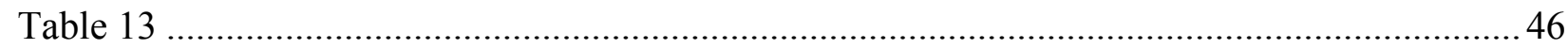

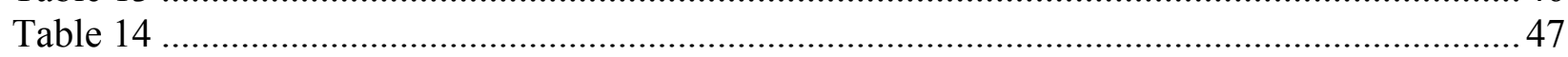

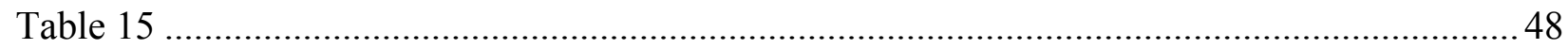




\section{List of Figures}

Figure 1. The twelve steps of integrated course design ............................................... 14

Figure 2.Taxonomy of significant learning ................................................................. 15

Figure 3. Interactive nature of significant learning ........................................................... 17

Figure 4. Key components of integrated course design ............................................... 18 


\section{Chapter I}

\section{"Education is not the filling of a pail, but the lighting of a fire." -William Butler Yeats}

\section{Introduction}

What would your educational experience as a student in the classroom look like if you took a moment to reflect? Would a majority of this experience be described as a "spectator sport," in which you sat at desks assembled in rows, taking notes, while the professor stood at the front of the classroom and lectured the entire time? Chickering and Gamson make a compelling statement, saying "Learning is not a spectator sport. Students do not learn much just by sitting in classes listening to teachers, memorizing pre-packaged assignments, and spitting out answers. They must talk about what they are learning, write about it, relate it to past experiences, apply it to their daily lives. They must make what they learn part of themselves" (1987, p. 4). A century ago, John Dewey (1916) stated that learning is an active, personally conducted affair.

Many individuals will answer "yes" to the above question because, as Bonwell and Eison (1991) point out, lecture is the dominant method by which we were taught, and it continues to be the primary method by which most of us teach. Yet, Barr and Tagg (1995) indicate that a paradigm shift is being embraced in American higher education, which they describe as the Learning Paradigm. The Instruction Paradigm, which the two identified as previously governing our colleges, has caused universities and colleges to create complex structures to meet the mission of delivering 50-minute lectures. However, Barr and Tagg specify, our mission is to produce learning for every student by whatever means work best.

The Learning Paradigm shift Barr and Tagg identified twenty years ago has clearly not evolved, considering David Sousa's (2011) acknowledgement that "lecture continues to be the most prevalent teaching method in secondary and higher education, despite evidence that it 
produces the lowest degree of retention for most learners" (p. 101). Dale Edgar (1969) proposed a general estimation that learners retain $90 \%$ of what they $d o$, as opposed to $10 \%$ of what they read and $20 \%$ of what they hear. If lecturing continues to be the most widespread method of teaching, and essentially only $20 \%$ of the information is retained, what can be done in our higher education classrooms to improve learning? Addressing this question is crucial if educators are committed to teaching and learning based on evidence rather than tradition (Freeman et al., 2014).

Angelo and Cross (1993) emphasize that "learning can and often does take place without the benefit of teaching- and sometimes even in spite of it- but there is no such thing as effective teaching in the absence of learning. Teaching without learning is just talking” (p. 3). Barkley (2010) claims the simplest answer to "how do we best accomplish helping students learn?" is setting up conditions that promote active learning. Barkley defines active learning as an "umbrella term that now refers to several models of instruction, including cooperative and collaborative learning, discovery learning, experiential learning, problem-based learning, and inquiry-based learning" (p. 16). The term "active learning" lacks a common definition, despite being used frequently in higher education literature.

Active learning is commonly contrasted to the traditional lecture method where students sit facing forward, passively receiving information from the professor. Barkley (2010) refers to active learning as an umbrella term suggesting several models of instruction, including cooperative and collaborative learning, discovery learning, experiential learning, problem-based learning, and inquiry-based learning (p. 16-17). It is common for active learning to be confused with some form of physical activity, but as Barkley clarified, active learning means the mind is actively engaged. Some consistent features of active learning include involving students in meaningful activities, mentally and/or physically, that encompasses them gathering information, 
and both thinking about and reflecting upon what they are doing (Barkley, 2010; Prince, 2004; Collins \& O’Brien, 2003; Bonwell \& Eison, 1991). Bonwell and Eison (1991) identified various researchers, including Chickering and Gamson, Ericksen, Cross, and Astin, who have expressed the need for active learning in the classroom.

Chickering and Gamson (1987) pointed out that students do not learn merely by sitting in class listening to teachers while memorizing prepackaged assignments and spitting out answers (p. 3). They learn what they care about and remember what they understand. Someone who is interested in losing weight and building muscle does not go to the gym and sit while the personal trainer tells him/her about the different workouts and plans. The individual must actively participate in his/her health, by engaging in the discussion, both physically and mentally.

Throughout the 1980s, a series of national reports urged faculty to engage students; however, research consistently show traditional lecture dominates university classrooms. Between $73 \%$ and $83 \%$ of college faculty report their primary method of instruction is lecturing, despite several studies showing students prefer strategies promoting active learning (Bonwell \& Eison, 1991; Cedaka, 2012). Bligh (2000) defines traditional lecture as “...continuous exposition by the teacher" (p. 4). Eison (2010) identifies multiple sources saying "lecturing involves the transfer of information from the notes of the instructor to the notes of the students without passing through the minds of either" (p. 2). Lectures are great for getting students to repeat information, but it is one of the worst teaching strategies for promoting in-depth understanding (Halpern \& Hakel, 2003). Halpern and Hakel (2003) also suggest it would be difficult to find a model worse than the one used for teaching in most institutions. Alan Guskin (1994) presents a clear message to colleges and universities about passive lecture-discussion formats where faculty talk and most students listen; it is contrary to almost every principle of optimal settings for student learning (p. 20). 
Albert Einstein is often credited with defining insanity as doing the same thing over and over again and expecting different results. If traditional lecture continues to be the predominant delivery method in higher education, yet research shows that students prefer and retain more information with active learning, then insanity exists in higher education. As cited by Bonwell and Eison (1991), "The spirit of America is innovation. In almost every area of life we crave the new and better...Yet college teaching stands out as one of the few fields in which innovation and improvement are neglected" (Eurich 1964, p. 49). Over a half century later, we continue to neglect innovation and improvement. Why?

People in general resist change, and Guskin (1996) contends that, the more significant the change, the greater the resistance (p. 29). Loren Ekroth (1990) identifies six global barriers to change:

1. The professional setting in which faculty work tends to be stable;

2. A professor's sense of professional definition tends to resist change;

3. The feedback circle in the classroom tends to be stable (that is, students and faculty share consistent expectations about each other's role in the classroom);

4. Trying something new arouses inevitable feelings of discomfort or anxiety;

5. Faculty can become self-enhanced as they think aloud and lecture; and,

6. Faculty see few incentives to change (that is, deviation from established methods invites risk but offers relatively few rewards) (as cited in Bonwell \& Eison, 1991, p. 53).

A majority of faculty find traditional teaching practices, specifically lecture, more comfortable than not. The Social Learning Theory, developed by Albert Bandura, emphasizes that new patterns of behavior are acquired through direct experience or by observing the behavior of others (Bandura, 1977). For many faculty, then, things are the way they are today because that 
is the way they have always been (Bonwell \& Eison, 1991, p. 54). They are content experts, but many are not taught how to teach. Consequently, faculty are left to teach the way they have learned, through experience and observation. In addition, based on the identified global barriers of Loren Ekroth presented above, course redesign to include active learning would be resisted by professors. Therefore, it is important to show the possible benefits of change. As Halpern and Hakel (2003) indicate, what professors do is far less important than what they ask students to do.

\section{Purpose Statement and Significance of the Study}

In 2012, the research site received a five-year, \$2 million grant from the United State Department of Education. The funds were provided to pilot a project designed to improve student success in targeted high-risk courses and overall retention. Courses identified in the current study had significant rates of Ds, Fs, and withdrawals, ranging from $31 \%$ to $50.7 \%$ of students. The purpose of this study was to examine courses that have incorporated active learning, including peer mentoring, into courses with high rates of Ds, Fs, and withdrawals, to determine if these techniques increase student success, as measured by overall course grades.

Bonwell and Eison (1991) suggests more studies need to be conducted on alternatives to lectures involving active learning (p. 78). Higher education needs to transform research into practice, specifically pedagogy. As Smith, Sheppard, Johnson, and Johnson (2005) point out, "...the real challenge in college teaching is not covering the material for the students, it's uncovering the material with the students" (p. 2).

Faculty members can begin to reform undergraduate education by taking risks and using strategies to promote active learning (Bonwell \& Eison, 1991). A majority of the active learning research comes from the STEM field, particularly physics, and is lacking in quantitative, nonlaboratory fields, such as business. As faculty redesign their courses, the results from this study can be used to enhance and enrich the teaching and learning process. The findings of the study 
could potentially provide encouragement for faculty resisting change and/or questioning whether or not they should take the uncertain leap and redesign courses to incorporate active learning.

In addition, The National Student Clearinghouse Research Center (2015) reported that student enrollment in West Virginia's degree-granting institutions decreased by 5.1\% from prior years versus an overall postsecondary enrollment decrease of $1.7 \%$. Colleges and universities have to adjust to revenue deficits, so institutions need to focus on retaining the students who are enrolling. Increased attention to student learning works as a way for faculty and institutions to improve overall retention rates, while also providing positive reinforcement to faculty.

\section{Research Questions}

1. Is there a statistically significant increase over the baseline classes in success rates, measured by a final overall course grade of $\mathrm{C}$ or above, of students in classes that incorporate active learning?

2. Are there statistically significant differences between males and females with respect to success rates, measured by a final overall course grades of $\mathrm{C}$ or above?

3. Are there statistically significant differences among ACT scores with respect to success rates, measured by a final overall course grades of $\mathrm{C}$ or above?

4. Are there statistically significant differences among students of differing socioeconomic status with respect to success rates, measured by a final overall course grades of $\mathrm{C}$ or above?

5. Is there a correlation between students attending peer mentoring sessions and success rates, measured by a final overall course grade of $\mathrm{C}$ or above?

\section{Research Hypotheses}

1. $\mathrm{H}_{1}$ - There is a significant difference in success rates when comparing students in classes that incorporate active learning and students who were in the baseline lecture courses. 
$\mathrm{H}_{0}$ - There is no significant difference in success rates when comparing students in classes that incorporate active learning and students who were in the baseline lecture courses.

2. $\mathrm{H}_{1}$ - There is a significant difference in success rates when comparing male and female students.

$\mathrm{H}_{0}$ - There is no significant difference in success rates when comparing male and female students.

3. $\mathrm{H}_{1}$ - There is a significant difference in success rates when comparing ACT scores of students.

$\mathrm{H}_{0^{-}}$- There is no significant difference in success rates when comparing ACT scores of students.

4. $\mathrm{H}_{1}$ - There is a significant difference in success rates when comparing socioeconomic status of students.

$\mathrm{H}_{0^{-}}$There is no significant difference in success rates when comparing socioeconomic status of students.

5. $\mathrm{H}_{1}$ - There is a significant correlation between students attending peer mentoring sessions and success rates.

$\mathrm{H}_{0}$ - There is no significant correlation between students attending peer mentoring sessions and success rates.

\section{Limitations of the Study}

Certain design limitations exist in this study. The current study was not an evaluation of faculty engagement in redesign level. Faculty members were given academic freedom to implement any active learning strategies necessary to obtain course objectives. Faculty were offered the same faculty development workshops and D. Fink's self-directed, course design workbook provided in appendix B. However, it is difficult to redesign courses in different 
subjects with different course objectives, and then implement the exact same strategies.

Therefore, future studies could examine course redesigns of the same course across different sections.

Another limitation of the design is the generality of peer mentoring success. The research question measured the success of students attending peer mentoring by a passing or failing grade. While this is important, it would be suggested in future studies to look at individual student success for students who normally are "C" students, and may have increased their grade to an "A." This success is important, but difficult to measure with a quantitative study. Therefore, it could be incorporated in a qualitative study, utilizing student focus groups.

A data type limitation existed in the current study. Socioeconomic status was determined by a student's Expected Family Contribution (EFC). The information students and families report on the Free Application for Federal Student Aid (FAFSA) is used to calculate an EFC. It measures financial strength according to a formula established by law (United States Department of Education, 2016). However, the same factors are not used as with socioeconomic status, but they can be interpreted similarly. Students' socioeconomic status was not available to this researcher; therefore, the EFC was used.

\section{Summary}

Between $73 \%$ and $83 \%$ of faculty report their primary method of instruction is lecturing, despite several studies showing students prefer strategies promoting active learning (Bonwell \& Eison, 1991; Cedaka, 2012). Halpern and Hakel (2003) acknowledged that lectures are great for getting students to repeat information, but it is one of the worst teaching strategies for promoting in-depth understanding. The purpose of this study was to examine courses that have incorporated active learning, including peer mentoring, into courses with high rates of Ds, Fs, and withdrawals 
to determine if these techniques increase student success, measured by overall course grades.

Limitations of the study were also addressed in this chapter. 


\section{Chapter II}

\section{Literature Review}

Several authors claim the attention span of a student during lecture is roughly 10-15 minutes (McKeachie \& Svinicki, 2013; Benjamin, 2002; Wankat, 2002; McKeachie, 1986). Bligh (2000) provides varying types of evidence to support the above claim. After that time, attention begins to drop dramatically, resulting in a loss of retention of lecture material. In fact, Hartley and Davies discovered students remember $70 \%$ of information presented in the first ten minutes, but only $20 \%$ of the material presented in the last ten minutes (as cited in Prince, 2004, p. 4).

Barr and Tagg (1995) discuss a dominant paradigm that mistakes instruction/teaching as a means to an end. "To say that the purpose of colleges is to provide instruction is like saying that General Motors' business is to operate assembly lines or that the purpose of medical care is to fill hospital beds" (p. 13). They continue to argue that our mission in higher education is not instruction; it is to produce learning to every student by whatever means work best.

Although evidence exists on better ways of teaching, research indicates faculty continue to use the methods they are most comfortable with (Csapo \& Wilson, 2001). In a study conducted at three different universities in different geographical regions and division ranking, Csapo and Wilson's (2001) findings suggested the belief by faculty that lecture continues to be the most effective and efficient means of conveying information. These findings appear in numerous studies, but even more significant is that only a very small number of faculty stated their teaching methods were influenced by any factors directly related to students, such as student interest (p. 69). This is alarming considering students are the reason universities exist. Thus, it is essential that universities put students back in their visions and missions for a hopeful future. 
The university where data was collected aspires to be nationally recognized as a model for accessible learner-centered institutions and promote student success (Fairmont State University, 2015). Therefore, to meet this vision, it is imperative for the university to put research into practice by implementing active learning pedagogy. A wide gap exists between what we say we want of higher education and what its structures actually provide (Barr \& Tagg, 1995; Bonwell \& Eison, 1991). Thus, for the $21^{\text {st }}$ century, colleges and universities need to discard the Instruction Paradigm and restructure what we do based on the Learning Paradigm (both of which were introduced in chapter one).

In defining the instruction and learning paradigms, Barr and Tagg (1995) argued that the mission, vision, culture, and structure of a college must all undergo the shift. They considered six dimensions as important functions in this paradigm shift from instruction to learning. Table 1 describes these comparisons:

Table 1

Comparing the Two Educational Paradigms

\section{Mission and Purposes}

\section{The Instruction Paradigm}

The Learning Paradigm

- Produce learning

- Elicit student discovery and construction of knowledge

- Create powerful learning environments

- Improve the quality of learning

- Achieve success for diverse students

\section{Criteria for Success}

\section{The Instruction Paradigm}

\section{The Learning Paradigm}

- Inputs, resources

- Quality of entering students

- Curriculum development, expansion

- Quantity and quality of resources

- Enrollment, revenue growth

- Quality of faculty, instruction
- Learning and student-success outcomes

- Quality of exiting students

- Learning technologies development, expansion

- Quantity and quality of outcomes

- Aggregate learning growth, efficiency 
- Quality of students, learning

\section{Teaching/Learning Structures}

The Instruction Paradigm

\section{The Learning Paradigm}

- Atomistic; parts prior to whole

- Time held constant, learning varies

- 50-minute lecture, 3-unit course

- Classes start/end at same time

- One teacher, one classroom

- Independent disciplines, departments

- Covering material

- End-of-course assessment

- Grading within classes by instructors

- Private assessment

- Degree equals accumulated credit hours
- Holistic; whole prior to parts

- Learning held constant, time varies

- Learning environments

- Environment ready when student is

- Whatever learning experience works

- Cross discipline/department collaboration

- Specified learning results

- Pre/during/post assessments

- External evaluations of learning

- Public assessment

- Degree equals demonstrated knowledge and skills

\section{Learning Theory}

\section{The Instruction Paradigm}

\section{The Learning Paradigm}

- Knowledge exists in each person's mind and is shaped by individual experience

- Knowledge comes in "chunks" and "bits" delivered by instructors

- Learning is cumulative and linear

- Fits the storehouse of knowledge metaphor

- Learning is teacher centered and controlled

- "Live" teacher, "live" students required

- The classroom and learning are competitive and individualistic

- Talent and ability are rare

- Knowledge is constructed, created, and "gotten"

- Learning is a nesting and interacting of frameworks

- Fits learning how to ride a bicycle metaphor

- Learning is student centered and controlled

- "Active" learner required, but not "live" teacher

- Learning environments and learning are cooperative, collaborative, and supportive

- Talent and ability are abundant

\section{Productivity/Funding}

\section{The Instruction Paradigm}

\section{The Learning Paradigm}

- Definition of productivity: cost per unit of learning per student

- Funding for learning outcomes 


\section{Nature of Roles}

The Instruction Paradigm

- Faculty are primarily lecturers

- Faculty and students act independently and in isolation

- Teachers classify and sort students

- Staff serve/support faculty and the process of instruction

- Any expert can teach

- Line governance; independent actors

\section{The Learning Paradigm}

- Faculty are primarily designers of learning methods and environments

- Faculty and students work in teams with each other and other staff

- Teachers develop every student's competencies and talents

- All staff are educators produce student learning and success

- Empowering learning is challenging and complex

- Shared governance; teamwork

Note. Table from Barr \& Tagg, (1995), p. 16-17.

As Barr and Tagg (1995) note, the transition from Instruction Paradigm to Learning Paradigm will not be instantaneous. Since this article dates back two decades, one can agree that the paradigm shift has not been sudden, and it continues to be a topic of discussion in the educational system. However, it has become a means through which organizations have begun to see the need for new approaches. Once the shift begins, everything has the potential for change. Higher education should be encouraged to reconstruct the ways in which they interact with and value students.

\section{Course Redesign}

L. Dee Fink (2013) addresses shortcomings of higher education, mentioning that faculty want their students to achieve higher types of learning, but they continue to use teaching practices that are not effective at promoting this desired learning. Research continues to report the primary method of instruction is lecture (Fink, 2013; Cedaka, 2012; Csapo \& Wilson, 2001; Sousa, 2001; Finkelstein, Seal, \& Schuster, 1998; Bonwell \& Eison, 1991). While lectures are great for getting students to gain fundamental information, Halpern and Hakel (2003) cite that it is one of the worst teaching strategies for promoting in-depth understanding. Fink (2013) presents astonishing 
research from others who find no significant difference between students who take courses and those students who do not. Because students are not learning general knowledge, not developing higher-level cognitive skills, and not retaining knowledge very well, he provides a solution which provides significant learning experiences for students.

The characteristics of a significant learning experience includes both a process and an outcome dimension. The process must engage students in their learning, and a higher level of energy must be associated with it. They will learn something valuable in their life, but they will also have had lasting change that will continue after the course is over. Fink (2013) provides a twelve-step model for integrated course design, presented in Figure 1.

\section{InItIAL Design Phase: Build Strong Primary Components \\ Step 1. Identify important situational factors \\ Step 2. Identify important learning goals \\ Step 3. Formulate appropriate feedback and assessment procedures \\ Step 4. Select effective teaching/learning activities \\ Step 5. Make sure the primary components are integrated \\ Intermediate Design Phase: Assemble the Components into a Coherent Whole}

Step 6. Create a thematic structure for the course

Step 7. Select or create an instructional strategy

Step 8. Integrate the course structure and the instructional strategy to create an overall scheme of learning activities

\section{Final Design Phase: Finish Important Remaining Tasks}

Step 9. Develop the grading system

Step 10. De-Bug possible problems

Step 11. Write the course syllabus

Step 12. Plan an evaluation of the course and of your teaching

Figure 1. The twelve steps of integrated course design. Adapted from "Creating Significant Learning Experiences," by L.D. Fink, 2013, p. 74.

Fink (2013) built on Benjamin Bloom and Associates' notorious cognitive taxonomy of educational objectives, which has been cited nearly 25,000 times and has been used for over six decades. The 1950s classification consisted of six categories of learning, which were arranged in a hierarchical sequence. The categories, ordered simple to complex and concrete to abstract, are 
knowledge, comprehension, application, analysis, synthesis, and evaluation (Bloom, 1984).

Fink's taxonomy of significant learning builds upon, but goes beyond these categories and includes six kinds of learning, as illustrated in Figure 2.

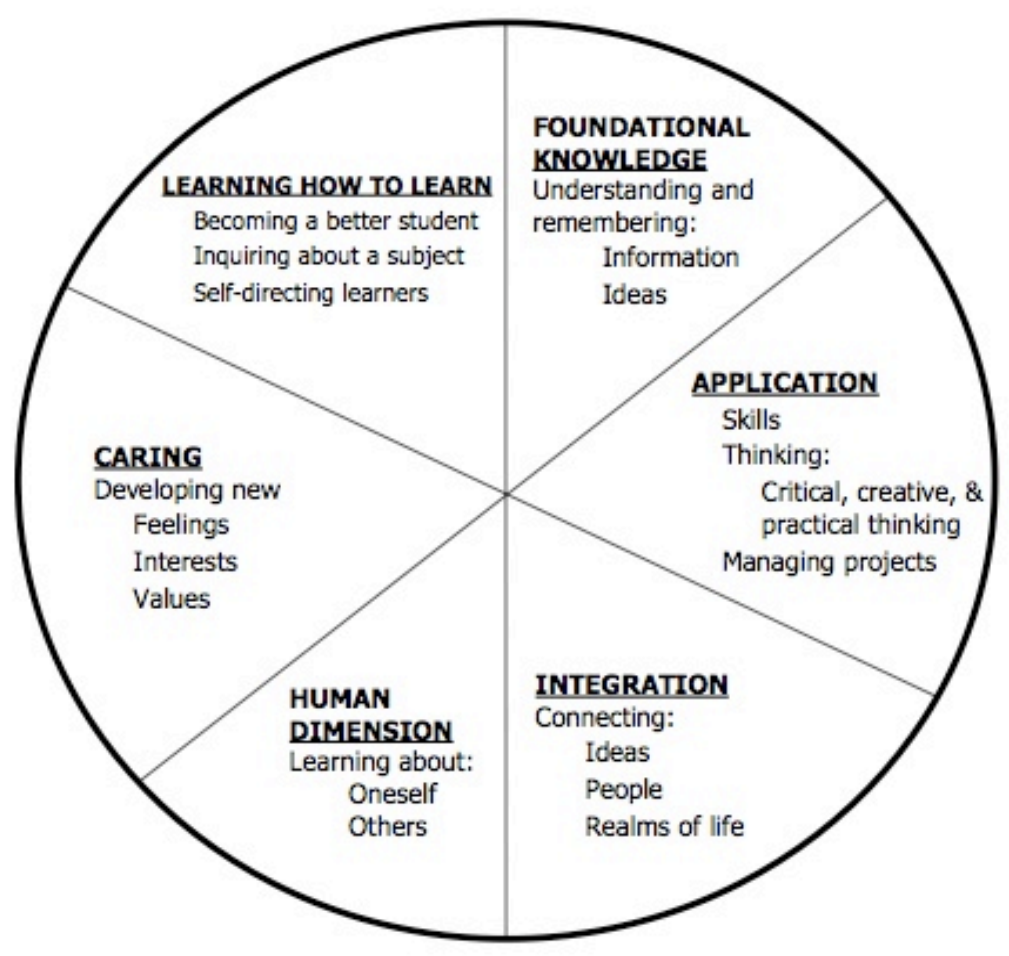

Figure 2.Taxonomy of significant learning. This figure illustrates L.D. Fink's six categories of significant learning. Adapted from "Creating Significant Learning Experiences," by L.D. Fink, 2013, p. 35.

The foundational knowledge category of significant learning is the specific information we want students to understand and remember, such as facts, principles, perspectives. This category provides the basic understanding that is necessary for other kinds of learning, and can be compared to Bloom's knowledge category. In the application category, students learn to engage in thinking critically, creatively, and practically, and developing skills. The integration category is beneficial for students to identify and connect their learning experiences. This encompasses the interdisciplinary learning we seek when creating academic programs as a whole. The fourth category is identified as human dimension, which intends for students to learn something in the 
course about themselves (self-image), or how they interact with others. And as Fink describes, they discover the personal and social implications of what they have learned. The fifth category is caring, and it happens when students care about something to a greater degree regarding their feelings, interests, and/or values in relation to a subject. The final category, learning how to learn, envisions teaching students to become self-directed learners, so they can keep learning after the course is over (Fink, 2013; Fink 2003).

The categories are reported from one to six, but as shown in Figure 3, Fink's Taxonomy of Significant Learning is intended to be interactive rather than hierarchical. Fink (2013) indicates this interrelation matters because the different kinds of learning are "synergistic" (p. 37). Teachers are not forced to give up one kind of learning for another, and in fact, it will enhance, not decrease student achievement in the other types of learning. Therefore, when a course is able to support all six categories of learning, a student has truly had a significant learning experience. 


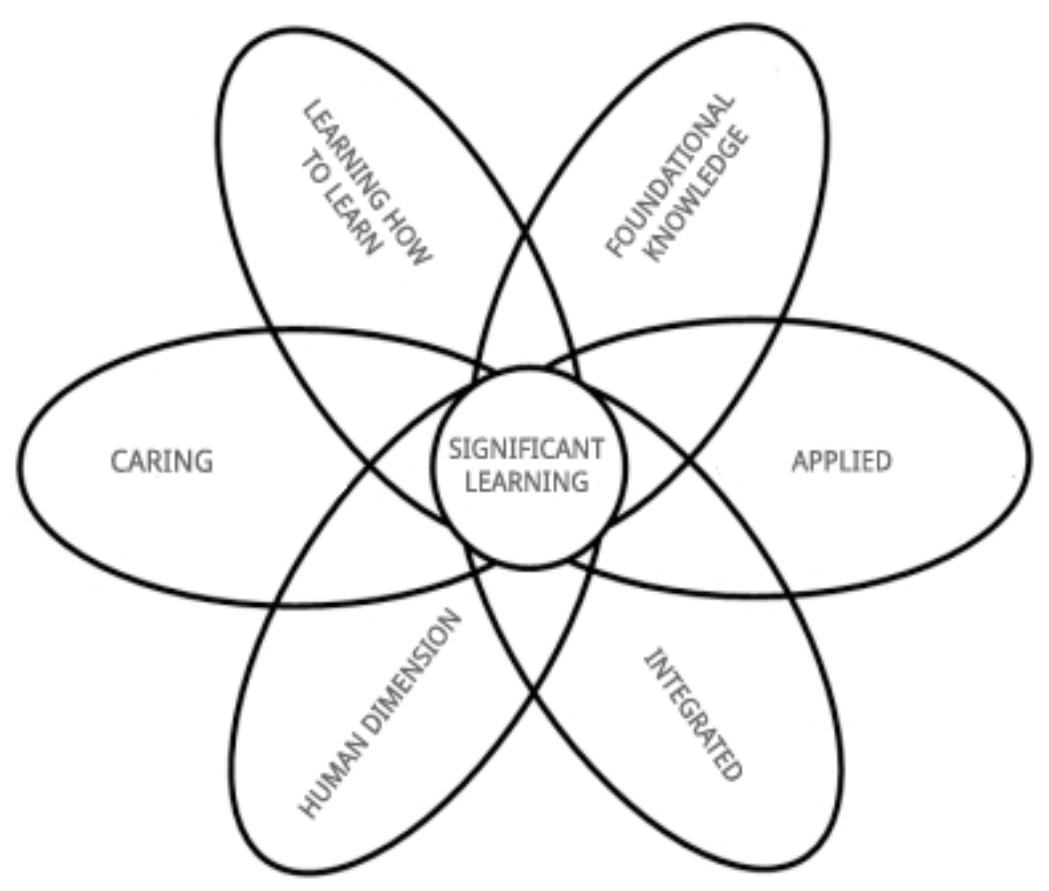

Figure 3. Interactive nature of significant learning. This figure illustrates L. D. Fink's six categories of significant learning being relational and interactive. Adapted from "Creating Significant Learning Experiences," by L.D. Fink, 2013, p. 37.

In order to design significant learning experiences for students, faculty need to be mindful regarding course design. Integrated course design (ICD) is used to develop courses or redesign courses to encourage learner-centered, significant learning for students. Fink's model of integrated course design is a comprehensive proposal that encompasses some of the work of Wiggins and McTighe (2005), which is cited significantly by authors (Fink, 2013; McKeachie \& Svinicki, 2013; Prince, 2004). In addition, Fink's design process includes common elements of Biggs and Tang (2011), who are cited over 13,500 times in higher education literature. The basic features of Fink's ICD are shown in Figure 4. 


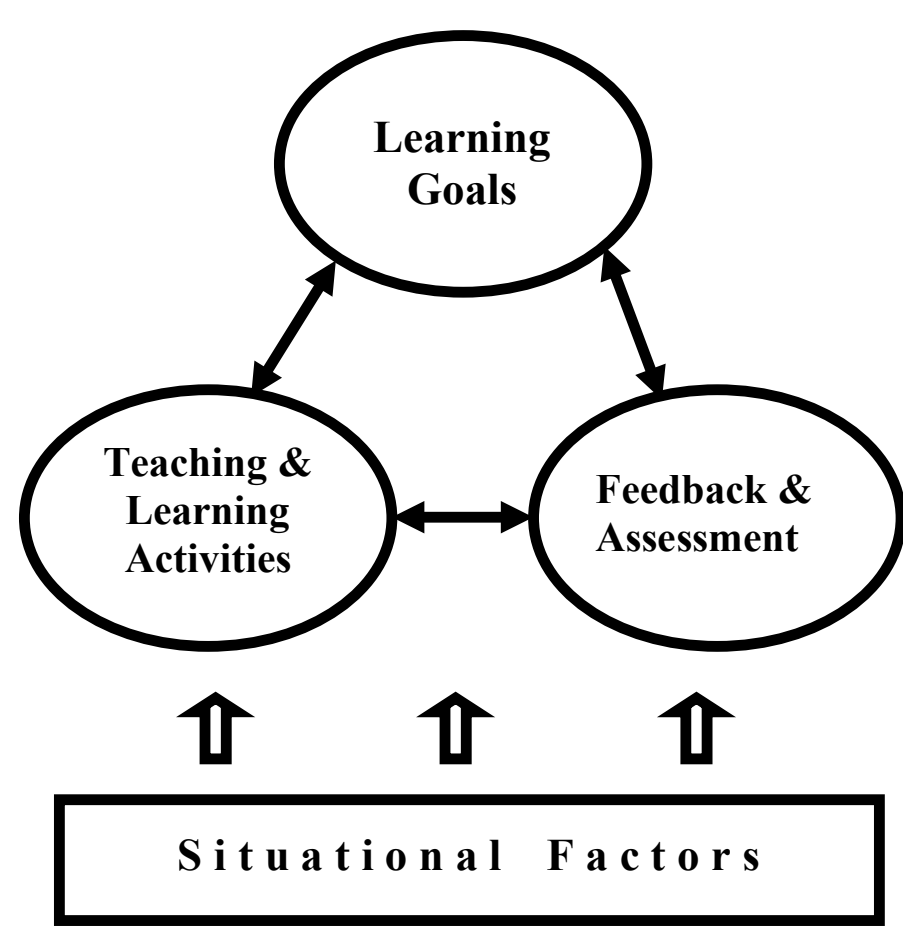

Figure 4. Key components of integrated course design. Adapted from "Creating Significant Learning Experiences," by L.D. Fink, 2013, p. 70.

Situational factors refer to the information that needs to be gathered and considered, which are provided more in depth in appendix B. Some factors to consider include specific context. In order for the faculty member to address these specific contexts, questions such as the number of students in the course, the level of the course, and which delivery method, online or in-person should be considered. Another situational factor to ponder is the expectation of others. Is this course expected to meet certain department goals, university goals, professional licensing requirements? Lastly, the nature of the subject, students, and teacher needs addressed. Is this subject primarily theoretical, practical, or a combination? What feelings do students have about this subject? What prior knowledge or experiences related to this subject do they bring with them? What beliefs and values does the teacher bring to the course? How do these compare with those of students? (Fink, 2007, p. 14). The information gathered from these different questions is 
then used, as the arrows indicate in figure 3, to make the decisions on how the course will operate. The three circles in the design indicate the decisions that need to be made.

The very first decision that needs to be made is what we want students to learn. Wiggins and McTighe (2005) label this as backward design. As the name implies, we must ask ourselves what we want our students to know after the course is over. Fink (2013) elaborates on this question and asks, "What is it I hope that students will have learned that will still be there and have value, several years after the course is over?" (p. 71). The answer to these forms the foundation of the learning goals. The six categories of learning, presented earlier, are helpful at this stage of design. The second decision, of what feedback and assessment will look like, is the reflection on how the faculty and students will know if they have achieved the intended learning goals. Last, the teaching and learning activities are decided on and are considered based on what the student needs to do in order to perform well on assessments. These three initial decisions need to be integrated, and should reflect and support one another.

The above information covers the first five steps in the ICD, which is the "Initial Phase: Build Strong Primary Components" Fink (2013) outlines (p. 74). The intermediate phase covers steps six through eight. Step six is the point where a course structure is created. The faculty member identifies the most important concepts, issues, topics, or themes, and arranges them in a sequence. In step seven, faculty identify specific teaching strategies, such as reading, lectures, class discussion, small-group activities, and others. The final step in the intermediate phase is integrating steps six and seven into an overall scheme of learning activities. At the conclusion of step eight, one should be able to lay out a weekly schedule.

The final phase, and steps nine through twelve, include what some would view as the finishing touches. The grading system, the course syllabus, and a plan of how you will evaluate the course and your teaching are developed in this phase. The potential problems are debugged, 
by attempting to anticipate problems and solving them ahead of time (Fink, 2013). The faculty who were a part of the redesign work done at the university were provided additional faculty development sessions on certain steps of the integrated course design. For example, faculty attended active learning and course syllabi workshops, along with a workshop entitled "How Research Can Inform Course Design, Active Learning, and Assessment.” This is outlined in chapter three.

A faculty member involved in course redesign for the current research, attended the Course Design Institute (CDI) at the University of Virginia, which has been assisting faculty members for over two decades with course design and redesign based on L. Dee Fink's work presented above. The hands-on, multi-day workshop is described as an intensive process, focused on substantial course redesign that promotes significant, long-term learning. The three components of the CDI's approach include Fink's taxonomy of significant learning, the concepts of backward and integrated course design (Center of Teaching Excellence of the University of Virginia, 2016). Some of his redesigned material is included in Appendices C, D, and E. Appendix D includes part of his course syllabus.

His syllabus is learner-centered, providing thought provoking interest into the course for students, evident throughout the material. Also, active learning is apparent and distinct throughout the syllabus, and gives meaning to why the course is important. The course description connects the importance of the course to students by applying real-life examples. Many of them will buy a house, a car, and/or save for retirement, so they connect to that scenario given in the course description. If he would have only noted that the concepts in the course are used by financial professionals, he would have lost interest of many students who would not currently identify with that field. It should also be noted that instead of the usual "Course Description" title, he asks a question, "Where are we going?" Furthermore, the question includes 
the use of "we" instead of "you." Appendix D shows his redesigned schedule of learning, while Appendix E reflects the lecture based course schedule. Instead of "Intro \& The Role of Managerial Finance," it is revamped to include a question for students to ponder before attending the class, "Why would anyone want to be a financial manager?" (Kremer, 2017).

Appendix F reflects another course redesign, where the faculty member provides a schedule of assignments for her Principles of Accounting students. Students are provided a color-coded schedule that provides evidence of active learning daily (Muto, 2016). The literature presented below provides a compelling argument to support active learning in the classroom.

\section{Active Learning}

Traditional lectures have been a core in business school curricula; however, business educational professionals suggest that active and experiential learning is critical to engage and retain today's generation of students (Roach-Duncan, 2010; McCarthy \& McCarthy, 2006). Teamwork, collaboration and communication skills are characteristics of successful workplace environments (Daly, Reid, Buckley \& Doyle, 2016). As educators, we should ensure that knowledge is created and built upon rather than transferred. We must foster and encourage the characteristics desired in today's workplace. To do so, active learning strategies need to be integrated into the classroom.

Freeman et al. (2014) meta-analyzed 225 studies, the largest and most comprehensive meta-analysis of the undergraduate STEM education to date, comparing student performance in undergraduate science, technology, engineering, and mathematics courses using traditional lecturing versus active learning. Their findings indicate students in traditional lecturing courses were 1.5 times more likely to fail than students in active learning courses. Active learning increased student performance on examinations by $6 \%$, and suggested a greater impact on student mastery of higher-versus lower-level cognitive skills (p. 8411). 
Carl Wieman, Nobel Prize winner in physics, along with colleagues Deslauriers and Schelew, compared two large $(\mathrm{N}=267$ and $\mathrm{N}=271)$, undergraduate introductory physics courses using two different instructional approaches with the same learning objectives. One of the courses was taught by the traditional lecture method, delivered by a faculty member with high student evaluations and several years' experience teaching the course. The findings of the traditional course were compared to those of an interactive learning style method, taught by a postdoctoral fellow using instruction based on research on learning. They found an increase in student attendance, higher engagement, and more than twice the learning in a course where instruction was based on research of learning (Deslauriers, Schelew, \& Wieman, 2011).

Similarly, Richard Hake's (1998) work, cited in almost 3,400 articles, examined pre- and post- test data for $62(\mathrm{~N}=6,542)$ introductory physics courses. The traditional courses, defined as using little to no use of interactive engagement methods and relying primarily on passive-student lectures, accounted for fourteen courses $(\mathrm{N}=2,084)$. The interactive engagement methods courses $(\mathrm{N}=4,458)$ were "designed at least in part to promote conceptual understanding through interactive engagement of students in heads-on and hands-on activities which yield immediate feedback through discussion with peers and/or instructors" (p. 65). Hake's findings suggest interactive engagement method courses enhance problem-solving abilities and statistically had an improvement of two-standard deviations above that of traditional courses.

Much of the research confirms that active learning provides opportunities for enhanced student engagement, performance, problem-solving abilities and, therefore, student learning (Freeman et al., 2014; Deslauriers, Schelew, \& Wieman, 2011; Hake, 1998; Chickering \& Gamson, 1987). However, a majority of the active learning research comes from the STEM field, particularly physics, and lacks in the quantitative, non-laboratory fields, such as business. 


\section{Student Peer Mentoring}

Many institutions, parents, and students define undergraduate quality by campus beauty, faculty reputational rankings, and the range of both recreational and support services offered to students (Guskin, 1994). As continued budget cuts occur, institutions are increasingly seeking ways to supplement traditional classroom learning (Colvin \& Ashman, 2010). Institutions that support mentoring programs show a commitment to quality education, which is appealing to parents and students. Formal mentoring is being widely implemented to assist with institutional and pedagogical goals. These goals include recruitment and retention of students, increasing learning, and enhancing relationships with faculty and other students (Rodger \& Tremblay, 2003).

Bonwell and Eison (1991) identify peer teaching as an active learning pedagogy, which has existed since the later part of the 18 th century. However, at that time, in the early $90 \mathrm{~s}$, it was recognized as a relatively new occurrence in higher education. The theoretical framework underlying peer mentoring is constructivism, where mentors "take on the role of facilitators to help learners process and understand information and construct their own knowledge, rather than the role of information givers (Ning \& Downing, 2010, p. 921). Peer mentoring provides unlimited amounts for student involvement, and he/she benefits from the immediate, on-going feedback from the mentor and other peers. The student is involved in the learning environment and influencing how the sessions will go, which contributes greatly to learner interest, motivation and metacognition development (Ning \& Downing, 2010).

Ning and Downing (2010) conducted a study with 430 first-year undergraduates from the business discipline with a program similar to the current university's School of Business Student Peer Mentor Program being studied. The academic support program provided undergraduate students enrolled in particular courses to regularly scheduled, out of class, peer-facilitated 
sessions. Aims of the study included the examination of the argument that peer-assisted learning leads to gains in motivation and information processing skills, alongside academic performance gains; and to establish whether or not the program had a positive influence on students' learning competence and use of study skills, mediating academic performance (p. 924). This study showed that participants in the peer program had significantly larger improvements than nonparticipants in information processing and motivation scores. In addition, data supported their hypothesis that the program had a significant direct effect on both learning competence and academic performance.

Fox and Stevenson (2006) using a mixed-methods study exploring the effectiveness of peer mentoring with accounting and finance students found that peer mentoring has a positive effect on academic performance of the first-year students. Third year students served as the mentors to first year students, using a semi-formal tutorial setting. The mentoring sessions addressed issues such as writing skills, study techniques, and examination preparation. The mentors did not serve the role as academic tutors; rather they shared their course experiences and the approaches they had used in their own coursework.

In a similar study, Rodger and Tremblay (2003) examined the retention and achievement of participating first-year university students in a peer mentoring program. A sample size of 983 first year students was used; 537 were assigned to participate in the program, while the remainder served as the control group, and agreed to take a motivation inventory and provide final grades. Results indicated the mentored students had significantly higher final grades than did students in the control group. However, they found no effect on retention from the first year to the second.

\section{Summary}

In conclusion, this chapter reviewed literature written by scholars who embrace the learning paradigm, as discussed by Barr and Tagg (1995), and promote active learning 
pedagogies, such as peer mentoring. Much of the discussion emphasizes the need for change in higher education. In particular, courses need to be designed to promote significant learning experiences, and employ teaching strategies that are used to increase and improve overall student learning. This chapter provided the framework for which courses in the study were redesigned. The intent is to contribute and build on to the current active learning research which lacks in the quantitative, non-laboratory courses such as business. 


\section{Chapter III}

\section{Research Design and Methodology}

\section{Methods}

This study is designed to parallel the five-year grant awarded to a small university located in the mid-Atlantic region, and to explore whether implementing active learning and student peer mentoring increases success rates, measured by a final overall course grade of a $\mathrm{C}$ or above. The researcher intends to utilize the findings of this research to implement best practices for course design to support and encourage faculty. The findings can assist administrators with budget planning and allocation of funding towards professional development for faculty.

This chapter presents the methodology, including the site selection, institutional profile, data collection, and data analysis that was used to address the research questions described in chapter one and included below:

1. Is there a statistically significant increase over the baseline classes in success rates, measured by a final overall course grade of $\mathrm{C}$ or above, of students in classes that incorporate active learning?

2. Are there statistically significant differences between males and females with respect to success rates, measured by a final overall course grade of $\mathrm{C}$ or above?

3. Are there statistically significant differences among ACT scores with respect to success rates, measured by a final overall course grade of $\mathrm{C}$ or above?

4. Are there statistically significant differences among students of differing socioeconomic status with respect to success rates, measured by a final overall course grade of $\mathrm{C}$ or above?

5. Is there a correlation between students attending peer mentoring sessions and success rates, measured by a final overall course grade of $\mathrm{C}$ or above? 


\section{Research Hypotheses}

1. $\mathrm{H}_{1}$ - There is a significant difference in success rates when comparing students in classes that incorporate active learning and students who were in the baseline lecture courses. $\mathrm{H}_{0^{-}}$There is no significant difference in success rates when comparing students in classes that incorporate active learning and students who were in the baseline lecture courses.

2. $\mathrm{H}_{1}$ - There is a significant difference in success rates when comparing male and female students.

$\mathrm{H}_{0}$ - There is no significant difference in success rates when comparing male and female students.

3. $\mathrm{H}_{1}$ - There is a significant difference in success rates when comparing ACT scores of students.

$\mathrm{H}_{0}$ - There is no significant difference in success rates when comparing ACT scores of students.

4. $\mathrm{H}_{1}$ - There is a significant difference in success rates when comparing socioeconomic status of students.

$\mathrm{H}_{0}$ - There is no significant difference in success rates when comparing socioeconomic status of students.

5. $\mathrm{H}_{1}$ - There is a significant correlation in students attending peer mentoring sessions and success rates.

$\mathrm{H}_{0^{-}}$There is no significant correlation in students attending peer mentoring sessions and success rates. 


\section{Site Selection and Institutional Profile}

The research site is located in a small, mid-Atlantic city with the United States Census Bureau (2015) estimating the population to be 18,740 people. It is the state's third largest university, with an enrollment around 4,600 students, of which 72\% receive some form of financial aid. The University offers more than 80 bachelor's programs and graduate programs in business, criminal justice, architecture, and education. The average class size is 22 students, with a 17:1 student to faculty ratio (Fairmont State University, 2015).

In fall 2016, the university reported a total of 3,751 undergraduate students, of which 2,060 were female and 1,691 were male. Thirty states were represented, with international students totaling 112. Among the 3,751 undergraduate students, 3,171 self-identified as white, 214 as black/African American, 133 as two or more races, 101 as non-U.S. citizens, 81 as Hispanic, 20 as Asian, 20 as race or ethnicity unknown, 8 as American Indian/Alaska Native, and 3 as Hawaiian/Pacific Islander. Table 2 provides the number of students, from fall 2016, in each age range. 
Table 2

Age Range of Fall 2016 Undergraduate Students

\begin{tabular}{ll}
\hline Age & Number of Students \\
\hline $00-18$ & 92 \\
$18-19$ & 1305 \\
$20-21$ & 963 \\
$22-24$ & 653 \\
$25-29$ & 335 \\
$30-34$ & 150 \\
$35-39$ & 94 \\
$40-49$ & 106 \\
$50-64$ & 50 \\
$65-99$ & 3 \\
\hline
\end{tabular}

Based on demographic data and self-reporting, more than half of the university's firsttime entering students are first generation college students $(60 \%)$ and low-income (66\% eligible for Pell grants). In addition, bachelor's degree completion rate is low: $34.8 \%$ within six years and $15.5 \%$ within four years. Hence, the self-report of over one-third (39\%) of entering freshman not being academically prepared for higher education (Revitalizing Curricula as Experiential, Collaborative and Technology-Rich, 2012). The ACT Profile Report (2011) for the state of West Virginia confirms the self-report of entering freshman, with a report of only $17 \%$ of students (25\% nationwide) meeting all four ACT benchmark scores indicating college-readiness. 
In 2012, the United States Department of Education awarded the university, a five-year, \$2 million Title III Strengthening Institutions Program grant to address institutional weaknesses of low student persistence and academic success in those programs. The project was designed to improve student success in targeted high-risk courses, ones that traditionally have high rates of Ds, Fs, and withdrawals (DFW), and to increase student retention.

\section{Data Collection}

Approval from the West Virginia University Institutional Review Board (IRB) was

obtained for this study, protocol \#1605127080. In addition, the selected institution's Institutional Review Board has granted permission to collect data from the student population.

The data came from students enrolled in the School of Business courses identified by the Title III grant as courses with high grades of Ds, Fs, and withdrawals. The courses identified for this dissertation are based on those identified courses, but were specifically chosen based on course redesign, which included active learning and implementation of student peer mentoring. The courses identified by the grant and meet the prior criteria have been identified in Table 3 . The DFW percentage rates are also included. For example, in the area of economics, $46 \%$ of students receive a DFW in the general studies economics course, macroeconomics, and microeconomics. In the general studies economics course, $50.7 \%$ of students receive a $\mathrm{D}$, F, or withdrawal from the course. 
Table 3

School of Business High Risk Courses: Percent DFW Rates- Fall 2011

\begin{tabular}{ll}
\hline Course & DFW Percentage Rate \\
\hline Accounting & $47 \%$ \\
$\quad$ Principles of Accounting I & $46.7 \%$ \\
Economics & $46 \%$ \\
$\quad$ Introduction to Economics & $50.7 \%$ \\
Macroeconomics & $49.8 \%$ \\
Microeconomics & $36.8 \%$ \\
Finance & $31 \%$ \\
Introduction to Financial & $31.3 \%$ \\
Management & \\
Information Systems Management & $36 \%$ \\
Introduction to Computing & $38 \%$ \\
Business Programming Logic & $34.8 \%$
\end{tabular}

Note. Adapted from Revitalizing Curricula as Experiential, Collaborative and Technology-Rich, (2012), p. 13.

Course Descriptions. The courses being analyzed in this study are 16-week semester long, and offered as 3-hour undergraduate courses. The economics course is a general studies course, which provides students with a broad background in the field. Students are exposed to both micro- and macroeconomic theory and international economics. The other two economics courses approach each subject from the point of view of micro- and macroeconomics.

The computing course is a general elective course meant to provide an overview of computing and its social implications, and serves as an introductory course for majors and non- 
majors. Topics include organization of a computer system, problem solving using productivity software applications, and investigations of emerging areas in information systems. The Business Programming Logic course is designed to introduce problem-solving and programming logic for business applications. Students are introduced to Visual Basic programming language.

The principles of accounting course covers fundamental accounting theory and procedure, including organization of accounts, the accounting cycle, and preparing financial and operating statements. The introduction to financial management course is intended to give students a background in the field of financial management, and places an emphasis on cost of capital, cost of external capital, cost of retained earnings, and covers material on investment and financial decisions ("Fairmont State University Undergraduate Academic Catalog," 2015-16).

Course Redesigns. As indicated above, the courses identified in this study were courses targeted by the Title III grant as high DFW courses and specifically chosen based on course redesign, which included active learning and implementation of student peer mentoring. The course redesign did not have a specific guideline, but faculty were provided several of the same faculty development training sessions. Five total faculty members, three females and two males, participated in the course redesigns. Two faculty members (one male, one female) participated in the accounting course redesigns; one female was responsible for all the economics course redesigns; one male was responsible for the finance course redesign; and one female was responsible for the two information systems management redesigns. Table 4 provides the overview and description of the sessions offered to assist faculty with their course redesign. 
Table 4

Professional Development Sessions Offered to Assist in Course Redesign

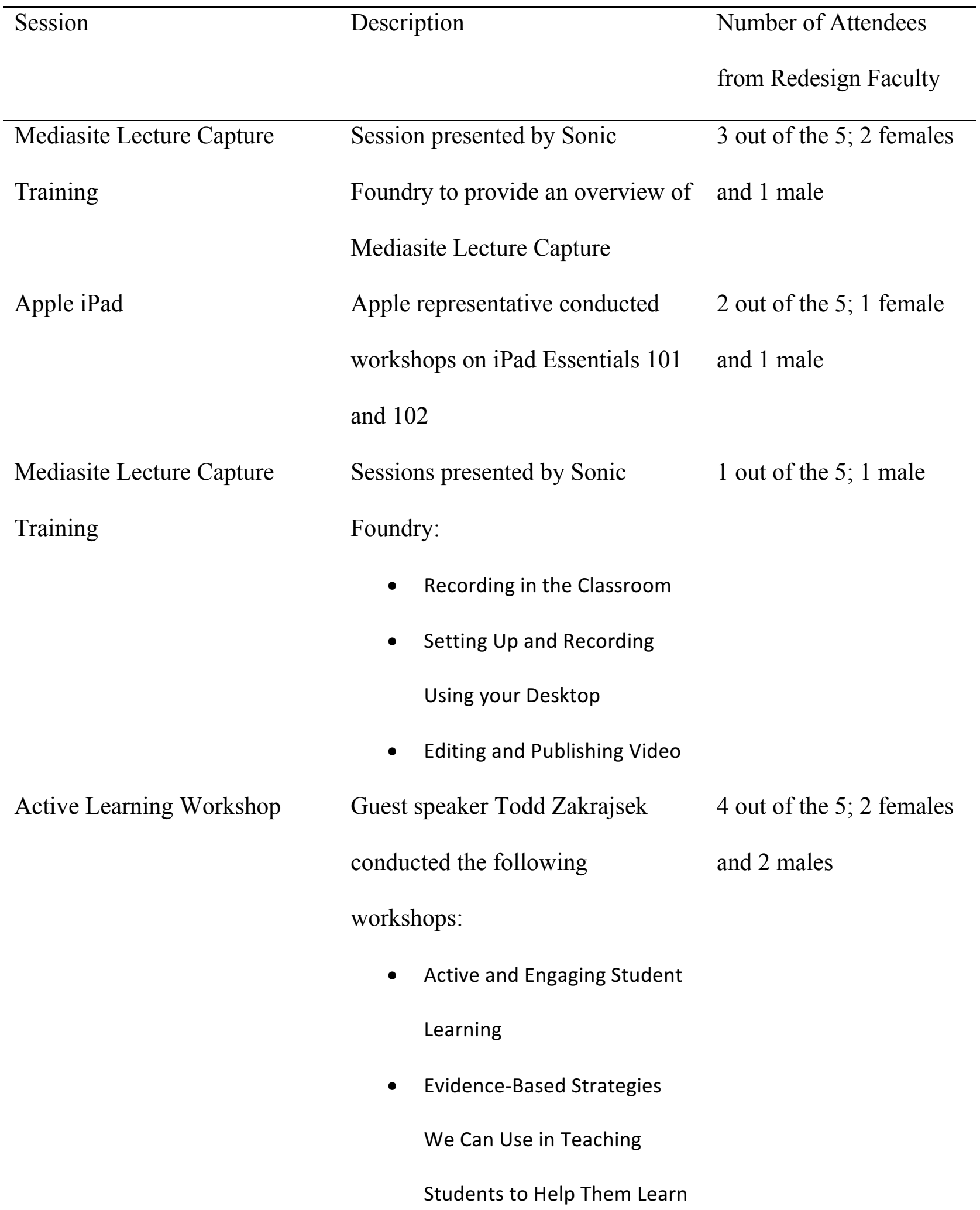


Better

- Identifying and Addressing

Critical Challenges in Creating

Effective Learning Experience

for our Students

“Sticky” Syllabi: Creating

Course Guides to Motivate

Students

How Research Can Inform

Course Design, Active

Learning, and Assessment

Practical and Effective

Strategies to Get Your Students

Engaged

Promoting Metacognition

through Zest, Grit and Sweat

Setting the Stage for Learning:

The Syllabus as a Learning

Resource
All-day workshop presented by

Drs. Christina Petersen and Chery

Neudauer

Three workshops presented by

Drs. Tim Wilson and Ollie Dreon

Session presented by Dr. Elizabeth

Barkley

Session presented by Dr. Lolita

Paff

Session presented by Dr. Lolita

Paff
4 out of the $5 ; 2$ females

and 2 males

4 out of the $5 ; 2$ females

and 2 males
4 out of the $5 ; 2$ females and 2 males

3 out of the $5 ; 1$ female and 2 males 3 out of the $5 ; 1$ female and 2 males

In addition, faculty were offered opportunities to attend different course design workshops. The faculty involved in course redesign were encouraged to utilize L. Dee Fink's Self-Directed Guide to Designing Courses for Significant Learning, found in the appendices and 
framework presented in chapter two. One faculty member attended the Course Design Institute (CDI) at the University of Virginia, which has been assisting faculty members for over two decades with course design and redesign based on L. Dee Fink's work presented in previous chapters. The hands-on, multi-day workshop is described as an intensive process, focused on substantial course redesign that promotes significant, long-term learning. The three components of the CDI's approach include a taxonomy of significant learning and the concepts of backward and integrated course design, presented and described in chapter two (Center for Teaching Excellence of the University of Virginia, 2016).

Peer Mentoring Program. The student peer mentoring program in the School of Business at the research site was established as a direct result of a five-year grant awarded to the university in 2012. The program recruits high-achieving students, identified by faculty members and referred to the Learning Coordinator to serve as peer mentors. Interested students are interviewed by the Learning Coordinator, and if hired, they participate in one-on-one training from the Learning Coordinator and an experienced peer mentor. During the training, they learn the theory of peer mentoring, including understanding the roles and responsibilities of a peer mentor, enriching communication skills, and facilitating learning. The peer mentors have regular communication with the Learning Coordinator and other peer mentors in person and through email, and meet on a regular basis both individually and as a group.

Prior to the beginning of the semester, the peer mentor is assigned to the supported course for the entire semester. Peer mentors attend each class and work with students on both an individual and group basis. Sessions are regularly scheduled, providing three group sessions per class throughout the week. Peer mentors lead and facilitate sessions in which students discuss difficult course material and concepts, take mock exams, and develop executive skills, such as working memory, organization, planning and prioritizing. The program targets high-risk, defined 
as courses with high DFW rates, rather than high-risk students. Students who participate in the program have varying levels of academic preparedness.

Peer mentors document student visits by utilizing a paper-based sign in sheet, and most recently an electronic form that communicates with Microsoft Excel. Monthly, each peer mentor compiles data and provides it to the Learning Coordinator. The students are not charged for this voluntary program and peer mentors are compensated monetarily for their time, funded by the Title III grant.

\section{Data Analysis}

Data were analyzed using quantitative data analysis technique. Data was transferred from Microsoft Excel Software to IBM's Statistical Analysis Software Program (SPSS), for data analysis. SPSS was utilized to analyze descriptive, inferential, and correlational statistics. Correlation analysis, used as the analysis for a few of the research questions, is one of the most often applied statistical procedures used by business administration for analyzing the relationship between two variables. The correlation coefficient can be used to measure the strength of the linear relationship between two variables. This coefficient ranges from -1.0 to +1.0 , where a correlation of $+/-1$ indicates a perfect linear relationship, whereas a correlation of 0 indicates no linear relationship. Once a correlation coefficient is established, it is subject to sampling error; therefore, a formal hypothesis testing procedure (i.e. t-test) was completed to determine whether the linear relationship between the variables existed. When conducting a test of significance, a null hypothesis was used, indicating there is no correlation between the variables, while the alternative hypothesis claimed there is a correlation (Groebner, Shannon, \& Fry, 2013). The value of significance was alpha-level of $\mathrm{p}=.05$.

Research Question One. Is there a statistically significant increase over the baseline classes in success rates, measured by a final overall course grade of C or above, of students in classes 
that incorporate active learning? Baseline classes were identified as courses having high rates of D, F, or withdrawal (DFW), in which lecture was the primary source of instruction. These courses were redesigned to incorporate active learning strategies and student peer mentoring. Chi-square $\left(\chi^{2}\right)$ examines whether there is an association between two categorical variables. The assumptions of chi-square state any one individual can belong to only one single category and each category should have at least $(\mathrm{n}=5)$ subjects (Field, 2009). The alternative hypothesis is that there is a significant difference in success rates when comparing students in classes that incorporate active learning and students who were in the baseline lecture courses. The null hypothesis is that there is no significant difference in success rates when comparing students in classes that incorporate active learning and students who were in the baseline lecture courses.

Research Question Two. Are there statistically significant differences between males and females with respect to success rates, measured by a final overall course grade of $C$ or above? Information regarding a student's gender was obtained from the Institutional Research Specialist at the research site. This information is reported on a student's application for admission into the University. Based on the categorical variables, a chi-square analysis was conducted to address research question two. The data analyzed for this question consisted of students who were in the active learning courses and not the baseline courses. The alternative hypothesis is there is a significant difference in success rates when comparing male and female students. The null hypothesis is there is no significant difference in success rates when comparing male and female students.

Research Question Three. Are there statistically significant differences among ACT scores with respect to success rates, measured by a final overall course grade of C or above? ACT and SAT scores are college admissions tests that measure a student's academic readiness for college. Scores for this research were obtained from the Institutional Research Specialist and included in 
the overall raw data provided to this researcher. Since students only have to provide scores for one admissions test, some SAT scores were the only ones available. Therefore, SAT scores were converted to ACT scores to keep the data consistent. The concordance tables for SAT to ACT were obtained from the research site's Office of Admissions and used to convert the SAT scores to ACT scores. Therefore, all data analyzed for research question three was based on a student's ACT composite score. The composite score is the average, rounded to the nearest whole number, of four multiple-choice subject scores, in English, mathematics, reading, and science; and scores are reported on a scale from 1 (low) to 36 (high) (“Using Your ACT Results,” 2015).

The data analyzed for this question consisted of students who were in the active learning courses, and not the baseline courses. To see if there was a relationship, a Pearson's correlation was conducted. Pearson's correlation requires only that data are interval for the findings to be an accurate measure of the linear relationships between the variables. The alternative hypothesis is that there is a significant difference in success rates when comparing ACT scores of students, while the null hypothesis is there is no significant difference in success rates when comparing ACT scores of students.

Research Question Four. Are there statistically significant differences among students of differing socioeconomic status with respect to success rates, measured by a final overall course grade of $C$ or above? Socioeconomic status was determined by a student's Expected Family Contribution (EFC). The information the student and his/her family reports on the Free Application for Federal Student Aid (FAFSA) is used to calculate an EFC. It is a measure of a student and/or a student's family's financial strength. It is calculated according to a formula established by law (United States Department of Education, 2016). The data analyzed for this question consisted of students who were in the active learning courses, and not the baseline courses. An independent t-test was used to evaluate the differences in means between two groups 
of socioeconomic status and success rates. The alternative hypothesis is that there is a significant difference in success rates when comparing socioeconomic status of students, while the null hypothesis is there is no significant difference in success rates when comparing student socioeconomic status of students.

Research Question Five. Is there a correlation between students attending peer mentoring sessions and success rates, measured by a final overall course grade of C or above? Student attendance logs were maintained by peer mentors who led mentoring sessions. These attendance logs were completed on-going in Microsoft Excel and turned in at the end of each semester. The data analyzed for this question consisted of students who were in the active learning courses and not the baseline courses. To see if there was a relationship, a Pearson's correlation was conducted. Pearson's correlation requires only that data are interval for the findings to be an accurate measure of the linear relationships between the variables. The alternative hypothesis is that there is a significant correlation in students attending peer mentoring sessions and success rates. The null hypothesis is there is no significant correlation in students attending peer mentoring sessions and success rates.

\section{Summary}

Chapter three restated the purpose of the study and research questions used to guide the method of inquiry. This study was designed to parallel with a five-year grant awarded to a midAtlantic region university and explore whether implementing active learning and student peer mentoring increased success rates, measured by a final overall course grade of a $\mathrm{C}$ or above. Data was collected from courses identified in the grant as high DFW (grades of D, F, or withdrawal) courses. Course descriptions, data collection procedures and analysis were discussed. All results are presented in the following chapter. 


\section{Chapter IV}

\section{Results}

This research study was designed to contribute and build on the current active learning research which lacks in the quantitative, non-laboratory courses such as business. The research investigated whether or not implementing active learning and student peer mentoring into courses with high DFW rates increases student success. This chapter describes the participants in the study and the results of analyses used to examine the research questions.

\section{Characteristics of Sample}

The sample size included a total of 1,778 students, but seven of those students were excluded because an individual grade was not reported. 817 students were enrolled in lecturebased courses and 954 students were enrolled in active learning courses. Therefore, the total number of students reported in the results were 1,771 total students. There were 946 males and 831 females enrolled in the courses with the average ACT composite score a 20 on a 1 (low) to 36 (high) reporting scale. The average expected family contribution was $\$ 7,353$.

\section{Research Question One}

The first research question asked, "Is there a statistically significant increase over the baseline classes in success rates, measured by a final overall course grade of $\mathrm{C}$ or above, of students in classes that incorporate active learning?"

Of the 1778 grades, 7 were invalid, which were incompletes awarded in those courses. Of the 1,771 students, 602 received a grade of a D, F, or withdrew, and 1,169 received a passing grade of an A, B, or C. In 2011, the lecture based courses (baseline classes) accounted for 817 students, of which 367 received a grade of a D, F, or withdrew, and 450 passed with a grade of an A, B, or C. In 2015-2016, the active learning courses accounted for 954 students, of which 235 
received a $\mathrm{D}, \mathrm{F}$, or withdrew, and 719 received a passing grade of an $\mathrm{A}, \mathrm{B}$, or $\mathrm{C}$. Table 5 provides frequencies and percentages.

Table 5

Pass and Fail Rates of Students Enrolled in Lecture-Based and Active Learning Courses

\begin{tabular}{lcrcc}
\hline & \multicolumn{2}{c}{ Pass } & \multicolumn{2}{c}{ Fail } \\
\cline { 2 - 5 } Course & $\mathrm{n}$ & $\%$ & $\mathrm{n}$ & $\%$ \\
\hline Lecture-Based & 450 & 55.1 & 367 & 44.9 \\
Active Learning & 719 & 75.4 & 235 & 24.6 \\
\hline
\end{tabular}

Chi-square analysis revealed a significant difference among active learning and lecture based courses $\chi^{2}(1, N=1778)=80.729, \mathrm{p}<.05$. Based on the $\mathrm{df}=1$, and $\mathrm{p}<.05$, the critical value of the chi-square distribution is 3.84. $\chi^{2}=80.729$, which is greater than 3.84 (Field, 2009). The null hypothesis is thus rejected, lending support to the notion there is a significant difference in success rates when comparing students in classes that incorporate active learning and students who were in the baseline, lecture courses. There were a higher proportion of students who succeeded in active learning courses than there were in lecture based courses. This seems to represent the fact that, based on the odds ratio, the odds of students passing were 2.48 times higher if they took a course that incorporated active learning strategies than a course primarily lecture-based. In addition, the assumptions of chi-square that one individual can belong to only one single category and that each category should have at least $(\mathrm{n}=5)$ subjects were met.

Table 6 shows the DFW percentage rates of both the baseline, lecture course, and then the redesigned, active learning courses. All the courses that were redesigned showed a decrease in the percentage of DFW rates. The last column in Table 6 indicates the decreased percentage. 
The most significant decrease, of $32.6 \%$, was found in the Business Programming Logic redesign.

Table 6

DFW Percentage Comparisons of Baseline Courses and Redesigned Active Learning Courses

\begin{tabular}{llll}
\hline Course & DFW & DFW Percentage & \% Decrease in \\
& Percentage & Redesigned & DFW Rates \\
& Baseline & Active Learning & \\
& & & \\
& & & \\
Principles of Accounting I & $46.7 \%$ & $30.9 \%$ & $-15.8 \%$ \\
Introduction to Economics & $50.7 \%$ & $23.7 \%$ & $-27 \%$ \\
Macroeconomics & $49.8 \%$ & $31.6 \%$ & $-18.2 \%$ \\
Microeconomics & $36.8 \%$ & $19 \%$ & $-17.8 \%$ \\
Introduction to Financial Management & $31.3 \%$ & $15.9 \%$ & $-15.4 \%$ \\
Introduction to Computing & $38 \%$ & $30.7 \%$ & $-7.3 \%$ \\
Business Programming Logic & $34.8 \%$ & $2.2 \%$ & $-32.6 \%$ \\
\hline
\end{tabular}

\section{Research Question Two}

The second research question asked, "Are there statistically significant differences among males and females with respect to success rates, measured by a final overall course grade of $\mathrm{C}$ or above?" Table 7 displays the results from the analysis. 
Table 7

Differences Among Male ( $n=942)$ and Female $(n=829)$ Students Success Rates

\begin{tabular}{lcccccc}
\hline & \multicolumn{2}{c}{ Pass } & \multicolumn{3}{c}{ Fail } & \multicolumn{3}{c}{ Total } \\
\cline { 2 - 7 } Gender & $\mathrm{n}$ & $\%$ & $\mathrm{n}$ & $\%$ & $\mathrm{n}$ & $\%$ \\
\hline Male & 595 & 63.2 & 347 & 36.8 & 942 & 53.2 \\
Female & 574 & 69.2 & 255 & 30.8 & 829 & 46.8 \\
\hline
\end{tabular}

The relationship between gender and success rates was significant, $\chi^{2}(1, N=1778)=7.257, \mathrm{p}<$ .05. Based on the $\mathrm{df}=1$, and $\mathrm{p}<.05$, the critical value of the chi-square distribution is 3.84 . We reject the null hypothesis since $\chi^{2}=7.257$, which is greater than 3.84 (Field, 2009). Male students were less likely to pass courses than female students. Based on the odds ratio, the odds of failure for males was 1.32 times higher than failure for females.

Table 8 provides a breakdown in overall course grade and gender. For example, 190 males received an overall course grade of an A, while 141 received an F overall.

Table 8

Gender Numbers of Course Grades

Overall Course Grade

\begin{tabular}{lccccccc} 
Gender & A & B & C & D & F & W & Total \\
\hline Male & 190 & 232 & 173 & 90 & 141 & 116 & 829 \\
Female & 189 & 220 & 165 & 73 & 101 & 81 & 942 \\
\hline Total & 379 & 452 & 338 & 163 & 242 & 197 & 1771
\end{tabular}

Note. Seven grades from data were not reported, indicating an incomplete was assigned. 
Table 9 shows the differences in males' and females' average ACT composite score and their expected family contribution amount. The male average ACT composite score was a 20.06, with an expected family contribution of $\$ 7,965.15$. The female average ACT composite score was a 20.43, with an expected family contribution of $\$ 6,656.21$. Overall, the average ACT composite score was a 20.23 , and an expected family contribution of $\$ 7,353.04$.

Table 9

ACT Score and EFC Differences Among Gender

\begin{tabular}{lll}
\hline Gender & Average ACT Comp Score & Average EFC \\
\hline Male & 20.06 & $\$ 7,965.15$ \\
Female & 20.43 & $\$ 6,656.21$ \\
\hline Overall & 20.23 & $\$ 7,353.04$ \\
\hline
\end{tabular}

\section{Research Question Three}

The third research question asked, "Are there statistically significant differences among ACT scores with respect to success rates, measured by a final overall course grade of $\mathrm{C}$ or above?" A Pearson-correlation was conducted to test the hypothesis. As hypothesized, there was a significant correlation among ACT scores and success rates, $r(1770)=.26, p<.01$. Students who passed courses tended to have a higher ACT score. The coefficient of determination, $\mathrm{R}^{2}$, is a measure of the amount of variability in one variable shared by the other (Field, 2009). Therefore, we can use the coefficient of determination to look at the relationship between ACT score and success rates. $(.26)^{2}=0.07$, which converts to $7 \%$. Although ACT scores are correlated with success rates, it accounted for only $7 \%$ of variation in success rates. Therefore, $93 \%$ of variability is accounted for by other variables. Tables 10 and 11 display the descriptive statistics. Table 11 further shows the relationship between ACT scores and success rates. 
Table 10

Means ACT Scores

\begin{tabular}{lll}
\hline Variable & $M$ & SD \\
\hline ACT Comp & 20.23 & 3.62 \\
\hline
\end{tabular}

Table 11

Relationship Between ACT Scores and Success Rates

\begin{tabular}{lccc}
\hline Success Rates & N & $\begin{array}{c}\text { ACT Score } \\
M\end{array}$ & SD \\
\hline Pass & 925 & 20.88 & 3.522 \\
Fail & 438 & 18.25 & 3.437 \\
\hline
\end{tabular}

Table 12 reports the average ACT composite of students receiving individual grades. The average ACT composite score for students receiving an A was a 22.44 compared to the average ACT composite score for students receiving an F was an 18.70.

Table 12

Overall Course Grade Compared to Average ACT Score

\begin{tabular}{ll}
\hline Overall Course Grade & Average ACT Comp \\
& Score \\
\hline A & 22.44 \\
B & 20.55 \\
C & 19.70 \\
D & 18.62 \\
F & 18.70 \\
W & 19.25 \\
\hline
\end{tabular}

\section{Research Question Four}

The fourth research question asked, "Are there statistically significant differences among socioeconomic status with respect to success rates, measured by a final overall course grade of C 
or above?" An independent t-test was used to evaluate the differences in means between two groups of socioeconomic status and success rates. The Expected Family Contribution (EFC) was used as a proxy to socioeconomic status. Table 13 reports the findings. In this sample, the mean EFC for students who passed the class was $\$ 8,244.63(\mathrm{SD}=\$ 15,747.03), \mathrm{N}=1169$, whereas the mean score for students who failed the class was $\$ 5,667.16(\mathrm{SD}=\$ 12,197.24), \mathrm{N}=602$. The results suggest, students who passed the course on average had a higher EFC than students who failed; $\mathrm{t}(1769)=3.51, \mathrm{p}<.001$.

Table 13

Descriptive Statistics for Socioeconomic Status of Success Rates

\begin{tabular}{cccc}
\hline & \multicolumn{3}{c}{ EFC (Expected Family Contribution) } \\
\cline { 2 - 4 } Success Rates & \multicolumn{2}{c}{$\mathrm{N}$} & $M$ \\
\hline Pass & 1169 & $\$ 8,244.63$ & $\$ 15,747.03$ \\
Fail & 602 & $\$ 5,667.16$ & $\$ 12,197.24$ \\
\hline
\end{tabular}

It can be interpreted that students who passed the course on average had a higher socioeconomic status since their expected family contribution to education was higher than those students who failed. However, even though the t-statistic is statistically significant, there was a small effect size. Therefore, Field (2009) suggests converting the $t$-value into an $r$-value to determine effect size. The following equation is used:

$$
r=\sqrt{ }\left(\frac{t^{2}}{t^{2}+d f}\right)
$$

Based on the equation, the r value equals .08. Cohen (1992) identifies a small effect size at .10, medium at .30 , and large at .50 . This provides an objective measure of the importance of the effect. With an effect size of .08, this indicates a small effect. Table 14 reports the average EFC among gender differences. 
Table 14

Gender Differences in Average EFC

\begin{tabular}{ll}
\hline Gender & Average EFC \\
\hline Male & $\$ 7,965.15$ \\
Female & $\$ 6,656.21$ \\
\hline
\end{tabular}

\section{Research Question Five}

The final research question asked, "Is there a correlation between students attending peer mentoring sessions and success rates, measured by a final overall course grade of C or above?" A Pearson-correlation analysis was the statistical method used to evaluate the strength of the relationship between students attending mentoring sessions and success rates. As hypothesized, there was a correlation between students having ever attended at least one peer mentoring sessions and passing the course, $r(0.02)=.15, p=.004$. It must be noted that the sample was restricted to only students $(n=356)$ enrolled in an active learning course with a peer mentor assigned to that course in the 2015 data. The coefficient of determination, $\mathrm{R}^{2}$, is a measure of the amount of variability in one variable shared by the other (Field, 2009). Therefore, we can use the coefficient of determination to look at the relationship between students attending peer mentoring and success rates. $(.15)^{2}=0.02$, which converts to $2 \%$. Although peer mentoring is correlated with success rates, it accounts for only $2 \%$ of variation in success rates. Therefore, $98 \%$ of variability is accounted for by other variables. Table 14 shows descriptive statistics that includes the number of students who attended and who did not attend compared to the students who passed or failed the course. 
Table 15

Descriptive Statistics for Peer Mentoring and Success Rates

Attendance to Peer Mentoring Sessions

\begin{tabular}{|c|c|c|c|}
\hline & $\begin{array}{l}\text { Attended } \\
\mathrm{N}\end{array}$ & $\begin{array}{c}\text { Did Not Attend } \\
\mathrm{N}\end{array}$ & Total \\
\hline \multicolumn{4}{|c|}{ Success Rates } \\
\hline Pass & 68 & 198 & 266 \\
\hline Fail & 10 & 80 & 90 \\
\hline Total & 78 & 278 & 356 \\
\hline
\end{tabular}

\section{Summary}

A total of 1,771 students, of which 817 students were enrolled in lecture-based courses and 954 students were enrolled in active learning courses, were included in the results. There were 946 males and 831 females enrolled in the courses with the average ACT composite score a 20 on a 1 (low) to 36 (high) reporting scale. The average expected family contribution was $\$ 7,353$. The results indicated that there was a significant difference in success rates when comparing students in classes that incorporated active learning and students who were in the baseline, lecture courses. There was a higher proportion of students who succeeded in active learning courses than there were in lecture based courses.

These findings do not show causation, just association, because there are other factors that impact overall success that cannot addressed. Additional findings suggest students who passed the course on average were female, had a higher ACT composite score, and had a higher socioeconomic status. In addition, there was a correlation between students having ever attended at least one peer mentoring sessions and passing the course. 


\section{Chapter V}

\section{Summary and Recommendations}

The intent of chapter five is to summarize the key findings of the study, present conclusions drawn from the results, and pose implications for future research.

\section{Summary of Key Findings from Results}

The overall purpose of this study was to examine courses that have incorporated active learning, including peer mentoring, into courses with high rates of Ds, Fs, and withdrawals, to determine if these techniques increase student success, measured by overall course grades. The following are the key findings:

\section{Significant differences in success rates among active learning and lecture based}

courses. Chi-square analyses revealed a higher proportion of students who succeed in active learning courses than in lecture based courses. The odds of students passing were 2.48 times higher if they took a course that incorporated active learning strategies than a course primarily lecture-based. These findings are comparable with the largest and most comprehensive metaanalysis conducted by Freeman et al. (2014), in which they found students in traditional lecturing courses were 1.5 times more likely to fail than students in active learning courses. The 225 studies analyzed by Freeman and colleagues were from undergraduate STEM education which represent more qualitative courses; however, the results of this study present positive results of student success in more quantitative courses suggesting the positive impact of active learning courses in both quantitative and qualitative courses. Thus, in higher education, we must stop talking about the positive implications of active learning courses, and begin implementing and expecting these techniques.

Obstacles exist with implementing these techniques into the classroom. The current research site was awarded a $\$ 2$ million grant; therefore, faculty were provided a wealth of 
development and training sessions. Some institutions may not have funding available to provide the same opportunities. However, several resources exist, including L. Dee Fink's self-directed guide to designing courses in Appendix B, that provide faculty with valuable information and assistance at no additional cost.

Active learning is effective across all class sizes, but the greatest effects are in small classes of less than 50 students (Freeman et al., 2014). The current research site has an average class size of 22 students. Current economics drive large class sizes. Universities implementing these strategies with more than 50 students per class may face additional obstacles with classroom management. Nevertheless, active learning strategies can still be effectively implemented.

2. Significant differences among males and females with respect to success rates. The relationship between student gender and success rates was significant, $\chi^{2}(1, N=1778)=7.257, \mathrm{p}$ $<.05$. Male students were less likely to pass courses than female students. Based on the odds ratio, the odds of failure for males is 1.32 times higher than failure for females. Halpern (2012) cited information presented by the United Nations Economic Commission for Europe, saying gender statistics can help eliminate gender-based stereotypes. In this study, the male average ACT composite score was a 20.06, while the female average was a 20.43 . Separating data by gender again, the expected family contribution for a male student was $\$ 7,965.15$, compared to a female's expected family contribution of $\$ 6,656.21$. Overall, the average ACT composite score was a 20.23 , and an expected family contribution of $\$ 7,353.04$. Considering the averages of both the EFC's and ACT composite scores are very similar, we can expect females to do better.

3. Significant differences among ACT scores with respect to success rates. Students who passed courses tended to have a higher ACT score. The coefficient of determination was calculated to look at the relationship between ACT score and success rates. The findings 
suggested that although ACT scores are correlated with success rates, it only accounts for $7 \%$ of variation. The average ACT composite score of students who passed was 20.88. It should be noted that based on the average ACT composite scores of students, the overall score decreased as the grades lowered. The average ACT composite score of students receiving an A was a 22.44 compared to the average ACT composite score for students receiving an F was an 18.70. These findings can assist peer mentoring programs by providing additional support to students who have a lower overall ACT composite score.

4. Significant differences among socioeconomic status with respect to success rates. The results suggest that students who passed the course on average had a higher EFC than students who failed. It can be interpreted that students who passed the course on average have a higher socioeconomic status since their expected family contribution to education is higher than those students who failed. However, ever though the t-statistic is statistically significant, the effect size is small. Based on these results, additional research could be conducted on socioeconomic status and student success.

\section{Correlation between students attending peer mentoring sessions and success rates.}

There was a correlation between students having ever attended at least one peer mentoring sessions and passing the course.

It is important to note that this research is not intended to say that the use of lecture should be avoided entirely in higher education. But, as Ken Bain (2004) found, no great teachers relied solely on lectures. Lectures can help students learn deeply, but these lectures must implement active learning strategies, such as engaging students in thinking through problems, and in reasoning rather than memorizing. As he notes, the lecture should be one element of a learning environment rather than the entire experience (p. 107). Lecture should not be used, as 
he describes, as an encyclopedic coverage of material, but a way to explain complex material while engaging, provoking and focusing students.

\section{Implications for Future Research}

The first recommendation is that more research should be conducted in quantitative business courses. A majority of the active learning research includes courses that have a lab component with active learning strategies easily identified. Besides peer mentoring, the current research broadly addressed the strategies implemented, so future research should consider looking at individual active learning strategies to find the strategies that are more beneficial to assist with better course design.

Secondly, a suggestion for future research would be to utilize a qualitative research design, where focus groups with faculty, peer mentors, and students would transpire. Baxter and Jack (2008) emphasize qualitative methodology, when applied correctly, is a valuable method to develop theory, evaluate programs, and develop interventions. These discussions would allow for more in depth information and holistic understanding regarding student success. For example, the researcher could see that a traditional " $C$ " student increased his/her letter grade by an entire letter grade after attending peer mentoring, and participating in a redesigned course that included active learning.

A longitudinal cohort study could be conducted to evaluate the impact of peer mentoring. The goals of peer mentoring include recruitment and retention of students, increasing learning, and enhancing relationships with faculty and other students (Rodger \& Tremblay, 2003). The current study only identified the successes of peer mentoring for a short time period, and was unable to truly evaluate whether or not students were recruited into the School of Business because of the program, or if they were retained throughout their academic careers based on the potential relationships and connections made with the peer mentor and other students in the 
mentoring groups. In order to advocate for the allocation of funding to support peer mentoring programs, a mixed-methods study on incoming freshman cohorts could be designed and carried out throughout their undergraduate academic careers.

\section{Conclusion}

Higher education faces challenges, but also opportunities. We face changing demographics, economical struggles, and fiscal politics, but we also have an opportunity to change our institutional culture and implement effective strategies and practices to see powerful outcomes of student learning. Felten et al., 2016 specifies that our challenge "is no longer simply to ascertain what it is we need to do; our challenge now is to do it, to create and sustain excellent undergraduate education for all of our students" (p. 9). The need for the paradigm shift from instruction to learning is clear, so now, we must stop doing the things we have become accustomed to that are no longer effective. We must understand student background, demographics, and characteristics that significantly affect performance and success in the classroom. An understanding of this information can support effectively designed educational policies and courses to address quality education.

What is clear at the conclusion of this dissertation is that it is necessary to redesign traditional lecture-based courses to implement active learning. With the expected benefits to student success, academic resources, such as faculty development to support course redesign, should be provided to faculty to successfully advance the learning paradigm. The importance of peer mentoring programs is also clear, and such programs should make an effort to focus on students with lower socioeconomic statuses and ACT/SAT scores. The significance of designing courses that incorporate active learning is convincing, and the knowledge base about these techniques that lead to success can continue to improve. 


\section{References}

ACT Profile Report (2011). Retrieved from

http://www.act.org/newsroom/data/2011/pdf/profile/WestVirginia.pdf.

Angelo, T.A. \& Cross, K.P. (1993). Classroom assessment techniques: A handbook for college teachers ( $2^{\text {nd }}$ ed.). San Francisco, CA: Jossey-Bass.

Bain, K. (2004). What the best college teachers do. Cambridge, MA: Harvard University Press.

Bandura, A. (1977). Social learning theory. Englewood Cliffs, NJ: Prentice-Hall.

Barkley, E.F. (2010). Student engagement techniques: A handbook for college faculty. San Francisco, CA: Jossey-Bass.

Barr, R.B. \& Tagg, J. (1995). From teaching to learning: A new paradigm for undergraduate education. Change, 27(6), 13-26.

Baxter, P., \& Jack, S. (2008). Qualitative case study methodology: Study design and implementation for novice researchers. The Qualitative Report, 13(4), 544-559.

Benjamin, L. T. Jr. (2002). Lecturing. In S. F. Davis \& W. Buskist (Eds.), The teaching of psychology: Essays in honor of Wilbert J. McKeachie and Charles L. Brewer (pp. 57-67). Mahwah, NJ: Erlbaum.

Biggs, J., \& Tang, C. (2011). Teaching for quality learning $\left(4^{\text {th }}\right.$ ed.). Berkshire, U.K.: Open University Press.

Bligh, D.A. (2000). What's the use of lectures? San Francisco, CA: Jossey-Bass.

Bloom, B. (1984). Taxonomy of education objectives book 1: Cognitive domain (2 ${ }^{\text {nd }}$ ed.). White Plains, NY: Addison Wesley Publishing Company.

Bonwell, C.C., \& Eison, J.A. (1991). Active learning: Creating excitement in the classroom. ASHE-ERIC Higher Education Report No. 1. Retrieved from http://files.eric.ed.gov/fulltext/ED336049.pdf. 
Cedaka, T.L. (2012). Training a multigenerational workforce: Understanding key needs and learning styles. Professional Safety, 57(3), 40-44.

Center for Teaching Excellence of the University of Virginia (2016). Course design institute. Retrieved from http://cte.virginia.edu/programs/course-design-institute/.

Chickering, A.W., \& Gamson, Z.F. (1987). Seven principles for good practice in undergraduate education. AAHE Bulletin, 39(7), 3-7.

Cohen, J. (1992). Quantitative methods in psychology: A power primer. Psychological Bulletin, $112(1), 155-159$.

Collins, J.W., \& O’Brien, N.P. (2003). The greenwood dictionary of education. Westport, CT: Greenwood Press.

Colvin, J.W., \& Ashman, M. (2010). Roles, risks, and benefits of peer mentoring relationships in higher education. Mentoring \& Tutoring: Partnership in Learning, 18(2), 121-134.

Csapo, N., \& Wilson, H. (2001). A study of business faculty preferences for teaching methods used and why. IACIS, 64-70.

Daly, P., Reid, K., Buckley, P., \& Doyle, E. (2016). Innovative business education design for $21^{\text {st }}$ century learning. Switzerland: Springer.

Deslauriers, L., Schelew, E., \& Wieman, C. (2011). Improved learning in a large-enrollment physics class. Science, 332, 862-864.

Dewey, J. (1916). Democracy and education: An introduction to the philosophy of education. New York: The Macmillan Company.

Edgar, D. (1969). Audio-visual methods in teaching (3 ${ }^{\text {rd }}$ ed.). New York: Dryden Press.

Eurich, A.C. (1964). The commitment to experiment and innovate in college teaching. Educational Record, 45, 49-55.

Fairmont State University (2015). About Fairmont State. Retrieved 
from http://www.fairmontstate.edu/aboutfsu/.

Fairmont State University Undergraduate Academic Catalog (2015-2016). Retrieved from http://www.fairmontstate.edu/files/institutionalforms/formrepo/FSU\%20Academic\%20Ca talog\%202015-16.pdf.

Felten, P., Gardner, J., Schroeder, C., Lambert, L., \& Barefoot, B. (2016). The undergraduate experience: Focusing institutions on what matters most. San Francisco, CA: Jossey-Bass.

Field, A. (2009). Discovering statistics using spss ( $3^{\text {rd }}$ ed.). Los Angeles, CA: Sage Publications. Fink, L.D. (2003). A self-directed guide to designing courses for significant learning. Retrieved from https://www.deefinkandassociates.com/GuidetoCourseDesignAug05.pdf.

Fink, L.D. (2013). Creating significant learning experiences: An integrated approach to designing college courses. San Francisco, CA: Jossey Bass.

Finkelstein, M., Seal, R, \& Schuster, J. (1998). The new academic generation. Baltimore, MD: Johns Hopkins University Press.

Fox, A., \& Stevenson, L. (2006). Exploring the effectiveness of peer mentoring of accounting and finance students in higher education. Accounting Education: An International Journal, 15(2), 189-202.

Freeman, S., Eddy, S.L., McDonough, M., Smith, M.K., Okoroafor, N., Jordt, H., \& Wenderoth, M.P. (2014). Active learning increases student performance in science, engineering, and mathematics. Proceedings of the National Academy of Sciences of the United States of America, 111(23), 8410-8415.

Groebner, D.F., Shannon, P.W., \& Fry, P.C. (2013). Business statistics $\left(9^{\text {th }}\right.$ ed.). Upper Saddle River, NJ: Pearson.

Guskin, A.E. (1994). Reducing student costs and enhancing student learning part II: Restructuring the role of faculty. Change, 26(5), 16-25. 
Guskin, A.E. (1996). Facing the future: The change process in restricting universities. Change, 28(4), 26-37.

Hake, Richard, R. (1998). Interactive-engagement versus traditional methods: A six-thousandstudent survey of mechanics test data for introductory physics courses. American Journal of Physics, 66(1), 64-74.

Halpern, D.F. \& Hakel, M.D. (2003). Applying the science of learning. Change, 35(4), 36-41.

Halpern, D.F. (2012). Sex differences in cognitive abilities ( $4^{\text {th }}$ ed.). New York, NY: Psychology Press.

Kremer, J. (2017). Introduction to Financial Management [Syllabus]. Fairmont, WV: School of Business, Fairmont State University.

McCarthy, P.R. \& McCarthy, H.M. (2006). When case studies are not enough: Integrating experiential learning into business curricula. Journal of Education for Business, 81(4), 201-204.

McKeachie, W.J. (1986). Teaching tips: A guidebook for beginning college and university teachers $\left(8^{\text {th }}\right.$ ed.). Lexington, MA: Heath.

McKeachie, W.J., \& Svinicki, M. (2013). McKeachie's teaching tips: Strategies, research, and theory for college and university teachers $\left(14^{\text {th }}\right.$ ed.). Belmont, CA: Wadsworth, Cengage Learning.

Muto, L. (2016). Principles of Accounting I [Syllabus]. Fairmont, WV: School of Business, Fairmont State University.

National Student Clearinghouse Research Center (2015). Current Term Enrollment Estimates Fall 2015. Retrieved from https://nscresearchcenter.org/currenttermenrollmentestimatefall2015/. 
Ning, H.K., \& Downing, K. (2010). The impact of supplemental instruction on learning competence and academic performance. Studies in Higher Education, 35(8), 921-939.

Prince, M. (2004). Does active learning work? A review of the research. Journal of Engineering Education, 93(3), 223-231.

Revitalizing curricula as experiential, collaborative and technology-rich. (2012). Fairmont State University, Fairmont, WV.

Roach-Duncan, J. (2010). Mixing business communication and business statistics with experiential learning: Student and instructor reflections on work-related undergraduate business research projects. Journal of Applied Research for Business Instruction, 8(3).

Rodger, S., \& Tremblay, P.F. (2003). The effects of a peer mentoring program on academic success among first year university students. Canadian Journal of Higher Education, $33(3), 1-17$.

Smith, K.A., Sheppard, S.D., Johnson, D.W., \& Johnson, R.T. (2005). Pedagogies of engagement: Classroom-based practices. Journal of Engineering Education, 94(1), 87101.

Sousa, D.A. (2011). How the brain learns (4 ${ }^{\text {th }}$ ed.). Thousand Oaks, CA : Corwin Press.

United States Census Bureau (2015). State and County Quick Facts. Retrieved from http://quickfacts.census.gov/qfd/states/54/5426452.html.

United States Department of Education (2016). The EFC formula, 2016-2017. Retrieved from https://studentaid.ed.gov/sa/sites/default/files/2016-17-efc-formula.pdf.

Using your ACT results. (2015). Retrieved from http://www.act.org/content/dam/act/unsecured/documents/Using-Your-ACT-Results.pdf.

Wankat, P. The effective efficient professor: Teaching, scholarship, and service. Boston, MA: Allyn and Bacon. 
Wiggins, G., \& McTighe, J. (2005). Understanding by design ( $2^{\text {nd }}$ ed.). Alexandria, VA: Association for Supervision and Curriculum Development. 


\section{Appendix A \\ IRB Approval from Research Site}

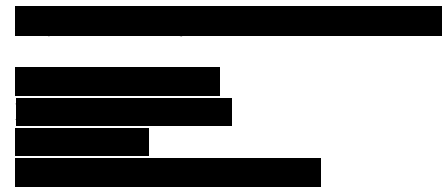

DATE: 9/2/2016

TO: Ashley Tasker

FROM: Mike —, Chairperson, Institutional Review Board

SUBJECT: Approval of research request- Grades and Active learning/mentoring

You have been granted a minimal risk approval by the University IRB. You may conduct your research exactly as specified in your application forms.

Any other changes in your research methods or protocol must be approved by the Institutional Review Board.

Good luck with your project!

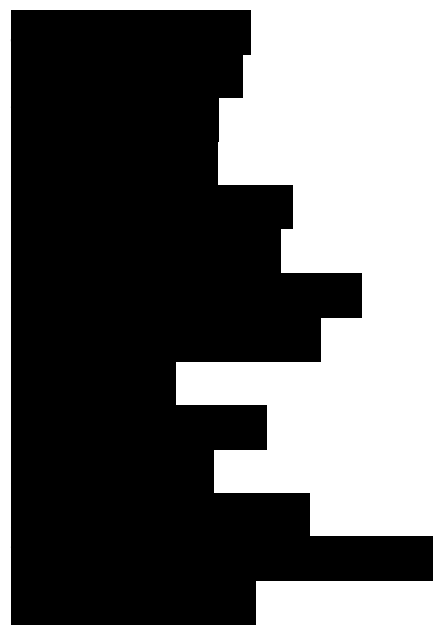

2016-2017 Reviewing IRB Committee members 


\title{
Appendix B
}

A Self-Directed Guide to Designing Courses for Significant Learning

A Self-Directed Guide to

\section{Designing Courses for Significant Learning}

\author{
L. Dee Fink, PhD \\ Director, Instructional Development Program \\ University of Oklahoma \\ Author of: \\ Creating Significant Learning Experiences: \\ An Integrated Approach to Designing College Courses
}

(San Francisco: Jossey-Bass, 2003) 


\section{A Self-Directed Guide to \\ Designing Courses for Significant Learning}

TABLE OF CONTENTS

$\begin{array}{ll}\text { Introduction } & 1\end{array}$

An Overview of Integrated Course Design 2

Model 1: The Key Components of Integrated Course Design 2

Designing an Integrated Course $\quad 4$

Initial Design Phase: Building Strong Primary Components 4

Preview of the Initial Design Phase: Designing Courses that Promote . . . 5

Step 1. Situational Factors $\quad 6$

Step 2. Learning Goals 8

Step 3. Feedback and Assessment 13

Step 4. Teaching/Learning Activities 16

$\begin{array}{ll}\text { Active Learning } & 16\end{array}$

Rich Learning Experiences $\quad 19$

In-Depth Reflective Dialogue 19

$\begin{array}{ll}\text { Information and Ideas } & 21\end{array}$

Step 5. Integration $\quad 21$

Final Check and Review of Initial Phase $\quad 23$

Model 2: Criteria for Assessing Course Designs 24

Intermediate Design Phase: Assembling the Components into a Coherent Whole 25

Step 6. Course Structure $\quad 25$

Step 7. Instructional Strategy 26

$\underline{\text { Step 8. Creating the Overall Scheme of Learning Activities }} 27$

Final Design Phase: Important Remaining Tasks 30

Step 9. How Are You Going to Grade? 30

Step 10. What Could Go Wrong? 31

Step 11. Let Students Know What You Are Planning 31

Step 12. How Will You Know How the Course Is Going? How It Went? 32

Concluding Counsel 33 


\section{A Self-Directed Guide to Designing Courses for Significant learning}

Introduction. When we teach, we engage in two closely related, but distinct, activities. First, we design the course by gathering information and making a number of decisions about the way the course will be taught. Second, we engage in teacher-student interactions as we implement the course we have designed. The concept of Teacher-Student Interaction as used here is a broad one that includes lecturing, leading discussions, running labs, advising, communicating by email, etc. In order to teach well, one must be competent in both course design and teacher-student interactions.

However, of these two activities, our ability to design courses well is usually the most limiting factor. Most of us have had little or no training in how to design courses. In addition, during the last two decades, research on college teaching and learning have led to some new ideas about course design that have, in essence, "raised the bar" in terms of what is possible. These include ideas such as active learning, significant learning, and educative assessment.

How can college teachers learn about and take advantage of these ideas? This SelfDirected Guide is intended to introduce a useful and systematic process for designing courses. It is based on the same components found in most models of instructional design, but it assembles these components into a relational, integrated model rather than a linear one. Among other benefits, this model provides clear criteria for determining when a course design is a good design.

This Guide consists of introductory comments, worksheets, and action questions in each of the three major phases of Integrated Course Design:

\section{Initial Design Phase: Build Strong Primary Components}

Step 1. Identify important situational factors

Step 2. Identify important learning goals

Step 3. Formulate appropriate feedback and assessment procedures

Step 4. Select effective teaching/learning activities

Step 5. Make sure the primary components are integrated

Intermediate Design Phase: Assemble the Components into a Coherent Whole

Step 6. Create a thematic structure for the course

Step 7. Select or create an instructional strategy

Step 8. Integrate the course structure and the instructional strategy to create an overall scheme of learning activities

\section{Final Design Phase: Finish Important Remaining Tasks}

Step 9. Develop the grading system

Step 10. De-Bug possible problems

Step 11. Write the course syllabus

Step 12. Plan an evaluation of the course and of your teaching

Read through the introductory comments in each step, and then complete as much of each worksheet and action item as you can. If you don't fully understand a particular idea or have difficulty applying it to your own course, do what you can, and then move on. Generally, you will be able to come back later and the ideas that you need will be clearer. 
In this Guide, I first present an overview of Integrated Course Design and then work through each of the major phases, one at a time.

\section{An Overview of Integrated Course Design}

The basic components in this model of Integrated Course Design are the same as those found in other models of instructional design: analyze the situational factors, formulate the learning goals, design the feedback and assessment procedures, and select the teaching/learning activities. What is distinctive about this model is that these components have been put together in a way that reveals and emphasizes their inter-relatedness. (See Model 1 below)

Model 1

\section{The Key Components Of INTEGRATED COURSE DESIGN}

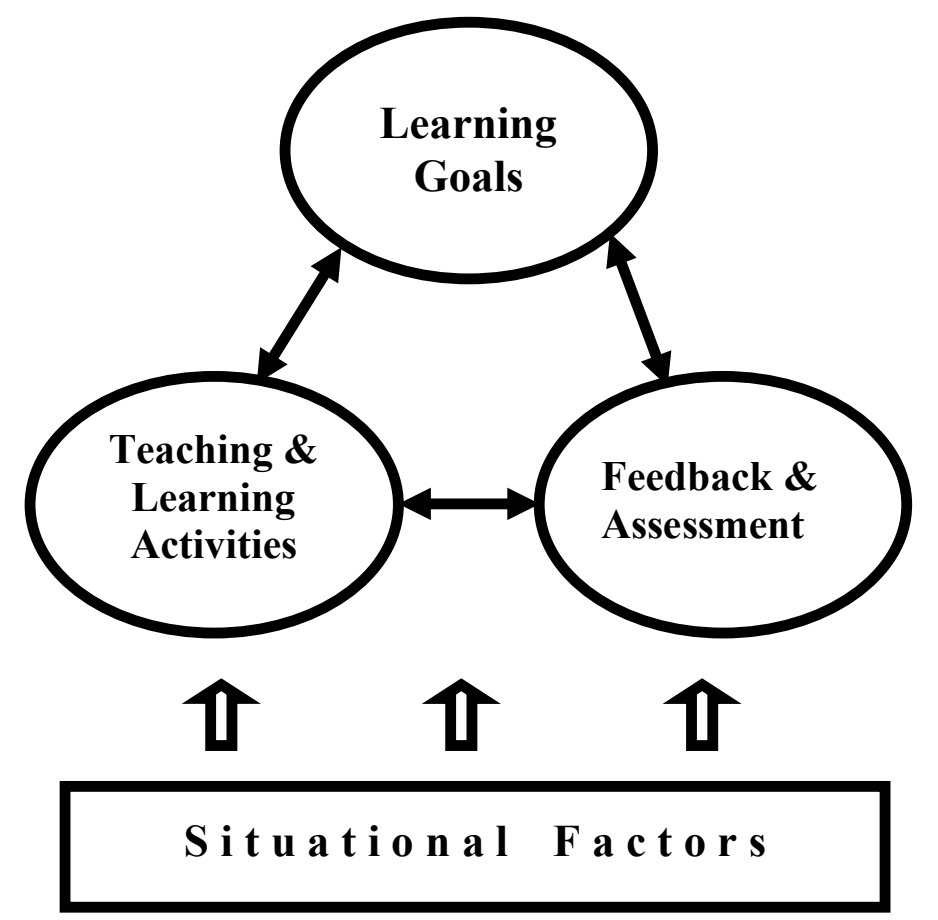

One of the benefits of this model is that it allows us to see the importance

One of the benefits of this model is that it allows us to see the importance of an integrated course and to know when we have one and when we do not. To illustrate this point, let me describe an extreme case of a un-integrated or dis-connected course.

Imagine a course in which the teacher says s/he wants students to (a) "learn all the important content" and (b) "learn how to think critically about the subject." These are the learning goals. But when you examine what actually happens in class, it is a 
straight lecture course (this is the "teaching/learning activity"). This creates the first problem: the teaching/learning activities are NOT aligned with the learning goals. The students might be able to learn the content from the lectures, but they definitely are not getting practice and feedback in learning how to think critically.

Now notice the dilemma this teacher faces when s/he attempts to write the midterm or final exam. S/he can legitimately ask "understand and remember" questions, i.e., content-related questions. But should $\mathrm{s} /$ he include thinking questions or not?

If $\mathrm{s} / \mathrm{he}$ does, the assessment part of the course will be properly connected to the learning goals. But the students will do poorly because they have not had the appropriate learning activities for critical thinking; hence there will also be a disconnect between the learning activities and any assessment on critical thinking. (The diagram below illustrates the situation when the teacher chooses this option.)

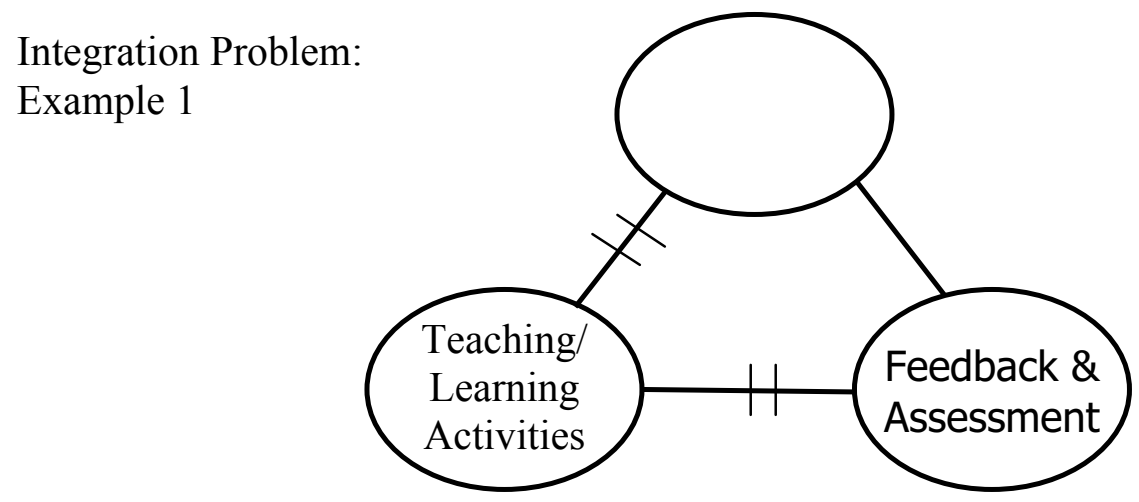

On the other hand, if the teacher chooses not to include thinking questions on the exam, the assessment will be consistent with the teaching/learning activities but not with the learning goals. (This option is shown in the following diagram.)

Integration Problem:

Example 2

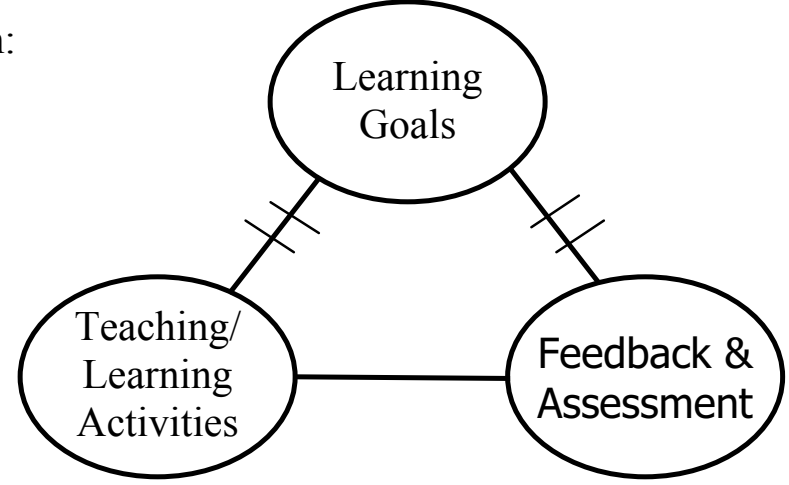

Notice the pattern: If a teacher breaks one of the connections in a course, inevitably another is broken. When two out of three key connections are broken, the course itself is "broken." This is why it is so important to create an integrated design.

Designing an Integrated Course. In designing a course, we are gathering information and making decisions about how the course will be taught. We want to engage in both of these activities so that there is a high likelihood that the students will have a significant learning experience. In order to do this, we need to work through the course design process in a systematic way. This means completing each step before 
going on to the next one. This is important because the later steps build on the earlier ones. For Integrated Course Design (Model 1), start by building strong primary components (INITIAL DESIGN PHASE); then assemble them into a coherent whole (INTERMEDIATE Design PHASE); and finally, finish several important tasks (FinAL DeSign PHASE).

\section{InItIAL Design Phase (Steps 1-5): Building Strong Primary Components}

The primary components of Integrated Course Design are shown in Model 1. The first component in the model is to gather information about the Situational Factors (e.g., how many students are in the course, what kind of prior knowledge are the students bringing to the course about this subject, etc.) [This component is shown as the rectangular box, "Situational Factors" in Model 1.] This information is then used to make the three major decisions about the course (shown as ovals in Model 1).

After you have gathered the information about the situational factors, your first decision is about the Learning Goals, i.e., what you want students to get out of the course. What is important for them to learn and retain, 2-3 years after the course is over? What kind of thinking or application abilities do you want them to develop? How do you want them to keep on learning after the course is over?

Using the principle of "Backward Design," we will next turn to decisions about Feedback and Assessment. The basic question here is: What will students do to demon-strate they have achieved the Learning Goals we set for the course? This will usually involve some paper/pencil tests but we will probably need to include other activities as well. The advantage of working on the Feedback and Assessment at this early stage of course development is that when we become clear about what constitutes successful student performance, it is much easier to develop effective teaching/learning activities.

Then we need to formulate the appropriate and necessary Teaching/Learning Activities. If we have significant learning goals and effective assessment procedures, we will most likely need to incorporate some kind of active learning into the course.

And finally we need to check our course design for Integration to make sure all the components are in alignment and support each other. Are the learning activities consistent with all the learning goals? Are the feedback and assessment activities consistent with the learning goals and the learning activities?

\section{Précis of the InItial Design Phase (Steps 1-5) DESIGNING COURSES THAT PROMOTE SIGNIFICANT LEARNING}

If professors want to create courses in which students have "significant learning experiences," they need to design that quality into their courses. How can they do that? By following the five basic steps of the instructional design process, as laid out below:

\section{Step 1. Give careful consideration to a variety of SITUATIONAL FACTORS}

- What is the special pedagogical challenge of this particular course? That is, what is the special challenge of teaching this subject to these students? 
- What is expected of the course by students? By the department, the institution, the profession, society at large?

- How does this course fit into the larger curricular context?

\section{Use the "BACKWARD DESIGN" Process}

This process starts at the "end" of the learning process and works "back" toward the beginning. Use information about the Situational Factors (Step 1, above), as you make the following key decisions:

Step 2. Learning Goals What do you want students to learn by the end of the course, that will still be with them several years later?

- Think expansively, beyond "understand and remember" kinds of learning.

- Suggestion: Use the taxonomy of "Significant Learning" (Figure 1) as a framework.

Step 3. Feedback \& Assessment Procedures What will the students have to do, to demonstrate that they have achieved the learning goals (as identified in Step " $A$ " above)?

- Think about what you can do that will help students learn, as well as give you a basis for issuing a course grade.

- Suggestion: Consider ideas of "Educative Assessment."

Step 4. Teaching/Learning Activities What would have to happen during the course for students to do well on the Feedback \& Assessment activities?

- Think creatively for ways of involving students that will support your more expansive learning goals.

- Suggestion: Use "Active Learning" activities, especially those related to:

- "Rich Learning Experiences" experiences in which students achieve several kinds of significant learning simultaneously

- "In-depth Reflective Dialogue" opportunities for students to think and reflect on what they are learning, how they are learning, and the significance of what they are learning.

- Suggestion: Assemble these activities into an effective instructional strategy, i.e., an interdependent sequence of learning activities, and a coherent course structure.

Step 5. Make sure that the Key Components are all INTEGRATED

- Check to ensure that the key components (Steps 1-4) are all consistent with, and support each other. 


\section{Step 1. Situational Factors}

The first thing to do when designing a course is to size up the situation carefully. This means reviewing information already known about the teaching and learning situation and, in some cases, gathering additional information. This information will be used to make important decisions about the course.

There are several potentially important situational factors affecting a course. The general categories I have found useful to consider are the following:

- Specific Context of the Teaching/Learning Situation

- General Context of the Learning Situation

- Nature of the Subject

- Characteristics of the Learners

- Characteristics of the Teacher

The specific context factors are always important. The other factors are sometimes important, sometimes not. But it's always useful to review all of them.

The general categories (and the specific factors associated with each category) are shown in the Step 1 Worksheet. Review each of these factors with regards to your specific course. If you have information about any factor, write it down. If you don't have information, but think it could be important, write down ideas about how you might obtain it. 


\section{SITUATIONAL FACTORS TO CONSIDER}

\section{Specific Context of the Teaching/Learning Situation}

How many students are in the class? Is the course lower division, upper division, or graduate level? How long and frequent are the class meetings? How will the course be delivered: live, online, or in a classroom or lab? What physical elements of the learning environment will affect the class?

\section{General Context of the Learning Situation}

What learning expectations are placed on this course or curriculum by: the university, college and/or department? the profession? society?

\section{Nature of the Subject}

Is this subject primarily theoretical, practical, or a combination? Is the subject primarily convergent or divergent? Are there important changes or controversies occurring within the field?

\section{Characteristics of the Learners}

What is the life situation of the learners (e.g., working, family, professional goals)? What prior knowledge, experiences, and initial feelings do students usually have about this subject? What are their learning goals, expectations, and preferred learning styles?

\section{Characteristics of the Teacher}

What beliefs and values does the teacher have about teaching and learning? What is his/her attitude toward: the subject? students? What level of knowledge or familiarity does s/he have with this subject? What are his/her strengths in teaching?

\section{Step 2. Learning Goals}

After you have reviewed the situational factors, decide what you want students to get out of the course. Many people take a content-centered approach to this task: "I 
want students to learn about topic $X$, topic $Y$, and topic $Z$." This is an easy, natural approach but it generally results in an overemphasis on "understand and remember" kinds of learning. These are important. But when teachers take a learning-centered approach, they usually identify several additional kinds of significant learning.

I recommend that teachers ask themselves: "What would I like the impact of this course to be on students, 2-3 years after the course is over? What would distinguish students who have taken this course from students who have not?"

When students and teachers think about what students can learn that is truly significant, their answers usually include, but do not focus on, "understand and remember" kinds of learning. More often they emphasize such things as critical thinking, learning how to creatively use knowledge from the course, learning to solve real-world problems, changing the way students think about themselves and others, realizing the importance of life-long learning, etc.

After many years of studying people's responses to the question of what constitutes significant learning, I have proposed a taxonomy of significant learning. It consists of six major types of significant learning, with a number of sub-categories. This taxonomy is shown in Figure 1 (next page). The taxonomy identifies significant kinds of learning that you may want to include as important learning goals for your course. 
Figure 1

\section{A TAXONOMY OF SIGNIFICANT LEARNING}

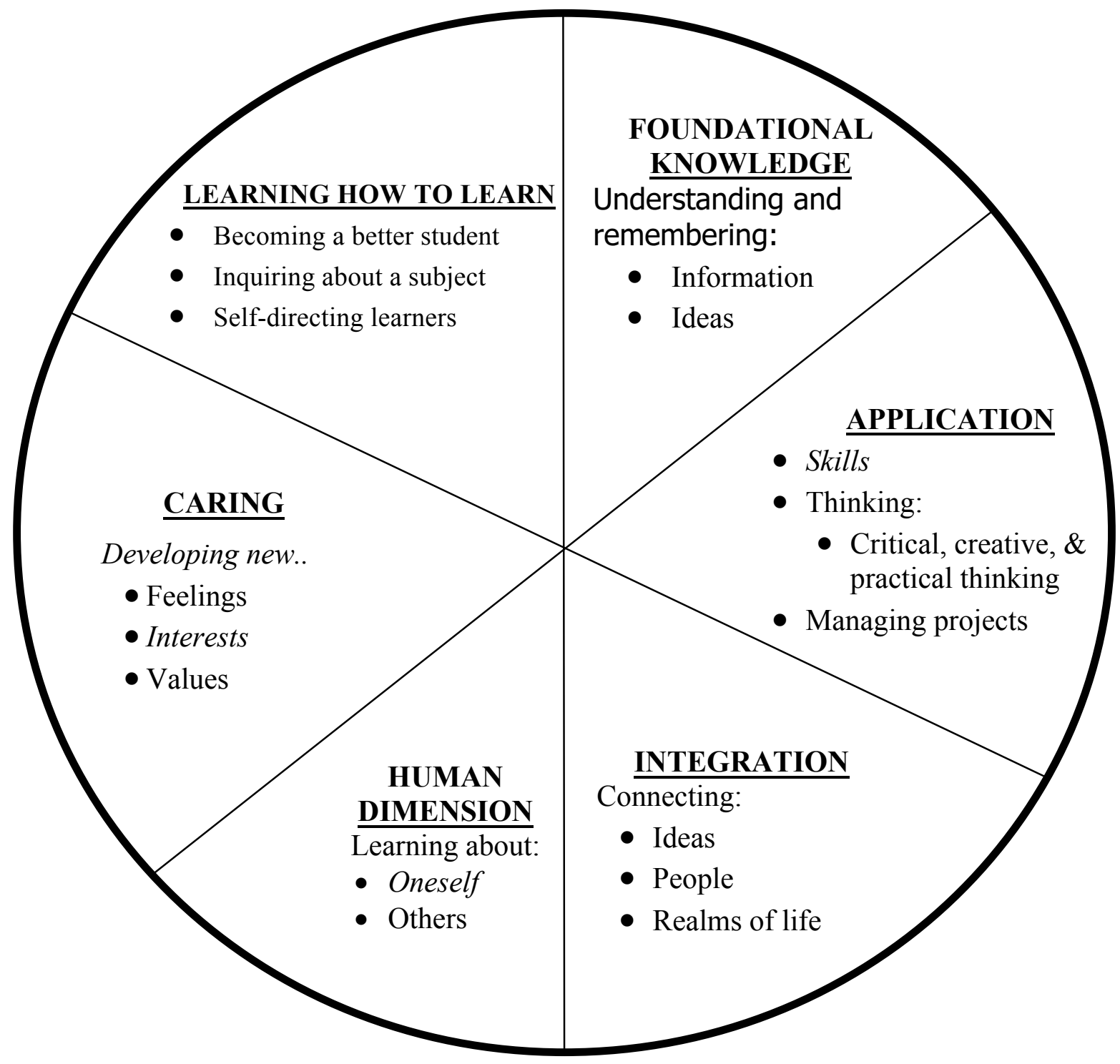

One important feature of this particular taxonomy is that each kind of learning is interactive, as illustrated in Figure 2 (next page). This means that each kind of learning can stimulate other kinds of learning. This has major implications for the selection of learning goals for your course. It may seem intimidating to include all six kinds of significant learning. But the more you can realistically include, the more the goals will support each other-and the more valuable will be your students' learning. 
Figure 2

\section{INTERACTIVE NATURE OF SIGNIFICANT LEARNING}

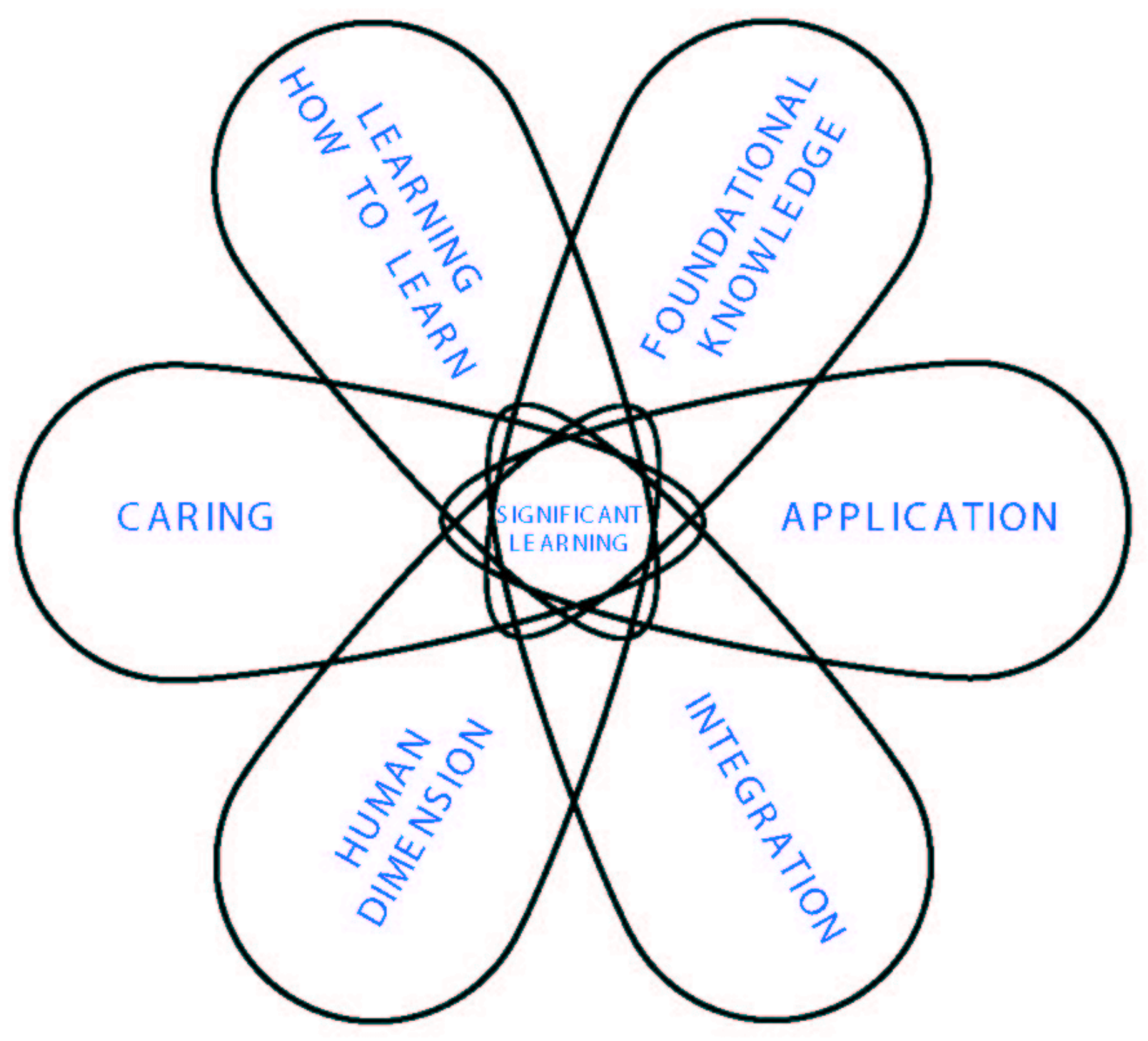


Step 2. Worksheet

\section{Questions for Formulating Significant Learning Goals}

"A year (or more) after this course is over, I want and hope that students will

\section{Foundational Knowledge}

- What key information (e.g., facts, terms, formulae, concepts, principles, relationships, etc.) is/are important for students to understand and remember in the future?

- What key ideas (or perspectives) are important for students to understand in this course?

\section{Application Goals}

- What kinds of thinking are important for students to learn?

- Critical thinking, in which students analyze and evaluate

- Creative thinking, in which students imagine and create

- Practical thinking, in which students solve problems and make decisions

- What important skills do students need to gain?

- Do students need to learn how to manage complex projects?

\section{Integration Goals}

- What connections (similarities and interactions) should students recognize and make...:

- Among ideas within this course?

- Among the information, ideas, and perspectives in this course and those in other courses or areas?

- Among material in this course and the students' own personal, social, and/or work life? 


\section{Human Dimensions Goals}

- What could or should students learn about themselves?

- What could or should students learn about understanding others and/or interacting with them?

\section{Caring Goals}

- What changes/values do you hope students will adopt?

Feelings?

Interests?

Values?

\section{"Learning-How-to-Learn" Goals}

- What would you like for students to learn about:

- how to be good students in a course like this?

- how to learn about this particular subject?

- how to become a self-directed learner of this subject, i.e., having a learning agenda of what they need/want to learn, and a plan for learning it? 


\section{Step 3: Feedback and Assessment Procedures}

In a content-centered course, two mid-terms and a final exam are usually considered sufficient feedback and assessment for the teacher to determine whether the students "got it" or not. But a learning-centered course calls for a more sophisticated approach to this aspect of course design. A set of feedback and assessment procedures collectively known as "educative assessment" is needed to go beyond "audit-ive-type assessment" (that which is designed solely to give the teacher a basis for awarding a grade). Educative assessment actually enhances the quality of student learning. In Figure 3 (next page), the four key components of educative assessment are contrasted with the more traditional audit-ive assessment.

Forward-Looking Assessment incorporates exercises, questions, and/or problems that create a real-life context for a given issue, problem, or decision to be addressed. To construct this kind of question or problem, the teacher has to "look forward," beyond the time when the course is over, and ask: "In what kind of situation do I expect students to need, or to be able to use this knowledge?" Then, create a question or problem that replicates this real-life context as closely as possible. The problem also should be somewhat open-ended and not totally pre-structured. If necessary, certain assumptions or constraints can be given, in order to be able to assess the quality of student responses.

To illustrate this distinction, let me draw from a course I have taught on world geography in which students have studied, for example, a unit on Southeast Asia. A backward-looking assessment would ask students to tell what the differences are in the population and resources of the various countries in that region. In a forward-looking assessment question, I would ask them to imagine that they are working for a company that wants to establish itself in that region; the company wants the students' opinions on which country has the necessary political stability, purchasing power for their product, prospects for economic growth, etc. This kind of question asks students to imagine a situation where they could actually use what they have learned.

Teachers should explain clearly the criteria and standards that will be used to assess student work. Teachers need to ask themselves, and then share with students: "What are the general traits or characteristics of high quality work in this area?" These are the criteria for evaluation. Then, on each of these criteria, how good does the work have to be, to be acceptably good or exceptionally good? The answers to these questions reveal the teacher's standards.

It is also important for teachers to create opportunities for students to engage in self-assessment. Later in life, students will need to assess their own performance, and they should start learning how to do that while in the course. You may want the class to do this initially in groups, and later individually. Somewhere along the way, students 
need to generate-and perhaps discuss-appropriate criteria for evaluating and assessing their own work.

As the students work to learn how to perform well, teachers need to provide feedback. High quality feedback will have the characteristics of "FIDeLity" feedback:

- Frequent: Give feedback daily, weekly, or as frequently as possible.

- Immediate: Get the feedback to students as soon as possible.

- Discriminating: Make clear what the difference is between poor, acceptable, and exceptional work.

- Loving: Be empathetic in the way you deliver your feedback.

Enhancing Learning with High Quality Feedback

Since the publication of my book, a group of educators in Scotland and England put together a very impressive list of 7 principles for giving feedback in a way that enhances student learning. The 7 principles are listed in the Appendix of this "Guide."

Note: The full document, the key part of which is only 13 pages long, can be downloaded from a website. The URL for this website is listed in the appendix.

Figure 3

\section{AUDIT-IVE AND EDUCATIVE ASSESSMENT}
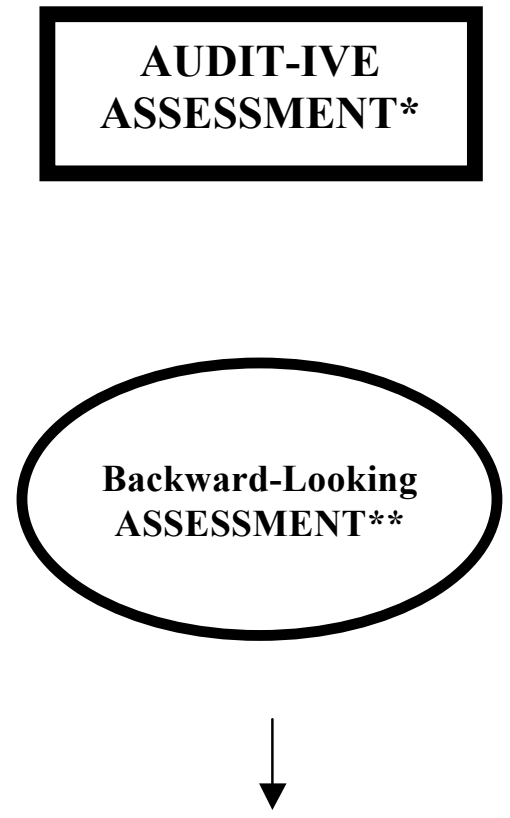

(Traditional) GRADING

\section{EDUCATIVE ASSESSMENT}
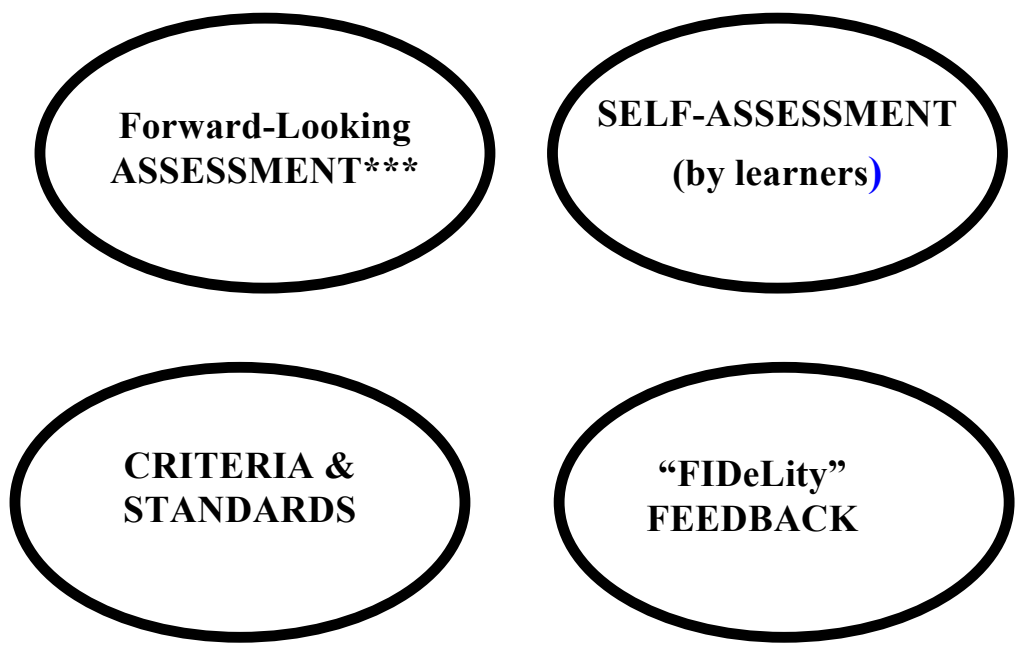

BETTER LEARNING

(as well as more authentic grading) 
Step 3. Worksheet

\section{Procedures for Educative Assessment}

1. Forward-Looking Assessment Formulate one or two ideas for forward-looking assessment. Identify a situation in which students are likely to use what they have learned, and try to replicate that situation with a question, problem, or issue.

2. Criteria \& Standards Select one of your main learning goals, and identify at least two criteria that would distinguish exceptional achievement from poor performance. Then write two or three levels of standards for each of these criteria.

3. Self-Assessment What opportunities can you create for students to engage in self-assessment of their performance?

4. "FIDeLity" Feedback What procedures can you develop that will allow you to give students feedback that is:

- Frequent

- Immediate
- Discriminating, i.e., based on clear criteria and standards

- Lovingly delivered 


\section{Step 4. Teaching/Learning Activities}

Often as college teachers thinking about what should happen in a course, we have used the traditional pattern of "lectures and discussions." Some courses are heavy on lectures; others lean more toward discussion. But to create the kind of significant learning advocated in Step 2, we will need new tools, new kinds of teaching and learning activities. Where can we find these? We need to understand, and then learn, how to incorporate more active learning into our courses.

Active Learning. One of the more powerful ideas to emerge in the literature on college teaching in the last two decades is the concept of active learning. In essence, the concept of active learning supports research that shows: students learn more and retain their learning longer if they acquire it in an active rather than a passive manner.

What do we mean by "active learning"? Active-learning advocates Bonwell and Eison (1991) describe active learning as "[involving] students in doing things and thinking about the things they are doing." By "doing things," they are referring to activities such as debates, simulations, guided design, small group problem solving, case studies, etc. My way of illustrating that definition is shown in Figure 4 . When students listen to a lecture or read a texbook, they are receiving "Information and Ideas" - an important part of the learning process but also one that is relatively passive. To make the learning more active, we need to learn how to enhance the overall learning experience by adding some kind of experiential learning and opportunities for reflective dialogue.

Figure 4

INITIAL VIEW OF PASSIVE AND ACTIVE LEARNING

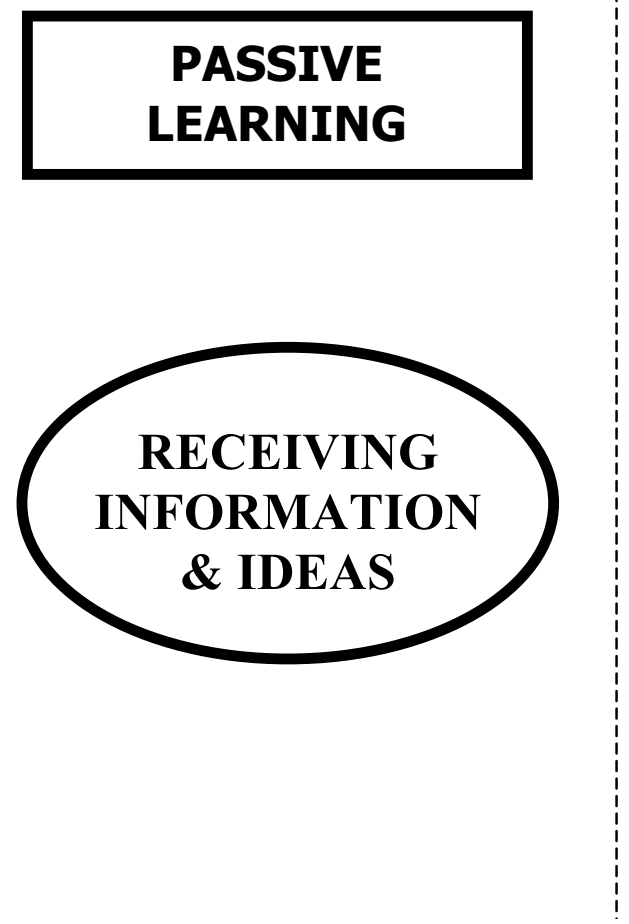

A C T I V E L E A R N I N G

\section{REFLECTIVE}

EXPERIENCE DIALOGUE, with:
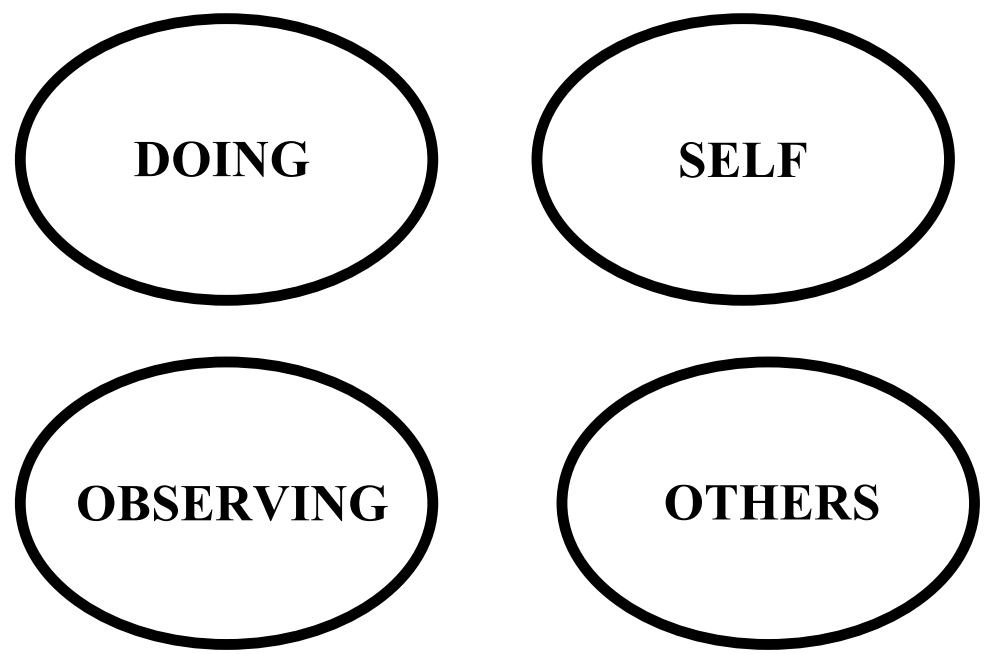
An Enlarged View of "Active Learning." In order to create a complete set of learning activities capable of achieving significant learning, we need an enlarged and more holistic view of active learning - one that includes "getting information and ideas" as well as "experience" and "reflection." Figure 5 illustrates a new conceptualization of active learning, one that makes all three modes of learning an integral part of a more complete set of learning activities.

Figure 5

\section{A HOLISTIC VIEW OF ACTIVE LEARNING}

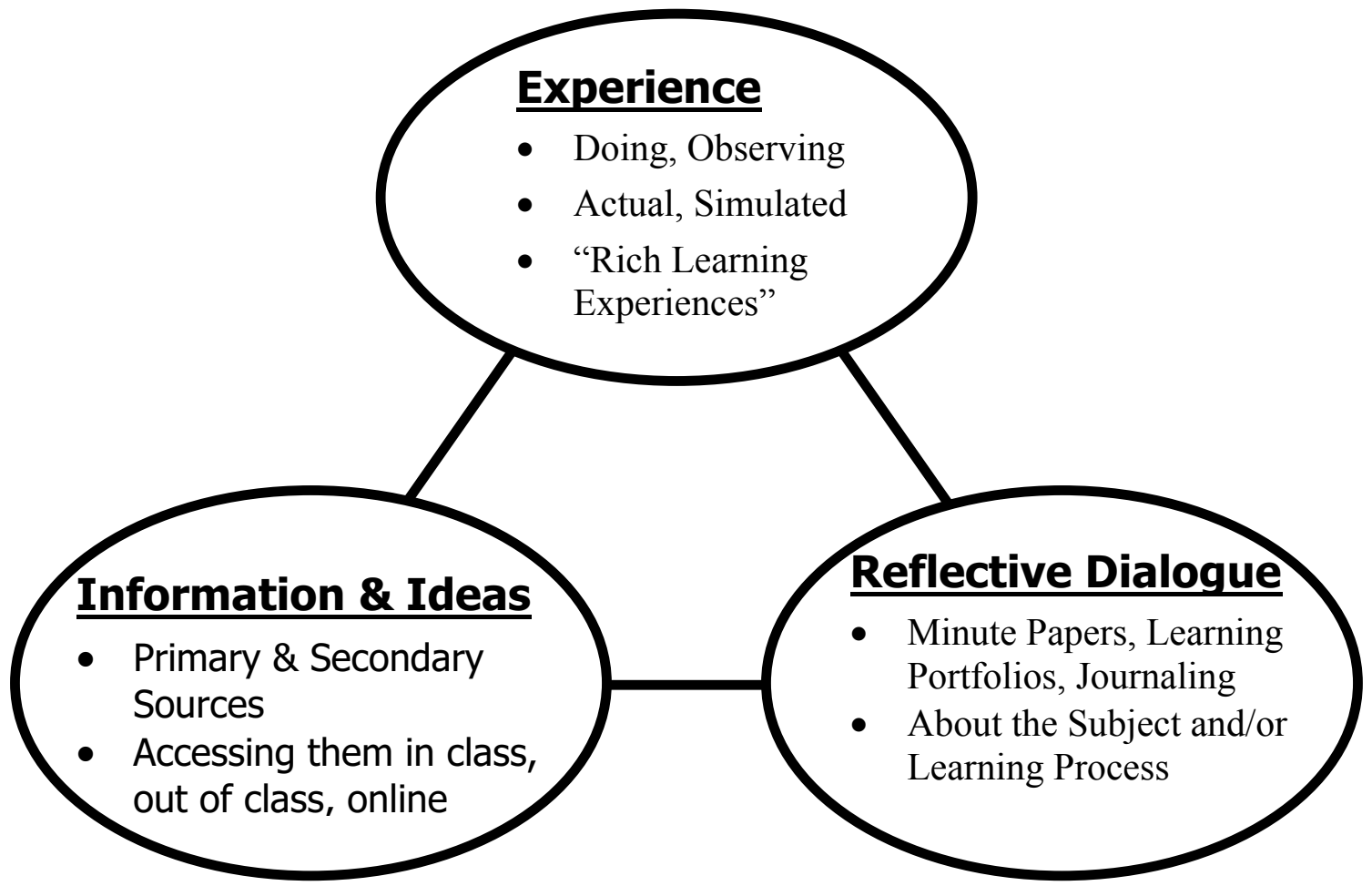

Two principles should guide our choice of learning activities. First, an effective set of learning activities is one that includes activities from each of the following three components of active learning: information and ideas, experience, and reflective dia-logue. Second, we should try to find direct kinds of learning activities, whenever pos-sible. Indirect, or vicarious, forms may be necessary in some cases. But when we can find direct ways of providing active learning, the quality of student learning expands.

From my own experience and from reading the literature on what effective teachers actually do in terms of this holistic view of active learning, I have found that good teachers incorporate all three components of active learning in a variety of ways. As shown in Table 1, sometimes teachers provide information and ideas, experience, and reflective dialogue directly; at other times it is done indirectly or even online. 
Table 1

\section{LEARNING ACTIVITIES FOR HOLISTIC, ACTIVE LEARNING}

\begin{tabular}{|c|c|c|c|c|c|}
\hline & \multirow{2}{*}{$\begin{array}{c}\text { GETTING } \\
\text { INFORMATION } \\
\text { \& IDEAS }\end{array}$} & \multicolumn{2}{|c|}{ EXPERIENCE } & \multicolumn{2}{|c|}{$\begin{array}{c}\text { REFLECTIVE DIALOGUE, } \\
\text { with: }\end{array}$} \\
\hline & & "Doing" & "Observing" & Self & Others \\
\hline DIRECT & $\begin{array}{l}\text { - Primary data } \\
\text { - Primary sources }\end{array}$ & $\begin{array}{l}\text { - "Real Doing," in } \\
\text { authentic settings }\end{array}$ & $\begin{array}{l}\text { - } \begin{array}{l}\text { Direct } \\
\text { observation of } \\
\text { phenomena }\end{array} \\
\end{array}$ & \multirow[t]{2}{*}{$\begin{array}{l}\text { - } \text { Reflective } \\
\text { thinking } \\
\text { - Journaling }\end{array}$} & \multirow[t]{2}{*}{$\begin{array}{l}\text { - Dialogue } \\
\text { (in or out } \\
\text { of class) }\end{array}$} \\
\hline $\begin{array}{l}\text { INDIRECT, } \\
\text { VICARIOUS }\end{array}$ & $\begin{array}{l}\text { - Secondary data } \\
\text { and sources } \\
\text { - Lectures, } \\
\text { textbooks }\end{array}$ & $\begin{array}{l}\text { - } \text { Case Studies } \\
\text { - Gaming, } \\
\text { Simulations } \\
\text { - Role Play }\end{array}$ & $\begin{array}{l}\text { - Stories } \\
\text { (can be accessed } \\
\text { via: film, oral } \\
\text { history, literature) }\end{array}$ & & \\
\hline ONLINE & $\begin{array}{l}\text { - Course website } \\
\text { - Internet }\end{array}$ & \multicolumn{2}{|c|}{$\begin{array}{l}\text { - Teacher can assign students to "directly } \\
\text { experience } \\
\text { - Students can engage in "indirect" kinds of } \\
\text { experience online. }\end{array}$} & \multicolumn{2}{|c|}{$\begin{array}{l}\text { - Students can reflect and then } \\
\text { engage in various kinds of } \\
\text { dialogue online. }\end{array}$} \\
\hline
\end{tabular}


To help you explore ways of developing more powerful learning experiences for your students, I suggest some ideas for each of three components of active learning: Rich Learning Experience, In-Depth Reflective Dialogue, and Information and Ideas.

Rich Learning Experiences. As you try to add an experiential component to the learning experience, look for "Rich Learning Experiences." Certain learning experiences are "rich" because they allow students to acquire several kinds of significant learning simultaneously. What are some ways this can be done? The list below identifies in-class and out-of-class activities that promote multiple kinds of significant learning-all at the same time.

\begin{tabular}{|c|c|}
\hline In Class: & Outside of Class: \\
$\bullet$ Debates & - Service learning \\
• Role playing & - Situational observations \\
- Simulations & - Authentic projects \\
$\bullet$ Dramatizations & \\
\hline
\end{tabular}

Action: Identify some learning activities to add to your course that will give students a "Doing" or "Observing" Experience. What "Rich Learning Experiences" are appropriate for your course?

In-Depth Reflective Dialogue. Another important ingredient of active learning is giving students time and encouragement to reflect on the meaning of their learning experience. There are various forms of reflective dialogue (See Table 2, next page). One can reflect with oneself (as in writing in a journal or diary) or with others (as in engaging in discussions with a teacher or others). Another key distinction is between substantive writing, in which one writes about a subject (e.g., a typical term paper), and reflective writing, in which one writes about one's own learning. In reflective writing, students address a different set of questions, such as: What am I learning? What is the value of what I am learning? How am I learning? What else do I need to learn? 
Table 2

\section{IN-DEPTH REFLECTIVE DIALOGUE}

With Whom?

- Oneself (journaling, learning portfolios)

- Others (teacher, other students, people outside class)

About What?

- Subject of the Course: (Substantive writing)

What is an appropriate and full understanding of this concept or topic?

- Learning Process: (Reflective writing)

- What am I learning?

- Of what value is this?

- How did I learn: best, most comfortably, with difficulty, etc.?

- What else do I need to learn?

\section{Written Forms?}

- One-minute papers

- Weekly journal writing

- Learning portfolios (end-of-course, end-of-program)

The literature on college teaching identifies numerous procedures to promote reflection. In the one-minute paper, the teacher poses a short, but well-focused, question for students to answer once a week or at the end of each class. Sample questions include: "What is the most important thing you learned today? What is the "muddiest point" of this class?" Slightly more ambitious is the practice of having students write weekly learning journals. Ask students to periodically reflect on their learning experience. You may need to guide this effort by providing some questions like the four listed above (or more specific versions of them).

Another excellent practice is for students to put together a learning portfolio at the end of the course. This is an 8-12 page narrative with an appendix of materials to support and illustrate the content of the narrative. In the narrative, students write reflectively about their learning experiences, again addressing questions like the those listed above.

Action: What kinds of Reflective Dialogue can you incorporate into your course? 
Information and Ideas. In order to free up some class time for the experiential and reflective activities identified above, you will probably need to explore alternative ways of introducing students to the key information and ideas of the course, i.e., the content. This might involve having them do more reading before they come to class. Or it may mean creating a course-specific website where you put content-related material. Or you can direct students to go to selected websites that have good content related to the course.

Action: Other than lectures, what ways can you identify to cause students to get their initial exposure to subject matter and ideas (preferably outside of class)?

\section{Step 5. Integration}

In this InITIAL DeSIGN PHASE (Steps 1-4), you have created strong primary components for the design of your course. In order to complete this initial phase, you need to check how well these four components are aligned. Step 5 Worksheet gives a detailed explanation of how these four components can be integrated with each other.

\section{Step 5: Integrating Steps 1-4}

\section{Situational Factors}

- Assuming you have done a careful, thorough job of reviewing the situational factors, how well are these factors reflected in the decisions you made about learning goals, feedback and assessment, learning activities?

- What potential conflicts can you identify that may cause problems? 
- Are there any disconnects between your beliefs and values, the student characteristics, the specific or general context, or the nature of the subject in relation to the way you propose to run the course?

\section{Learning Goals and Feedback \& Assessment}

Issues to address include:

- How well do your assessment procedures address the full range of learning goals?

- Is the feedback giving students information about all the learning goals?

- Do the learning goals include helping the students learn how to assess their own performance?

\section{Learning Goals and Teaching/Learning Activities}

- Do the learning activities effectively support all your learning goals?

- Are there extraneous activities that do not serve any major learning goal?

\section{Teaching/Learning Activities and Feedback \& Assessment}

- How well does the feedback loop work to prepare students for understanding the criteria and standards that will be used to assess their performance?

- How well do the practice learning activities and the associated feedback opportunities prepare students for the eventual assessment activities?

A good tool for checking on integration, especially on Steps \#2-4 above, is to use the Worksheet 1 on the following page. First, fill in a list of your learning goals for the course. If possible, have one for each kind of significant learning in the taxonomy. Second, for each major learning goal, identify how you would know whether students have achieved that kind of learning, i.e., what kind of feedback and assessment can you use? Third, again, for each major learning goal, identify what students will have to do to achieve that kind of learning. You will often find that the assessment and the learning activity are the same or very similar.

But working through this exercise can be very valuable by ensuring that you in fact have specific kinds of assessment and learning activities for each of your learning goals and that you don't just give "lip service" to them.

After you finish your final check (below), then you can start the process of assembling these several activities into a coherent whole (Phase II, starting on p. 28). 
Worksheet 1

\section{Worksheet for Designing a Course}

\begin{tabular}{|c|c|c|c|}
\hline Learning Goals for Course: & $\begin{array}{l}\text { Ways of Assessing } \\
\text { This Kind of Learning: }\end{array}$ & $\begin{array}{c}\text { Actual Teaching-Learning } \\
\text { Activities: }\end{array}$ & $\begin{array}{l}\text { Helpful Resources: } \\
\text { (e.g., people, things) }\end{array}$ \\
\hline 1. & & & \\
\hline 2. & & & \\
\hline 3. & & & \\
\hline 4. & & & \\
\hline 5. & & & \\
\hline 6. & & & \\
\hline
\end{tabular}


Final Check and Review of Initial Design Phase. A major benefit of this planning model is that it provides specific criteria for assessing the quality of course design. There are five primary criteria, four of which are illustrated by the highlighted areas of Figure 6 on the next page. It suggests that good course design meets the following criteria.

\section{The basic design for this course is good if it includes...}

1. In-Depth Analysis of Situational Factors It is based on a systematic review of all the major situational factors, in order to define the situational constraints and opportunities of the course.

2. Significant Learning Goals It includes learning goals focused on several kinds of significant learning, not just "understand-and-remember" kinds of learning.

3. Educative Feedback and Assessment It includes the components of educative assessment: forward-looking assessment, opportunities for students to engage in self-assessment, clear criteria and standards, and "FIDeLity" feedback. These allow the feedback and assessment to go beyond auditive assessment.

4. Active Teaching/Learning Activities It includes learning activities that engage students in active learning by incorporating powerful forms of experiential and reflective learning, as well as ways of getting basic information and ideas.

5. Integration/Alignment All the major components of the course are integrated (or aligned). That is, the situational factors, learning goals, feedback and assessment, and the teaching/learning activities all reflect and support each other.

If the course design rates "High" on each of these five criteria, then the basic components of good design are in place. 
Figure 6

\section{Criteria for Assessing Course Designs}

(The major criteria are shown in bold)

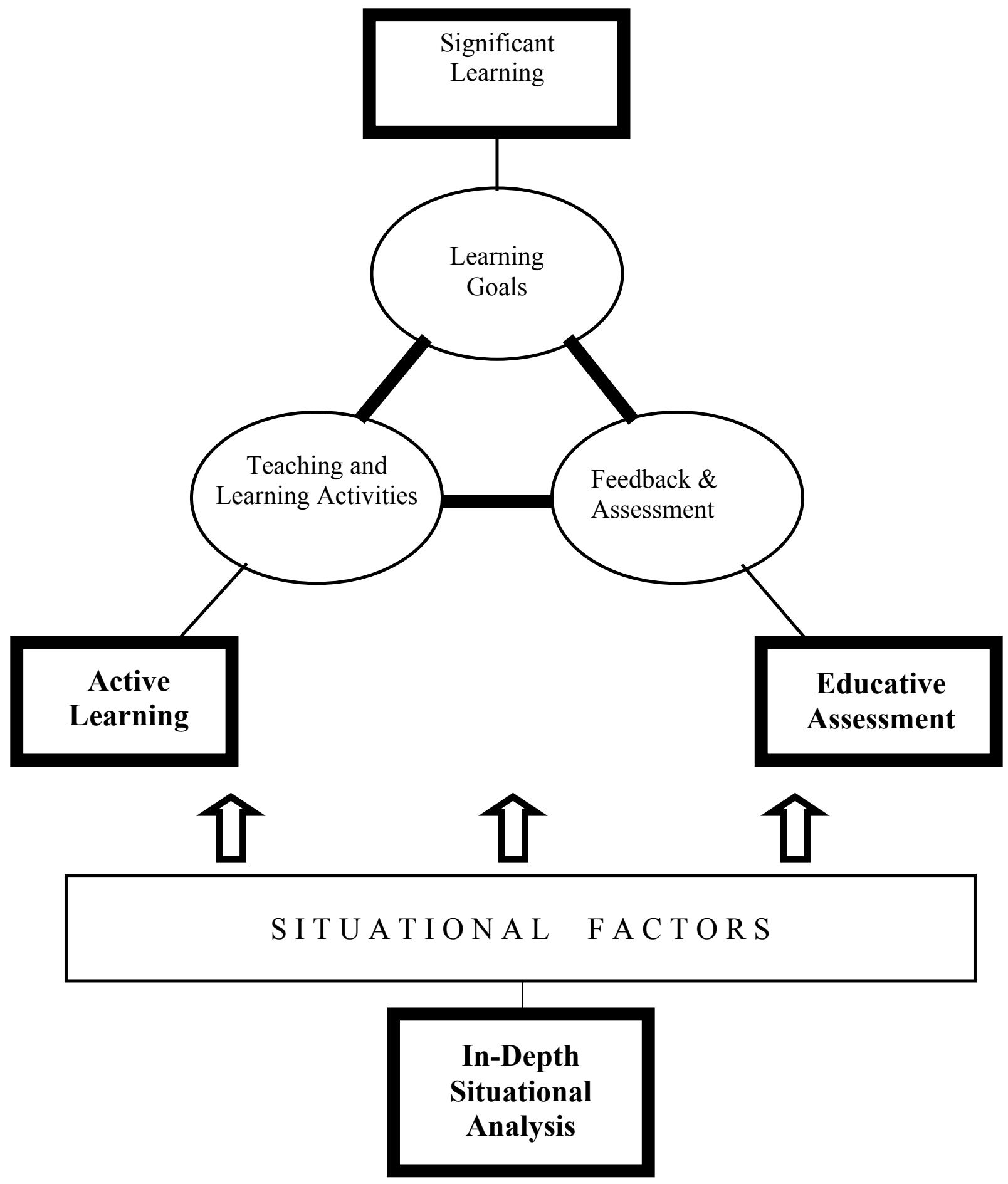


INTERMEDIATE PHASE (Steps 6-8)

Assembling the Components into a Coherent Whole

After you have created the basic components of the course, identify ways of organizing these activities into a powerful and coherent whole. This is done by creating a course structure, selecting or creating an instructional strategy, and then integrating the structure and strategy into an overall scheme of learning activities.

\section{Step 6. Course Structure}

Creating a course structure simply means dividing the semester into 4 to 7 segments that focus on the key concepts, issues, or topics that constitute the major foci of the course. Then you arrange these concepts or topics into a logical sequence and decide how many weeks or class sessions to allocate to each one (See Figure 7). One major value of doing this is seeing more readily how to create questions or assignments for students that gradually become more complex and more challenging.

Figure 7

\section{A Sequence for Increasing the Complexity of Assignments}

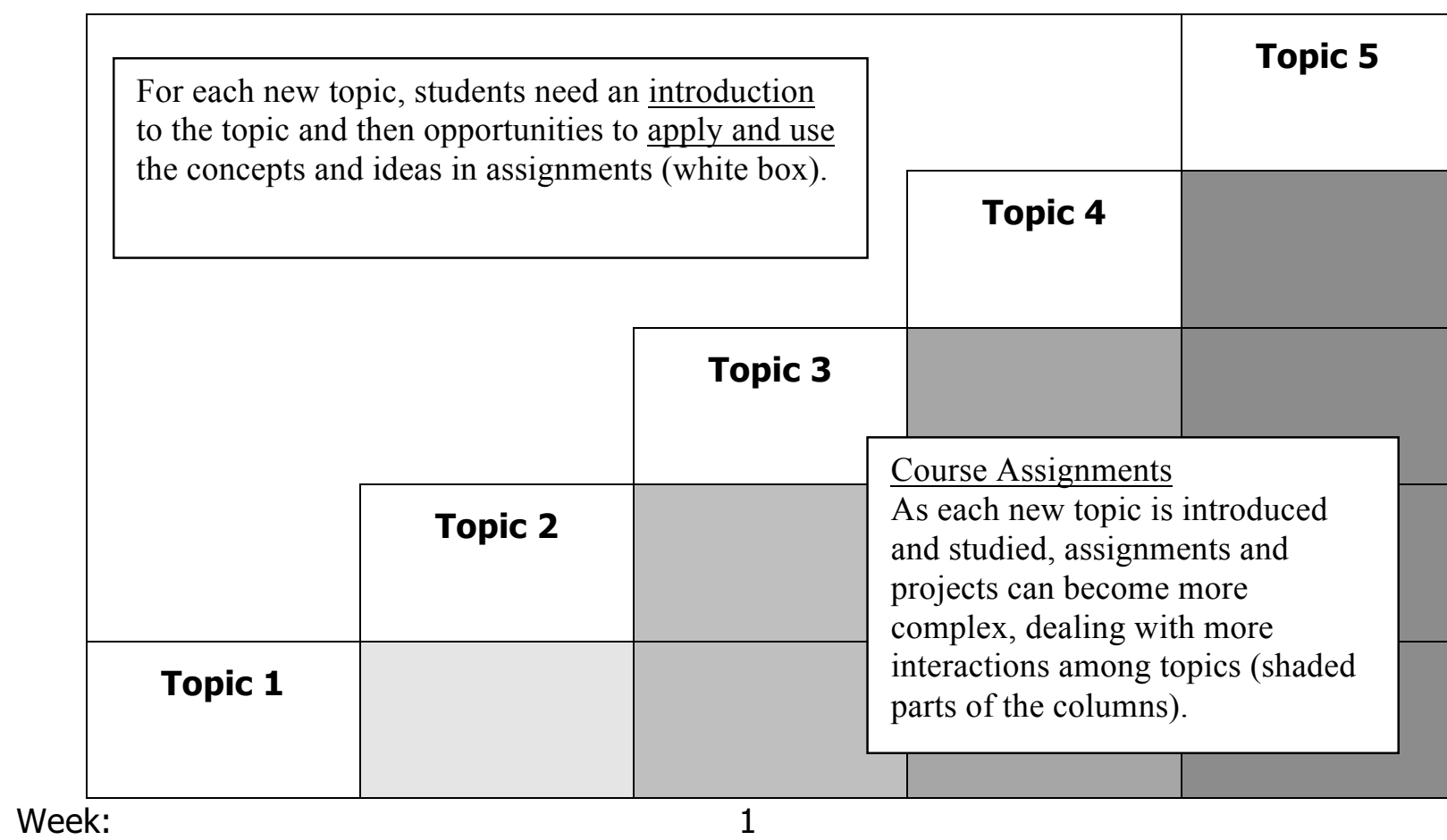

Operationally, this diagram should be read as a series of columns: 
- Initially students study Topic 1 and learn how to apply these ideas (white box).

- Then they study Topic 2, do some application problems for Topic 2 (white box), and then work on topics relating Topic 1 to Topic 2 (shaded box).

- This pattern is then repeated, with Topics 3, 4 and 5.

By the end of the course, students will have had practice and feedback at integrating all the course topics with each other.

\section{Action:}

- Identify 4 to 7 major concepts, issues, or topics for your course.

- What is the appropriate sequence for introducing these to the students?

- What initial ideas do you have for assignments or problems that would reflect the increasing complexity of the subject as students move from topic to topic?

\section{Step 7. Instructional Strategy}

One important conceptual distinction needs to be made between teaching techniques and an instructional strategy. A teaching technique is a discrete, specific teaching activity. Lecturing, leading discussions, setting up small group work all are teaching techniques. An instructional strategy, on the other hand, is a set of learning activities, arranged in a particular sequence so that the energy for learning increases and accumulates as students go through the sequence. This usually requires, among other things, that you set up some activities that (a) get students ready or prepared for later work, (b) give them opportunities to practice-with prompt feedback-doing whatever it is you want them to learn to do, (c) assess the quality of their performance, and (d) allow them to reflect on their learning. To assist in this, the diagram below can help you develop a sequence of in-class and out-of-class activities. I affectionately call this the "Castle Top" diagram (Figure 8). The question marks ask you to identify the learning activity for each in-class and out-of-class block of time. The goal is to create a sequence of activities that build on each other.

Figure 8 - The "Castle Top" Template for Creating an Instructional Strategy

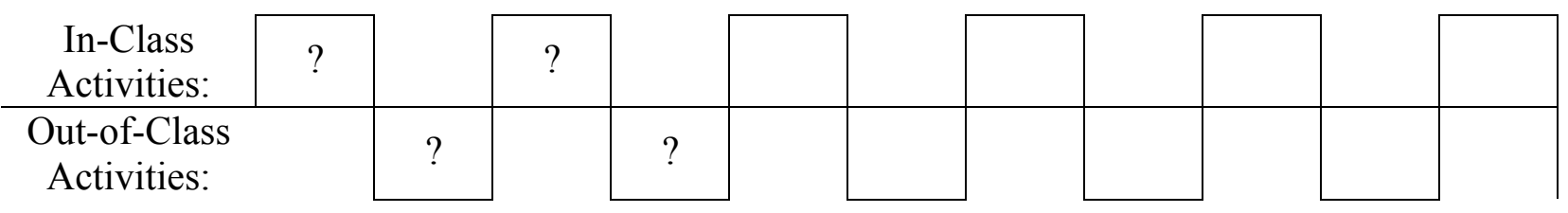

Action: Sketch out a sequence of varied activities using some of the learning activities you identified in Phase I. 


\section{Step 8. Creating the Overall Scheme of Learning Activities}

At this time you need to dynamically integrate the course structure and the instructional strategy for the whole course. It can be helpful to create a diagram of the course structure and the instructional strategy - and then find ways to enhance how these two components work together. Your scheme might look like this:

Figure 9

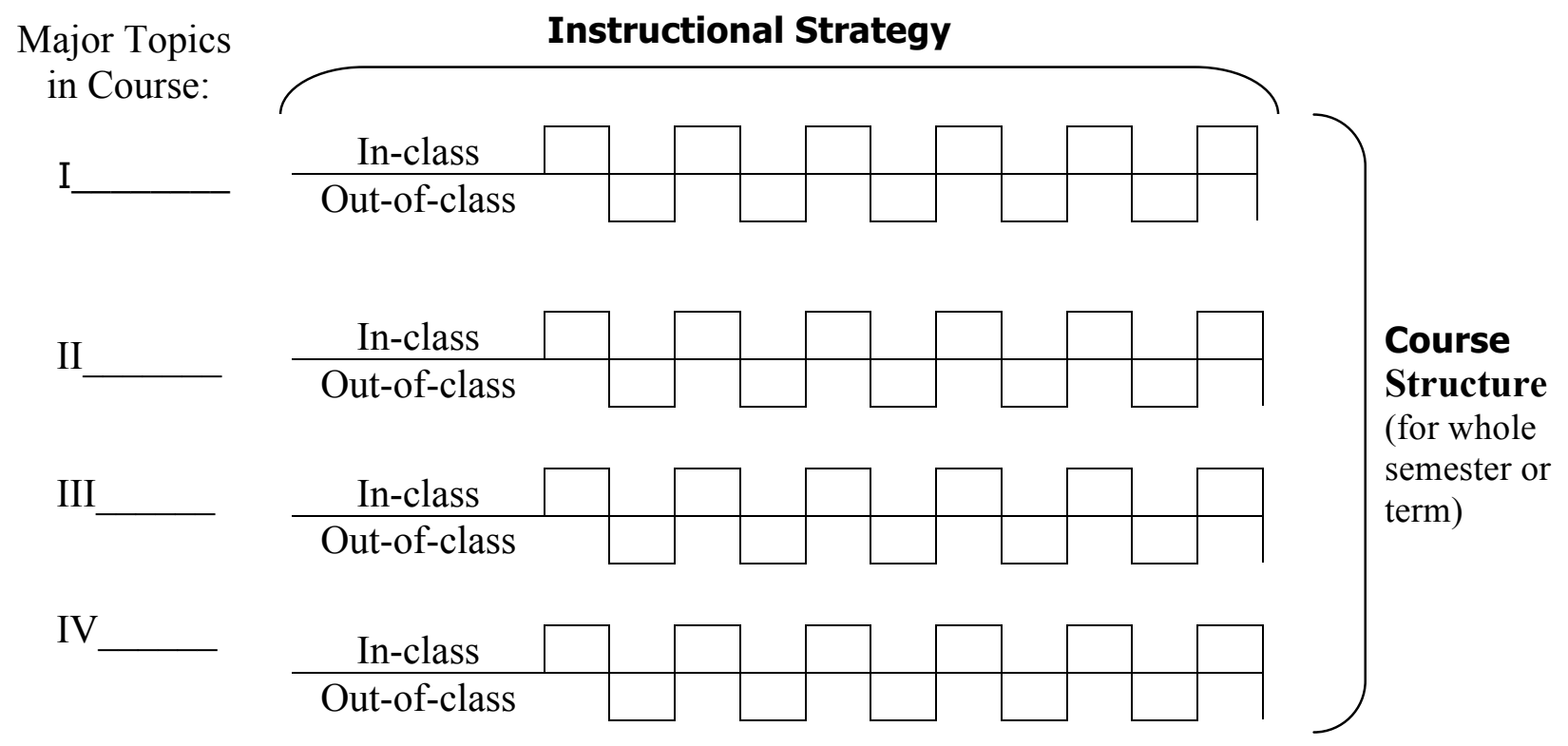

Figure 9 above is an example of only one possibility. It would obviously need to be adjusted to fit the circumstances of a given course. This diagram allows us to see one more important principle for good course design: the need for both differentiation and integration of learning activities.

Differentiation can be reflected in these ways:

- Variety in the type of learning activities from day-to-day, within each 1-3 week block of time.

- Development in the complexity and challenge of the learning, from course topics I-IV.

Integration should be reflected both within each topical unit of time and in the progression through each of the topical units.

At the conclusion of this Step 8, you should be ready to lay out a week-by-week schedule of activities for the whole semester. Worksheet 2 on the following page can be a useful form for creating this schedule. As you do this, consider these questions:

- What activities need to come first, i.e., how should the course begin?

- With what activities do you want to conclude, i.e., how should the course end? 
- What sequence of activities will enhance learning in the middle of the course?

Action Using Worksheet 2 (on the following page), pace out the sequence of learning activities for the course. Planning out the schedule concludes the INTERMEDIATE DESIGN PHASE of the course design process.

You now have an integrated set of components assembled into a coherent whole. You are ready for the FinAL DESIGN PHASE, in which there are a few additional tasks to complete. 
Worksheet 2

Sequence of Learning Activities

\begin{tabular}{|c|c|c|c|c|c|c|}
\hline Week & Class & Between & Class & Between & Class & Between \\
\hline 1 & & & & & & \\
\hline 2 & & & & & & \\
\hline 3 & & & & & & \\
\hline 4 & & & & & & \\
\hline 5 & & & & & & \\
\hline 6 & & & & & & \\
\hline 7 & & & & & & \\
\hline 8 & & & & & & \\
\hline 9 & & & & & & \\
\hline 10 & & & & & & \\
\hline 11 & & & & & & \\
\hline 12 & & & & & & \\
\hline 13 & & & & & & \\
\hline 14 & & & & & & \\
\hline 15 & & & & & & \\
\hline $\begin{array}{c}\text { Final Exam } \\
\text { or Project }\end{array}$ & & & & & & \\
\hline
\end{tabular}




\section{Final Design Phase (Steps 9-12): Important Remaining Tasks}

Four important remaining tasks need to be undertaken in order to complete the design of your course.

\section{Step 9. How Are You Going To Grade?}

At this time, you are ready to develop your grading system. It should reflect the full range of learning goals and activities, but it is also important to remember that you do NOT have to grade everything. In addition, the relative weight of each item as it affects the course grade should reflect the relative importance of that activity.

Action: What are the key components of your grading system?

Action: What will be the relative weight of the grade components? Are you going to determine that yourself, or will you involve the class in this process? 
Step 10. What Could Go Wrong?

Now "de-bug" the design by analyzing and assessing your "first draft" of the course. Among other things, this means checking for possible problems. For example:

- Will the students have time to do their out-of-class assignments?

- Will they be able to obtain the necessary resources? (e.g., How many students will be trying to obtain reading material reserved in the library at the same time?)

Action: What problems might arise in the course design as you envision it at this time? What might you do to solve these problems?

\section{Step 11. Let Students Know What You Are Planning (Syllabus)}

Now it is the time to write the syllabus. This should include, among other things:

- General management information-instructor, office hours, phone, etc.

- Goals for the course

- Structure and sequence of class activities, including due dates for major assignments/tests/projects

- Text and other required reading material

- Grading procedures

- Course policies: attendance, Honor Code, work turned in late, make-up exams, etc.

Action: What information do you want in the course syllabus?

Action: How do you want to communicate the syllabus to studentson paper, online?

\section{Step 12. How Will You Know How The Course Is Going? How It Went?}

It is very important to plan an evaluation of the course itself and of your own teaching. This is the only way you can get the information and insights you need in order to make the course better and to improve your own teaching over time.

As you do this, remember these points: 
- You can collect feedback throughout the semester as well as at the end.

- You can use a variety of information sources:

- video/audio tape of the class sessions

- student ratings of instruction

- student interviews and/or questionnaires

- outside observers (e.g., colleagues, instructional consultant, Students Consulting on Teaching)

- test results

Also consider specific issues:

- the degree to which your goals for the course were achieved

- the effectiveness of particular learning activities

- your ability to interact effectively with students

Action: What sources will you use to evaluate the course and your teaching?

Action: What questions are you trying to answer with this evaluation?

Concluding Counsel. Congratulations! You have now finished designing your course. There are two closing caveats for you to consider.

Stay Flexible. The first point to remember is that, although developing a good design or plan for your course is very important, it is only a plan. Like all plans, you need to keep it flexible and subject to change as it is implemented.

$1^{\text {st }}, 2^{\text {nd }}$, and $3^{\text {rd }}$ Order Changes. If this is your first attempt at designing a course based on this model, don't be discouraged if your design does not rate a "10" on all the steps and criteria. It is wise to think of making $1^{\text {st }}$ order, $2^{\text {nd }}$ order, and $3^{\text {rd }}$ order changes. This simply means that on your first attempt to improve the design of your 
course, focus only on a few changes. But be sure to make some changes in each of the three phases because each affects and reinforces the other. For example, start by making changes to the strong primary components (INITIAL DESIGN PHASE):

- Do a somewhat more in-depth analysis of the situational factors;

- Add one new kind of significant learning to your list of learning goals;

- Add one additional kind of educative assessment;

- Add one new kind of active learning in which the students engage; and

- Check to make sure the components are integrated/aligned.

Once you have strong primary components, then you can work on assembling these into a more coherent whole (INTERMEDIATE DESIGN PHASE):

- Clarify or simplify the structure of your course;

- Create a differentiated set of learning activities (perhaps using the "Castle Top" diagram, Figure 8); and,

- Lay out some kind of scheme for the overall set of learning activities.

When you have a coherent scheme of learning activities, you can finish the remaining tasks (FinAL DeSIGN PHASE):

- Coordinate your grading system with the design of the course;

- De-bug potential problems;

- Put together a syllabus that communicates the design of the course more clearly; and/or

- Plan a more thorough evaluation of the course and of your own teaching.

Each time you teach, make an assessment of how well the design worked; then next time, make another, more ambitious set of changes. This way, you can work through $2^{\text {nd }}$ order changes, followed by $3^{\text {rd }}$ order changes, and so forth.

Again, congratulations! When you work seriously on making the kinds of changes described here, you gradually become more and more competent as a course designer. By committing to Designing Courses for Significant Learning, you increase your power and effectiveness as someone responsible for the quality of other peoples' learning experience!

\section{Appendix}

\section{Principles of FORMATIVE FEEDBACK}

Source: Enhancing Student Learning Through Effective Formative Feedback, by C. Juwah, D. Macfarlane-Dick, B. Matthew, D. Nicol, D. Ross, \& B. Smith. Higher Education Academy, York, England. June, 2004.

1. Facilitate the development of self-assessment (reflection) in learning.

- E.g., when students hand in work, ask them what kinds of feedback they would like.

2. Encourage teacher and peer dialogue around learning. 
- Use one-minute papers about learning, assignments, and feedback.

- Ask students to identify examples of feedback comments they found particularly helpful.

3. Help clarify what good performance is (the goals, criteria, and standards expected).

- Provide better definitions of requirements using carefully constructed criteria sheets and performance level definitions.

4. Provide opportunities to close the gap between current and desired performance.

- Increase the number of opportunities for resubmission of work.

5. Deliver high quality information to students about their learning.

- Relate feedback to predefined criteria.

- Provide feedback soon after a submission.

- Provide corrective advice, not just information on strengths/weaknesses.

6. Encourage positive motivational beliefs and self-esteem.

- Provide opportunities for low-stakes tasks with feedback before giving high-stakes task with grades.

- Provide grades on written work only after students have responded to feedback comments.

7. Provide information to teachers that can be used to help shape the learning.

- Have students identify where they are having difficulties when they hand in assessed work.

- Use anonymous one-minute papers at end of a class session.

The full document can be found online at:

http://www.heacademy.ac.uk/resources/detail/id353_effective_formative_feedback_juwah_etal (click on "Download Publication") 


\section{Appendix C \\ Parts from a Course Syllabus from Introduction to Financial Management}

Textbook: Required - Principles of Managerial Finance, Brief, $6^{\text {th }}$ or $7^{\text {th }}$ Edition by Gitman \& Zutter

A Financial Calculator is required. Highly recommended is the Texas Instruments BA II Plus which may be obtained at the Bookstore, from Staples, or from Amazon. Use of cellphone financial calculator apps is prohibited.

Note: We will be using Moodle, not Blackboard, for this course.

\section{Where are we going? (aka Course Description)}

Financial managers are decision makers. What do financial managers do? They decide how deciding how to raise funds for the firm through sales of stocks, bonds, or even high yield PIKtoggle debentures with warrants attached; they choose how to invest those funds within the business; and they determine how much of the firm's earnings should be distributed to shareholders as dividends versus how much retained in the business for reinvestment;

To make these decisions, managers use concepts such as the time value of money, the relationship between risk and return, and financial statement analysis. These concepts are broadly applicable and are also used by other financial professionals, such as: investment managers, bankers, insurance agents, real estate developers, and personal financial planners.

Buying a house, buying a car, saving for retirement (or for your own children's college education), are all financial decisions that require, if they are to be done well, the concepts that you will learn in this course. You will find finance to be a mix of "glorified" accounting, and applied microeconomics, with important elements of macroeconomics, statistics, math, ethical considerations, and psychology. It is an ever-changing world, undergirded by key concepts, that offers a variety of career opportunities, and personal rewards.

\section{How will we get there? (aka Course Objectives)}

- Define key terms and concepts used in the financial world.

- Choose from an array of investment options by considering the risk/return tradeoff, and your personal or firm risk-aversion characteristics.

- Assess financial performance of a firm or division using financial ratios.

- Apply time value of money techniques to make professional capital investment decisions, and envision how these concepts relate to the purchase of homes, autos, or investment products in your personal life.

- Think critically about the ethical aspects of financial decisions and reflect upon the implications for yourself, your employer, and society. 


\section{How will we know we've arrived? (aka Assessment)}

There are a total of 1000 points available. Your grade will be based on the number of points that you gather. $900=A, 800=B, 700=C, 600=D$, Below $600=F$

Exams: Have you built a foundation of basic financial knowledge? 3 exams @ 200 points each =600 points. In order to ensure your learning, three noncumulative multiple choice $\&$ short answer exams (no true/false!) will assess your fundamental knowledge of the course: terminology, concepts, and calculations. Exams may be made-up only under exceptional circumstances.

Team Project: Imagine consulting on financial matters with a Board of Directors! 3 parts@80 points each $=240$ points. Working in teams of 4 students, you will serve as consultants to the Board of Directors of "Hammarlund Corporation" during this semester. You will be provided with financial statements, comparative industry financial ratios, a sales forecast for the firm, information on the firm's risk characteristics and competitive position, financial market information, and capital investment opportunities that are available. Using concepts you will learn in this class, you will assess liquidity, debt bearing-capacity, and profitability. You will prepare a cash budget, and pro-forma financial statements, and additional analysis necessary to report to the Board.

Hammarlund's Board eagerly awaits:

- Your assessment of the firm's financial performance

- Your projected funding needs and recommended sources of funding

- Your recommended capital budget

Paper on an Ethical Issue in Finance: What if you saw this happening at work? What if you see this happening in society? 100 points. During the class we will discuss a number of ethical lapses that have occurred within the financial industry in recent years. From a financial publication (The Wall Street Journal, Barron's, Bloomberg Businessweek, Forbes, or Fortune, or the financial pages of a major newspaper) identify a recent case poor ethical judgment or financial scandal. By recent, I mean something discovered or resolved since August 2015. (No Madoff, WorldCom, Enron, etc.)

Describe in your own words who was involved, what happened, and how this could have occurred. What was the time frame involved? Very importantly, reflect on the motivation of those involved in the fraud, who the victims were, and what anyone did to stop the unethical activity. What should be done internally in corporations or as a societal response to prevent a something similar from happening again? Cite your references! As much of this assignment is "reflective" a single source may be fine, but multiple sources tend to enhance the papers. As you write your paper, keep the previous paragraph in mind.(3-5 pages.....quality is NOT equal to quantity)

Participation (Concept Checks/Homework/In-class Exercises/Class Discussion/and Peer Mentoring attendance): How to prepare to do well on the exams, team project, and paper. 60 points. To prepare you for the Exams, the Team Project, and Paper, I will use a combination of concept checks (aka pop quizzes), some assigned homework, some in-class practice exercises, and class discussion. These will be lightly graded. The intent is to prepare you for the major assignments. Participating in these, as well as attending peer mentor sessions, will pay large dividends beyond the points noted above. I will review the totality of your work in these areas to assign points at the end of the semester. 
Appendix D

Redesigned Schedule of Learning for Introduction to Financial Management

\section{$\underline{\text { Date }} \underline{\text { Day }} \underline{\text { Topic(s) }}$}

1/18 W Why would anyone want to be a financial manager?

1/23 M Can we decipher a mysterious financial world?

$1 / 25$ W What happened in 2008, and will it happen again?

1/30 M Financial statements can be fun! Seriously. Really.

2/1 W Can our customers pay their bill?

2/6 M How can we tell if management is doing a good job?

2/8 W Do you like to solve puzzles?

2/13 M Currently profitable companies in bankruptcy. How?

2/15 W If your budgeting is sloppy, will a bank loan to you?

2/20 M Failing to plan is planning to fail. How to forecast.

2/22 W First Exam

2/27 M I rather have my money now, wouldn't you?

3/1 W What's the key to saving for retirement?

3/6 M So, how much will that car payment be?

3/8 W How can $\$ 156,000$ and $\$ 255,000$ be the same?

3/13 M SPRING BREAK

3/15 W SPRING BREAK

3/20 M What is the Fed doing to interest rates?!

$3 / 22 \quad \mathrm{~W}$ Bonds are safe. Aren't they?

3/27 M Why do we have market crashes?

$3 / 29$ W So, just what is that stock worth?

\section{Text Ch. $\underline{\text { Assessment/Activity }}$}

1

$1 \& 2$

2

3

3

3

3

4

4

4

Team Project Due: Part A

5

5

5

5

Team Project Due: Part B

6

6

7

7
First Exam

Form Teams of 4

Intro to Team Project

Ethics Paper Due 
4/3 M What is a realistic rate of return?

4/5 W Risk matters. But how should we measure it?

8

4/10 M Second Exam

4/12 W Ah, those pesky flotation costs! 9

4/17 M What is WACC, and why does it change? 9

4/19 W Payback: Karma or Project Selection Method? 10

4/24 M What if selection methods give conflicting answers? 10

4/26 W But what are the RELEVANT cash flows? 11

5/1 M That return looks good, but did you consider risk? 11

$5 / 3 \quad$ W Real Options: Let's think strategically. 11

5/8 M Final Exam

1:00 PM Final Exam

$\begin{array}{ll} & \\ 0 & \\ 1 & \\ 1 & \text { Team Project Due: Part C } \\ 1 & \\ : 00 \text { PM } & \text { Final Exam }\end{array}$




\section{Appendix E \\ Previous Course Schedule for Introduction to Financial Management}

\begin{tabular}{|c|c|c|}
\hline ATE & DAY & CHAPTER/TOPIC \\
\hline $1 / 20 / 2015$ & Tuesday & Intro \& 1 The Role of Managerial Finance \\
\hline $1 / 22 / 2015$ & Thursday & 2 The Financial Market Environment \\
\hline $1 / 27 / 2015$ & Tuesday & 3 Financial Statements and Ratio Analysis \\
\hline $1 / 29 / 2015$ & Thursday & 3 Financial Statements and Ratio Analysis \\
\hline $2 / 3 / 2015$ & Tuesday & 3 Financial Statements and Ratio Analysis \\
\hline $2 / 5 / 2015$ & Thursday & 3 Financial Statements and Ratio Analysis \\
\hline $2 / 10 / 2015$ & Tuesday & 4 Cash Flow and Financial Planning \\
\hline $2 / 12 / 2015$ & Thursday & 4 Cash Flow and Financial Planning \\
\hline $2 / 17 / 2015$ & Tuesday & 4 Cash Flow and Financial Planning \\
\hline $2 / 19 / 2015$ & Thursday & 5 Time Value of Money (sections 5.1 and 5.2) \\
\hline $2 / 24 / 2015$ & Tuesday & 1st EXAM \\
\hline $2 / 26 / 2015$ & Thursday & 5 Time Value of Money \\
\hline $3 / 3 / 2015$ & Tuesday & 5 Time Value of Money \\
\hline $3 / 5 / 2015$ & Thursday & 5 Time Value of Money \\
\hline $3 / 10 / 2015$ & Tuesday & 6 Interest Rates and Bond Valuation \\
\hline $3 / 12 / 2015$ & Thursday & 6 Interest Rates and Bond Valuation \\
\hline $3 / 17 / 2015$ & Tuesday & SPRINGBREAK \\
\hline $3 / 19 / 2015$ & Thursday & SPRINGBREAK \\
\hline $3 / 24 / 2015$ & Tuesday & 7 Stock Valuation \\
\hline $3 / 26 / 2015$ & Thursday & 7 Stock Valuation \\
\hline $3 / 31 / 2015$ & Tuesday & 8 Risk and Return \\
\hline $4 / 2 / 2015$ & Thursday & 8 Risk and Return \\
\hline $4 / 7 / 2015$ & Tuesday & 2ND EXAM \\
\hline 4/9/2015 & Thursday & 9 The Cost of Capital \\
\hline $4 / 14 / 2015$ & Tuesday & 9 The Cost of Capital \\
\hline $4 / 16 / 2015$ & Thursday & 10 Capital Budgeting Techniques: Certainty and Risk \\
\hline $4 / 21 / 2015$ & Tuesday & 10 Capital Budgeting Techniques: Certainty and Risk \\
\hline $4 / 23 / 2015$ & Thursday & 11 Capital Budgeting Cash Flows and Risk Refinements \\
\hline $4 / 28 / 2015$ & Tuesday & 11 Capital Budgeting Cash Flows and Risk Refinements \\
\hline $4 / 30 / 2015$ & Thursday & 11 Capital Budgeting Cash Flows and Risk Refinements \\
\hline $5 / 5 / 2015$ & Tuesday & 14 Working Capital and Current Assets Management \\
\hline $5 / 7 / 2015$ & Thursday & 14 Working Capital and Current Assets Management \\
\hline
\end{tabular}




\section{Appendix F \\ Schedule of Assignments from Principles of Accounting I}

Schedule of Assignments

Date $\quad$ Assignment

08.15 Introduction

In-Class Activity

08.17 Download, print, and bring to class Chapter 1 Lecture Worksheets

- Read pp. 2-5, 12-25

08.22

- DoBE1-2,E1-5,E1-6,E1-11,P1-2A part(a)P1-2A Template

- Read pp. 5-11

- While reading, memorize the following terms (including proper spelling) and their definitions: internal users, external users, Sarbanes-Oxley Act, generally accepted accounting principles, Financial Accounting Standards Board, Securities and Exchange Commission, International Accounting Standards Board, International Financial Reporting Standards, relevance, faithful representation, historical cost principle, fair value principle, monetary unit assumption, economic entity assumption, proprietorship, partnership, corporation. For the activity, you must read a definition and write down the term it describes. A word bank will not be given and no abbreviations will be accepted (ex. "GAAP" will not be accepted for "Generally Accepted Accounting Principles").

08.24 Do BE1-6,BE1-7,E1-2,E1-4,E1-7,P1-2A part(b),P1-4A all parts (also prepare an owner's equity statement) $\mathrm{P} 1-4 \mathrm{~A}$ Template

08.29

- Download, print, and bring to class Chapter 2 Lecture Worksheets

- $\quad$ Read pp. $48-70$

- Watch T-Accounts presentation and complete the T-Accounts worksheet. Memorize the information on the completed worksheet before coming to class. You will not be allowed to refer to the worksheet during the activity.

08.31 Quiz\#1: T-Accounts

WileyPLUS Assignment \#1 Due

- DoBE2-1,E2-3,E2-7,P2-1A,P2-2A (provide explanations for journal entries even if instructions state otherwise) 
Date $\quad \underline{\text { Assignment }}$

09.07 Quiz\#2: Financial Statements

WileyPLUS Assignment \#2 Due

- Do P15-A, E2-14, P2-3A (provide explanations for journal entries even if instructions state otherwise)

- For P2-3A, use the following chart of accounts: P2-3A Chart of Accounts. Also, for P2-3A part (b), post to the general ledger, not to t-accounts.

\subsection{2}

09.14

\section{EXAM\#1: CHAPTERS $1 \& 2$}

- Download, print, and bring to class Chapter 3 Lecture Worksheets

- Read pp. 92 - 115 (stop at "Appendix 3A")

- While reading, memorize the following terms and their definitions: accrual-basis accounting, accrued expenses, accrued revenues, adjusted trial balance, adjusting entries, calendar year, cash-basis accounting, expense recognition (matching) principle, fiscal year, interim periods, prepaid expenses (prepayments), revenue recognition principle, time period assumption, unearned revenues.

09.19

09.21 Quiz\#3: Adjusting Entries

WileyPLUS Assignment\#3 Due

- Download, print, and bring to class Chapter 4 Lecture Worksheets

- $\quad$ Read pp. $148-168$

09.26

- Do E3-5, E3-8, BE4-4, E4-4, E4-7

- Read pp. $169-174$

- Watch The Classified Balance Sheet presentation and complete The Classified Balance sheet worksheet. Memorize the information on the completed worksheet before coming to class. You will not be allowed to refer to the worksheet during the activity.

09.28 Quiz\#4: Closing Entries \& Classified Balance Sheet

WileyPLUS Assignment \#4 Due

- Do E4-8, E4-15, E4-17, P3-5A

10.03

\section{EXAM \#2: CHAPTERS $3 \& 4$}

10.05 Download, print, and bring to class Chapter 5 Lecture Worksheets

- Read pp. $206-222$

- While reading, complete the Chapter 5 Read to Know worksheet. Memorize the completed worksheet (including proper spelling of terminology) before coming to class. You will not be allowed to refer to the worksheet during the activity. $\underline{\text { In-Class Activity }}$

Terminology Scratch-Off Quiz

Classified Balance Sheet Relay

Read to Know Crossword Puzzle 
$\underline{\text { Date }}$

10.10

Assignment

- Do BE5-4,BE5-5,P5-1A

- Watch the Single-Step Income Statement and Multiple-Step Income Statement presentations and complete the Single-Step \& Multiple-

Step Income Statement worksheet. Before coming to class, be able to prepare a single-step and multiple-step income statement (similar to Check Your Skills section of the worksheet). You will not be allowed to refer to the worksheet during the activity.

10.12 Quiz \#5: Merchandising Journal Entries \& Multiple-Step Income Statement WileyPLUS Assignment \#5 Due

- Do BE5-6, BE5-7, BE5-9, E5-8, E5-9, E5-13, P5-4A

10.17

10.19

10.24 Quiz\#6: Determining Inventory

WileyPLUS Assignment \#6 Due

- $\quad$ Do E5-7, E5-10, E5-14, E6-11, E6-12, E6-13, E6-14, P6-1A, *P6-9A

10.26

EXAM \#3: CHAPTERS 5 \& 6 (EXCLUDING PERIODIC INVENTORY \& INCLUDING APPENDIX 6A)

10.31

11.02

- Download, print, and bring to class Chapter 7 Lecture Worksheets

- Read Chapter 7

- Watch the Subsidiary Ledger presentation and complete the Subsidiary Ledger worksheet. Before coming to class, be able to calculate balances in subsidiary accounts and control accounts (similar to Check Your Skills section of the worksheet). You will not be allowed to refer to the worksheet during the activity.

- Do BE7-4, BE7-5, E7-4, E7-5, E7-8 part a only, P7-1A finish part(a), P7-2A finish part (a), P7-3A finish part (a)

11.07 Quiz\#7: Subsidiary Ledgers \& Special Journals WileyPLUS Assignment \#7 Due

- Download, print, and bring to class Chapter 8 Lecture Worksheets

- Read pp. $354-370$ (stop at "Petty Cash Fund")
In-Class Activity

Income Statement Relay

Read to Know Bingo

Subsidiary Ledger Relay 
$\underline{\text { Date }}$

11.09

Assignment

- Do E8-2, E8-6

- Read pp. $370-382$

- Watch the Bank Reconciliation video and complete the Bank Reconciliation worksheet. Before coming to class, be able to reproduce the basic format for a bank reconciliation.

11.14 Do BE8-8, BE8-11, BE8-15, E8-9, E8-14, P8-2A, P8-3A

- Download, print, and bring to class Chapter 9 Lecture Worksheets

- Read pp.404-414 (stop at "Disposing of Accounts Receivable")

11.16 Quiz\#8: BankReconciliation

WileyPLUS Assignment \#8 Due

- E9-3 parts b and c, E9-4

- $\quad$ Read pp. $417-423$

$11.21 \quad$ NOCLASS-THANKSGIVINGRECESS

11.23 NOCLASS-THANKSGIVINGRECESS

11.28 Do E9-11, E9-14, P9-2A parts b, c, d

- Watch the Determining Maturity Dates video and complete the Determining Maturity Dates worksheet. Before coming to class, be able to determine the maturity date of notes (similar to Check Your Skills section of the worksheet).

11.30 Quiz\#9: Valuing Receivables \& Maturity Dates of Notes WileyPLUS Assignment \#9 Due

- Do E7-10,E8-8, E8-11, P8-1A, E9-5, E9-12, P9-5A parts a, b, c, d
In-Class Activity

Bank Reconciliation Puzzle

\section{Determining Maturity Dat \\ Game of Chance}

